\title{
Applied Bioengineering in Tissue Reconstruction, Replacement, and Regeneration
}

\author{
Juan M. Colazo, BSc, ${ }^{1,2}$ Brian C. Evans, PhD, ${ }^{3}$ Angel F. Farinas, MD, ${ }^{4}$ Salam Al-Kassis, MD, \\ Craig L. Duvall, $\mathrm{PhD},{ }^{3}$ and Wesley P. Thayer, $\mathrm{MD}, \mathrm{PhD}^{3,4}$
}

\begin{abstract}
To this day, tissue reconstruction and replacement to address extensive tissue defects due to trauma, tumor resection, genetic and/or chronic diseases, or excessive debridement present a major clinical challenge. Traditional reconstructive techniques most commonly utilize autologous tissue. Undoubtedly, autologous composite tissue transfers or "flaps," skin grafts, as well as the harvesting of bone and/or cartilage have substantially improved the health, functional, and aesthetic outcomes of millions of patients. Unfortunately, these procedures are not without their drawbacks. These include increased operative time, complexity, cost, limited availability of qualitative autologous tissue, wound healing complications, tissue flap failure, and substantial donor-site morbidity. Recently, collaborative research teams - consisting of surgeons, scientists, and engineers - have made substantial progress in their attempts to solve these problems. This article provides historical perspective, covers the major limitations of current standards of care, and reviews recent advances and future prospects in applied bioengineering in the context of tissue reconstruction, replacement, and regeneration.
\end{abstract}

Keywords: reconstructive surgery, tissue replacement, donor-site morbidity, wound healing, tissue engineering, regenerative medicine, biomaterials, drug delivery, stem cells, immunobiology, genetic engineering

\section{Impact Statement}

The use of autologous tissue in the reconstruction of tissue defects has been the gold standard. However, current standards still face many limitations and complications. Improving patient outcomes and quality of life by addressing these barriers remain imperative. This article provides historical perspective, covers the major limitations of current standards of care, and reviews recent advances and future prospects in applied bioengineering in the context of tissue reconstruction, replacement, and regeneration.

\section{Introduction}

\section{Robbing Peter to Pay Paul: the "Robin Hood Principle"}

$\mathbf{R}$ ECONSTRUCTIVE SURGERY TOOK off during World War I as ballistic and artillery injuries increased dramatically. ${ }^{1}$ Surgeons, by necessity, had to develop creative ways to reconstruct missing and/or damaged tissues to protect exposed vital structures such as vessels, nerves, bones, and muscle. Over time, the use of regional soft-tissue "flaps" became the norm. "Flap" is now the common term for a surgical procedure that involves the relocation of tissue on the body from one area to another, often to provide coverage and/or fill in tissue voids. ${ }^{2}$ Furthermore, autologous har- vesting of ribs, cartilage, and bone was also performed, and has now become common practice, especially for complex trauma cases. ${ }^{3}$

In modern times, about 6 million reconstructive procedures are performed in the United States every year, with 5,834,353 being performed in 2017. "Robbing Peter to Pay Paul" also known as the "Robin Hood Principle," has been the guiding principle of reconstructive surgery. An example of this principle is the transverse rectus abdominis myocutaneous (TRAM) flap used for breast reconstruction, usually after a mastectomy procedure. This procedure consists in fashioning a flap that is composed by cutaneous abdominal muscular and adipose layers, which is transferred en-bloc to the thoracic wall, as a unit, to

\footnotetext{
${ }^{1}$ Vanderbilt University School of Medicine, Vanderbilt University Medical Center, Nashville, Tennessee

${ }^{2}$ Medical Scientist Training Program, Vanderbilt University Medical Center, Nashville, Tennessee.

${ }^{3}$ Department of Biomedical Engineering, Vanderbilt University, Nashville, Tennessee.

${ }^{4}$ Department of Plastic Surgery, Vanderbilt University Medical Center, Nashville, Tennessee.
} 
cover a defect (Table 1). That is, tissue is taken from a donor site that is "Peter," and transposed to a site that needs soft tissue coverage called a recipient site that is "Paul." This approach can lead to complications, which are widely referred to as "donorsite morbidity." For example, regarding the TRAM flap, common donor-site morbidities include postoperative abdominal bulges, epigastric fullness, and hernias (Table 1). Another common example of the "Robin Hood Principle" is the universally utilized skin graft. ${ }^{6}$ In injuries that have an increased damaging potential, such as severe burns and/or trauma, the zone of injury may extend to tissue levels below the skin, such as the fat or muscle. Skin is harvested from a donor site (typically an area that surgeons believe will heal well and result in an inconspicuous scar) and applied to the affected area, accelerating the healing process. The grafted skin will cover the damaged area and incorporate into the vascular bed of the recipient site. The donor site should heal ad integrum since skin is taken at just 12 thousandths of an inch thick. Although this may be true in most patients, chronic long-term wound healing complications such as pain, infections, discoloration, and scarring have all been well documented in the literature (Table 1). These occur to a higher extent in certain patient populations such as diabetics, patients with peripheral artery disease, immunocompromised individuals, elderly individuals, and many others. ${ }^{7}$

Throughout the years, teams consisting of surgeons, engineers, and scientists have worked together to construct new technologies for their eventual translation to the clinic and/or operating room. In this review, we describe common tissue grafts and flaps-by location, tissue type, and reported complications-and review progress in the fields of applied bioengineering.

\section{Tissue Flap Distinctions}

\section{By location}

- Local flaps are fashioned by reorganizing immediate adjacent tissue to close the defect by freeing and stretching tissue out. From least to most complex, local flaps include advancement flaps, rotation flaps, and transposition flaps.

- Regional (or interpolation) flaps involve donor tissue that is transferred above or underneath normal tissue to reach the defect. The blood supply is still connected to the donor site, denominated a "pedicle". 8

- Distant flaps are indicated when the defect site is remote from the donor site. This class of flap is considered the most complex. Direct or tubed flaps are examples of distant flaps in which the flap is constructed in such a way that keeps the donor and recipient tissue linked by the donor's blood supply, denominated a "bridge." This permits the flap to survive until the recipient sire creates the new vascular network, at which the bridge is divided completing the transfer. ${ }^{9}$ A free flap is another example of a distant flap, in which the blood supply from the donor site has been completely detached. The flap is then termed to be in "ischemia time" receiving no blood supply until it is microsurgically anastomosed to a recipient site vessel(s). ${ }^{10}$

\section{By tissue types}

Flaps are often classified by the type of tissue(s) that constitute them. Surgeons often describe five different classes of flaps based on their tissue composition. ${ }^{10,11}$

- Cutaneous flaps are composed by full-thickness skin and underlying superficial fascia (i.e., Scarpa's), and are used to fill smaller defects. ${ }^{12,13}$ Local cutaneous flaps are commonly used in facial plastic surgery to provide better color and texture match, an example being the V-Y advancement flap used in rhinoplasty. Regional cutaneous flaps are commonly utilized for regions of the head and neck (e.g., the scalp is a good regional donor site for skin defects in the neck). Distant cutaneous flaps are commonly utilized for major skin defects on the extremities such as severely burned

Table 1. Common Reconstructive Procedures, Their Graft/Flap Classification, Their Clinical Use, and Literature-Reported Patient Morbidities

\begin{tabular}{|c|c|c|c|c|}
\hline Procedure & Type of graft/flap & Clinical use & Related patient morbidities & References \\
\hline Skin graft & Cutaneous graft & $\begin{array}{l}\text { Extensive wounding } \\
\text { from trauma, burns, } \\
\text { complex infections, } \\
\text { etc. }\end{array}$ & $\begin{array}{l}\text { Pain, risk of infection, discoloration, } \\
\text { and scarring-that are sometimes more } \\
\text { troublesome for patients than the primary } \\
\text { wounds themselves. }\end{array}$ & 12,13 \\
\hline Rib harvest & $\begin{array}{l}\text { Bone and/or } \\
\text { cartilage graft }\end{array}$ & $\begin{array}{l}\text { Head and neck } \\
\text { reconstruction, most } \\
\text { commonly nasal }\end{array}$ & $\begin{array}{l}\text { Pneumothorax, pulmonary complications, } \\
\text { wound infection, and considerable } \\
\text { postoperative pain. }\end{array}$ & 14 \\
\hline $\begin{array}{l}\text { Bone harvest } \\
\text { (e.g., iliac crest } \\
\text { bone graft) }\end{array}$ & Bone graft & $\begin{array}{l}\text { Bone grafting-spine, } \\
\text { cranioplasty, } \\
\text { and trauma }\end{array}$ & $\begin{array}{l}\text { Vascular injury, nerve injury, hematoma, ureteral } \\
\text { injury, hernia, cosmetic defects, chronic } \\
\text { pain, infection, fracture, and pelvic instability. }\end{array}$ & 21 \\
\hline LD muscle flap & Muscle flap & Breast reconstruction & $\begin{array}{l}\text { Limited shoulder range of motion, decreased } \\
\text { joint stability, reduced strength, } \\
\text { and multiple scars. }\end{array}$ & 18 \\
\hline PMM flap & Muscle flap & Chest wall defects & $\begin{array}{l}\text { Higher postoperative versus preoperative } \\
\text { DASH score-a marker of upper } \\
\text { extremity dysfunction. }\end{array}$ & 19 \\
\hline TRAM flap & $\begin{array}{l}\text { Musculocutaneous } \\
\text { flap }\end{array}$ & Breast reconstruction & $\begin{array}{l}\text { Abdominal contour abnormalities: abdominal } \\
\text { bulge, epigastric fullness, and hernia. }\end{array}$ & 16,17 \\
\hline
\end{tabular}

DASH, Disability of the Arm, Shoulder, and Hand; LD, latissimus dorsi; PMM, pectoralis major muscle; TRAM, transverse rectus abdominis myocutaneous

Source: Demirtas et al., ${ }^{12}$ Voineskos et al., ${ }^{13}$ Thomson et al., ${ }^{14}$ Edsander-Nord et al., ${ }^{16}$ Kroll et al.,${ }^{17}$ Smith, ${ }^{18}$ Sun et al., ${ }^{19}$ and Dimitriou et al. ${ }^{21}$ 
hands. Distant flaps are harvested from sites depending on the normal turgor, accessibility, and potential for hiding the donor site with clothing (e.g., the groin remains a privileged site for harvest of full-thickness skin grafts as a relatively large area can be obtained, while still allowing direct closure and a scar that is easily hidden). Skin flaps are commonly utilized in conjunction with other tissues for complex reconstruction procedures [e.g., two-stage auricular reconstruction in congenital microtia utilizing (1) a cartilage framework derived from harvested rib cartilage ${ }^{14}$ followed by (2) a full-thickness skin graft performed 5 months later ${ }^{15}$ ].

- Fasciocutaneous flaps consist of cutaneous tissue, plus subcutaneous tissue with corresponding deep fascia, leading to more robust inset with a more reliable blood supply and ability to cover a deeper and broader defect. A regional fasciocutaneous flap commonly used for hand reconstruction is the radial forearm flap. This flap is also commonly used distantly as a free flap for head and neck reconstruction, specifically intraoral reconstruction.

- Musculocutaneous flaps include an extra layer of muscle, which brings along added vascularity and provides bulk that can fill a deeper defect. ${ }^{16,17} \mathrm{Re}$ gionally, the anterolateral thigh (ALT) flap is used for open tibial fractures. Distantly, the ALT flap has been used as a free flap for esophageal reconstruction.

- Muscle flaps can provide necessary thickness/bulk and/ or functional muscle, while allowing normal skin closure of the donor site. ${ }^{18,19}$ If skin cover is needed at the recipient site, a skin graft can support the muscle flap. For coverage, the Gracilis flap is commonly used as a regional/interpolation flap for open tibial fractures. Functionally, distant muscle flaps (e.g., gracilis muscle flap) have been used in facial reanimation surgery for patients suffering from facial nerve palsy. ${ }^{20}$

- Bone flaps replace bone and/or cranial defects. ${ }^{21}$ Distant bone flaps most commonly used for jaw reconstruction include the free fibula flap and the scapular flap.

\section{By literature-reported clinical use and patient morbidities}

A number of specific donor-site morbidities are associated with different types of tissue grafts and flaps currently utilized in tissue reconstruction (Table 1).

\section{Tissue Expansion}

\section{Traditional methods and limitations}

Before tissue expansion, surgeons were limited in their ability to reconstruct damaged tissue, especially in patients with severe systemic tissue damage. In 1957, Neumann introduced the use of tissue expansion in reconstructive surgery, ${ }^{22}$ and later popularized by Radovan $(1982,1984)^{23,24}$ and Argenta et al. ${ }^{25}$ Currently, the most common use of tissue expander in plastic surgery is breast reconstruction. Other indications include repairing cutaneous anomalies caused by congenital defects, trauma, surgery, and as aid in certain cosmetic procedures. ${ }^{26}$ The conventional procedure involves inserting a balloon made from silicone that expands below the skin adjacent to the defect. The device is filled gradually over time, with saline or carbon dioxide, causing the skin to stretch and grow. ${ }^{27}$
Conventional tissue expansion provides several advantages:

(1) Similar tissue quality for coverage due to the donor site being adjacent to the defect, that is, color, texture, and hair-bearing qualities.

(2) The blood supply from the donor site remains intact, and therefore the risk of necrosis is miniscule.

(3) Scars are often less conspicuous, because the contributor skin is contiguous to the defect during surgical closure.

This technique is not exempt of complications, such as infection, ischemia-necrosis, perforation, leakage, migration, and wound dehiscence; this is all caused by an increased intraluminal balloon pressure. ${ }^{27}$ Traditionally, follow-up in the clinic is needed for the injection of saline or air by a medical professional, which is both time consuming and expensive. ${ }^{28}$ That being said, the recent XPAND prospective and randomized trial by Ascherman et al. provided preliminary results that their prototype allowed breast reconstruction patients to fill their expanders at home on their own accord. ${ }^{29}$ Furthermore, tissue expanders are poorly tolerated by some patients due to pain, especially in the pediatric setting. ${ }^{27}$ The gradual expansion can be protracted, taking months controlled by the extension of the area in need of reconstruction. The expander during this time creates an obvious bulge that can be quite noticeable and concerning for patients. For some patients, theses inconveniences are enough for them to consider other options. ${ }^{26}$ Also, physical restrictions may preclude the application of expanders in some anatomical locations, such as cleft palate and other craniofacial defects. ${ }^{30}$ Development of revolutionary prototypes of tissue expander technologies is warranted.

\section{Hydrogel-based self-inflating tissue expanders}

To address the shortcomings of the traditional procedure, a self-inflating device composed of a silicone membrane was introduced. This membrane was filled with highly osmotic solution like hypertonic saline, drawing water into the tissue expander. ${ }^{31}$ However, it took a prolonged time to achieve full expansion and the tissue resulted in necrosis. ${ }^{32}$ To develop an alternative to these unpleasant issues, the use of hydrogels as tissue expanders has been investigated. Hydrogels' can absorb and preserve copious amounts of water or transudate, ultimately expanding in size. ${ }^{33,34}$ To promote adequate expansion of tissue, a hydrogel must resist opposing mechanical resistance from the neighboring tissues and/or the skin. ${ }^{35}$ Conveniently, elastic hydrogels have been shown to withstand elongation and compression subsequent to full expansion. Thus, elastic hydrogels are an encouraging option as tissue expanders for reconstruction.

Historically, a hydrogel tissue expander was first developed to treat congenital anophthalmia. The osmotic active components of this type of device were poly(vinylpyrrolidone) (PVP) and poly(hydroxyethyl methacrylate) (pHEMA). ${ }^{36}$ Building on this knowledge, Wiese et al. designed a selfexpanding expander that reached a higher swelling state than typical PVP/poly(methyl methacrylate) (PMMA) hydrogels by exchanging the $\mathrm{CH}_{3}$ groups in the PVP/PMMA hydrogel chains for carboxylic groups. ${ }^{34}$ The device's swelling capacity $(\mathrm{Q}=$ maximum swelling volume/anhydrous volume $)$ 
A
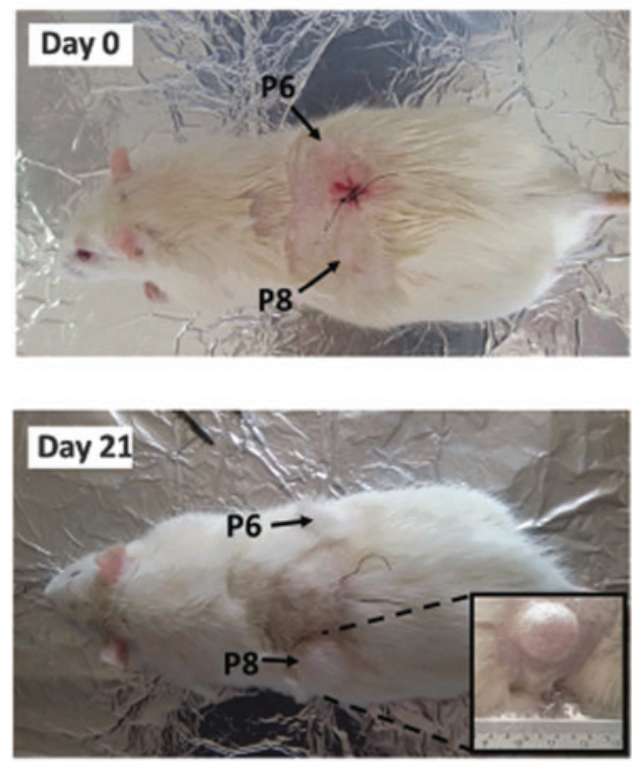

D

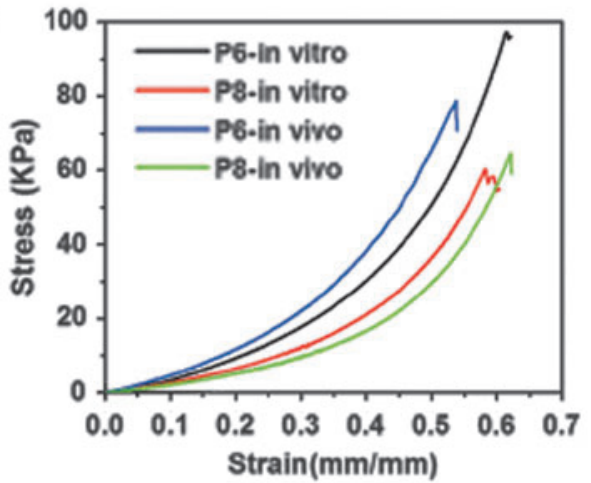

\section{After 4 Days}

B
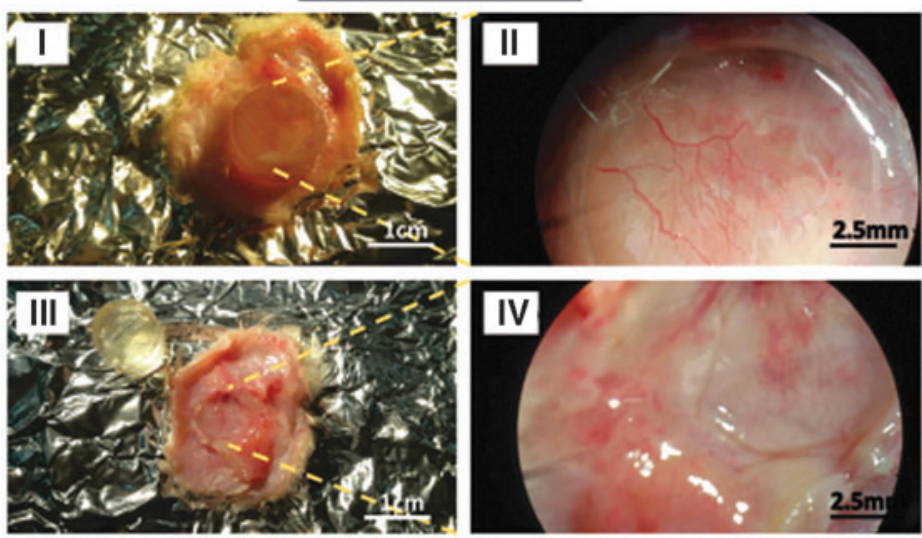

After 21 Days
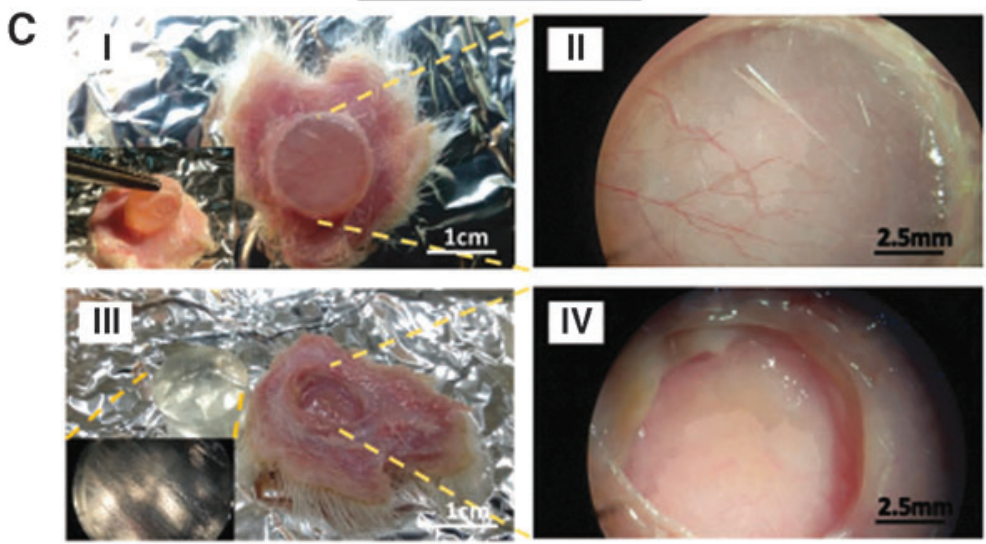

E

\begin{tabular}{|ccccccc|}
\hline & Sample & $\begin{array}{c}\text { Compressive } \\
\text { Modulus }(\mathrm{KPa})\end{array}$ & $\begin{array}{c}\text { Compressive Strain } \\
\text { at break }(\mathrm{mm} / \mathrm{mm})\end{array}$ & $\begin{array}{c}\text { Compressive } \\
\text { Strength }(\mathrm{KPa})\end{array}$ & $\begin{array}{c}\text { Mass Swelling } \\
\text { ratio }(\%)\end{array}$ & $\begin{array}{c}\text { Volume Swelling } \\
\text { ratio }(\%)\end{array}$ \\
\hline After 4 days & P6 & $65.7 \pm 5.6$ & $0.53 \pm 0.04$ & $98.1 \pm 6.3$ & $888.3 \pm 5.7$ & $903.4 \pm 22.3$ \\
\cline { 2 - 7 } & P8 & $32.6 \pm 3.4$ & $0.55 \pm 0.037$ & $80.4 \pm 7.2$ & $992.3 \pm 34.4$ & $1029 \pm 54.9$ \\
\hline After 21 days & P6 & $58.9 \pm 4.9$ & $0.53 \pm 0.06$ & $93.2 \pm 10.1$ & $923.9 \pm 28.4$ & $953.6 \pm 36.8$ \\
\cline { 2 - 7 } & P8 & $27.3 \pm 5.6$ & $0.62 \pm 0.058$ & $64.5 \pm 5.7$ & $1102.9 \pm 50.3$ & $1108 \pm 61.9$ \\
\hline
\end{tabular}

FIG. 1. Results of in vivo studies on engineered PEGDA expanders performed by Jamadi et al. (A) Day 0: two expanders (P6 P8) were implanted in each rat. Day 21: Both expanders generated enough swelling dilate adjacent tissue. The skin expanded in all cohorts was in good condition with viable hair growth. (B) In vivo study 4 days after subcutaneous implantation (P8). (B.I) The explanted area includes expanded skin and the developed granulation tissue that surrounded the expanders. (B.II) Granulation tissue with blood vessels magnified under loupe microscope. (B.III) The expander was explanted from the overlying expanded skin and granulation tissue and retained its original shape. (B.IV) Expanded skin (magnified under loupe microscope) demonstrated signs of mild inflammation. (C) In vivo study 21 days after subcutaneous implantation (P8). (C.I) The expanded skin and the developed fibrous capsule surrounded the expanders. (C.II) Fibrous capsule with blood vessels (magnified under loupe microscope). (C.III) The expander was explanted from the overlying expanded skin and fibrous capsule. The expander device retained its original shape. (C.IV) Skin on the site of expansion (magnified with loupe microscope) demonstrated little-to-no inflammation. (D) Representative stress-strain curves of P6 and P8 hydrogels before and after implantation (day 21), both in the expansion state (E) Mechanical and swelling properties of explanted hydrogels on PODs 4 and 21. PEGDA, poly(ethylene glycol) diacrylate; POD, postoperative day. Copyright Wiley-VCH Verlag GmbH \& Co. KGaA. Reproduced with permission from Jamadi et al. ${ }^{42}$ Color images are available online. 
depended on the degree of ionization of the polymer material. Furthermore, the authors present this material to be biocompatible as monocytes did not migrate or attach to the hydrogel and therefore did not phagocytose the material or show any sign of a foreign body reaction. Currently, mostly of hydrogel-based tissue expanders frequently used in the clinical arena consist of VP and MMA copolymers. ${ }^{37-40}$ However, research efforts have been focused on discovering alternative novel biomaterials. Janovák et al. developed thermoresponsive hydrogels composed of poly(N-isopropylacrylamide) (PNIPAAm) as osmotic tissue expanders. ${ }^{41}$ In their study, they determined that swelling and mechanical properties can be manipulated through polymer composition, crosslink density $\left(v=\rho / \mathbf{M}_{c}\right.$, where $\rho$ is the density of the polymer and $M_{c}$ is the molecular weight of polymer segments between two crosslinks), and concentration and hydrophilicity of fillers. This work reinforces the idea that biomaterials may be modified depending on clinical necessity (i.e., patient-specific anatomy). Furthermore, Jamadi et al. were able to create poly(ethylene) glycol (PEG)-based hydrogels with adjustable mechanical and swelling features by creating composite mixtures of differing molecular weights. ${ }^{42}$ The composite PEG-based expanders were able to be compressed up to $60 \%$ of their initial height and could be loaded cyclically for multiple times without mechanical hysteresis. Studies in vivo indicated that these hydrogels were able to produce an expanding pressure high enough to distend the neighboring tissue, while maintaining its original configuration (Fig. 1).

Currently, an important limitation when applying the hydrogel-based tissue expanders is the isotropic expansion, meaning that the swelling happens evenly in all directions. Therefore, Swan et al. developed a novel hydrogel able to control unequal expansion, or in an anisotropic manner. ${ }^{43}$ This novel feature broadens the clinical applications for which these materials could be implemented. Repairing an anatomical defect can now be established without the risks of device extrusion and unfavorable expansion. In in vitro studies, anisotropic expansion was achieved in a hydrogel polymer network composed of MMA and VP by annealing the xerogel for a specified period of time under a compressive load. The authors were able to modify the anisotropic conditions and composition, increasing expansion ratio up to $1500 \%$. In a follow-up study, Swan et al. implanted their device under the mucoperiosteal plane of swine palates. ${ }^{44}$ In vivo results demonstrated a significant volume expansion of the area after 6 weeks, without prominent inflammatory reaction.

Hydrogel-based tissue expanders have many advantages over conventional methods. The lack of a filling port and its malleability allows the device to be applied in any anatomical site. Traditional expanders require close follow-up with a health care professional for regular inflation. Hydrogels do not require regular, percutaneous inflation, ultimately reducing patient morbidity and health care costs.

\section{Vascularized Composite Allotransplantation: From Mythology to Clinical Reality}

A major advancement in modern reconstructive surgery has been the reshaping of human form with tissue from a donor, referred to as vascularized composite allotransplantation (VCA) ${ }^{45}$ (Fig. 2). VCA has been practiced in the United States since 1998 with the first documented case being a larynx transplant. ${ }^{46}$ VCA donation and transplantation were integrated into the OPTN/UNOS Organ Procurement and Transplantation Network (OPTN) in 2014, ultimately establishing a national network for VCA donation. Due to this classification, many clinicians propose VCA to become more widespread, especially as new therapies and protocols are transferred from the bench to the bedside. $^{47}$

VCA is an allogeneic transplant surgery like solid organ transplantation (SOT; e.g., lungs, kidneys, and hearts), but instead involves a collection of tissues including skin, vasculature, nerves, muscles, and others. Currently, its most common uses in reconstructive surgery involve the face and hands, with penile transplantation recently becoming common with the first U.S. transplant performed at Massachusetts General Hospital in 2016 and the first U.S. full penis/ scrotal transplant performed at Johns Hopkins Hospital in 2018. ${ }^{48-50}$ While the actual operative technique of VCA surgery is not easy, most procedures are successful due to their elective nature, the assembly of organized medical and surgical teams, and personalized planning - which can take anywhere from months to years. ${ }^{51}$ So why is VCA, specifically hand and face transplantation, not more common? To put it simply, unlike most solid organ transplants, VCA is not usually considered lifesaving and can carry significant

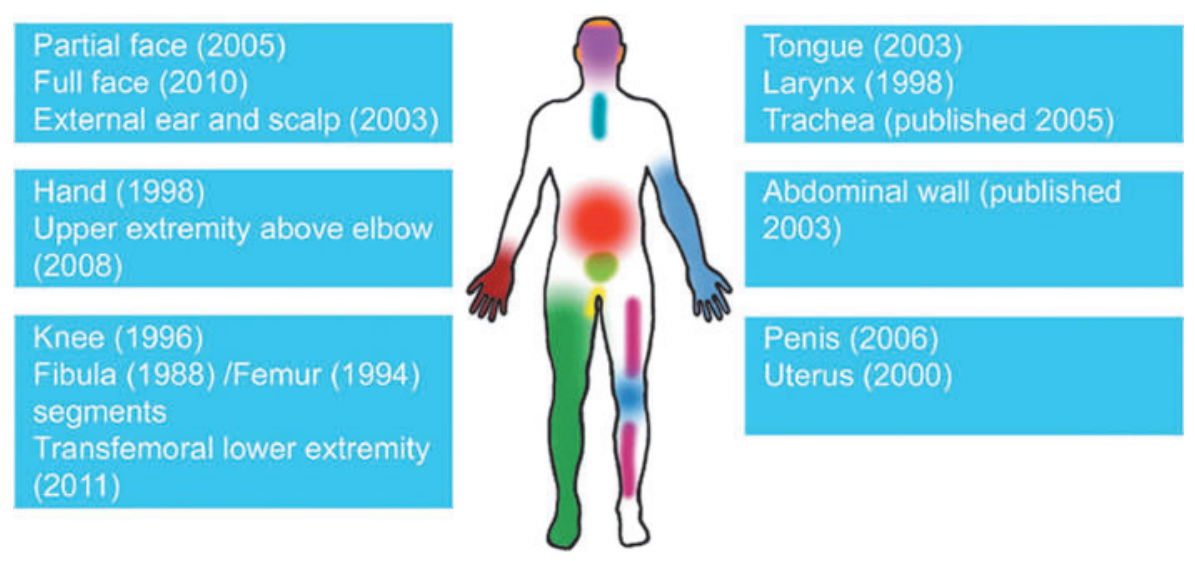

FIG. 2. Global progress in clinical vascularized composite allotransplantation (VCA) by year of transplantation and/or publication by Edtinger et al. Figure reproduced with permission from Springer Nature, the original figure was published under the Creative Commons Attribution 4.0 International License. ${ }^{45}$ Individual references. ${ }^{53-67}$ Color images are available online. 
risk-medical, psychological, and social. When specifically talking about penile transplant, significant efforts are being made in elaborating guidelines to mitigate ethical concerns and psychological complications. ${ }^{52}$ Failure of the patient to adapt emotionally and/or psychologically is correlated with more clinical complications. Important factors for success include having good friends and family support, intact coping mechanisms, and financial means to allocate near a transplant team; plus, the fact of being able to handle the stress of being a public figure, because of the high probability of the media to cover the story. Nonetheless, these procedures are "life enhancing" and should therefore be considered in certain patient populations.

Allogeneic transplant surgery, in simplicity, involves taking a donor's body part and attaching it to a recipient in a way that it integrates biologically to become healthy, living tissue. ${ }^{68}$ However, when transplanting a body part or organ into a recipient, the immune system will recognize the tissue as foreign and commence to reject it. Currently, the only way for transplanted tissue to survive is to have a strict immunosuppressant medication regimen. ${ }^{69}$ As an adverse effect, patients on this type of treatment are prone to infections and certain types of malignancies. Ultimately, the benefit of life and improvements in long-term quality of life (QOL) from SOT have made this treatment option the gold standard for organ failure, in light of its complications and risks. ${ }^{70}$ However, for faces and limbs, the reward is quite different with a higher risk because the immunosuppression protocols are currently harsher. Research has shown that the incidence of having a single acute rejection episode in the postoperative period surpasses $80 \%$ in face and hand transplants, compared to only $20 \%$ for renal allografts. ${ }^{71,72}$ The explanation of why the incidence of rejection in VCA is so much higher than SOT is still a mystery, but Kueckelhaus et al. (2017) suggest three main causes: a more competent immune system in VCA recipients, VCA-specific immune responses and immunogenicity, and an overall inexperience of immunosuppressive therapy in such a novel field. ${ }^{73}$ Many researchers believe that a main proponent is the inclusion and involvement of skin in VCA, since skin is known to be the most immunogenic tissue; VCA transplants are large in size and are composed of different tissues, affecting the immune response at levels. ${ }^{73}$ More specifically, the skin contains a number of elements capable of self-triggering the host immunological system. Some mechanisms include the following: production of cytokines by innate activated cells (e.g., fibroblasts) to stimulate antigen-presenting cells (APCs), activation of dermal dendritic cells (DCs) into APCs through cytokines produced, recruitment of memory cells by an activated capillary endothelium expressing human leukocyte antigen (HLA) Class I and II, transendothelial migration of lymphocytes by endothelial expression of adhesion molecules, clonal expansion and maturation of $\mathrm{T}$ cells into effector and memory cells causing vast destruction through their effector mechanisms when the migration reaches superficial layers of the skin like the epidermis, and many more. ${ }^{74-76}$ Unlike SOT, in VCA, transplantation antibody-mediated rejection is not quite well understood, although some authors have described the presence of complement components (C4d) inside the graft. ${ }^{53}$ Antibodies are known to "complement fix," that is, to activate the complement cascade. Therefore, antibodies are thought to be important, but further research in this area is warranted. Furthermore, another issue that plays a major role in VCA graft failure is ischemic-reperfusion injury (IRI). ${ }^{77}$ IRI occurs when a tissue source undergoes ischemia for a prolonged period (e.g., during procurement), and then is quickly perfused causing the rapid synthesis of reactive oxygen species (ROS), especially hydrogen peroxide $\left(\mathrm{H}_{2} \mathrm{O}_{2}\right)$, which results in cellular and tissue toxicity.

Along with graft failure, another major issue in VCA is functional outcome over time. These surgeries require the connection of peripheral nerves from the recipient site to the donor tissue. The rate of peripheral axonal growth commonly agreed upon in the scientific community is about $1-2 \mathrm{~mm}$ per day. Therefore, peripheral nerve regeneration research, in the context of VCA and in isolated nerve injuries, is of great interest to reconstructive surgeons. ${ }^{78}$ Thus, it can take full limb and face transplant recipients a year before they recover adequate, but never full, motor and sensory function. ${ }^{78}$ Currently, VCA patients must go through stringent physical training regimens of at least $2 \mathrm{~h}$ a day, with constant functional outcome testing (as imaging modalities are still experimental), to ensure successful nerve coaptation (bringing the proximal recipient stump together with the distal donor stump) and to return to their everyday activities.

To this date, over $200 \mathrm{VCA}$ surgeries have been performed $^{45}$ (Fig. 2). Due to the limitations specified above, they have had variable outcomes. As of today, a limited number of specific institutions in the United States have approval to perform VCA and patients must go through a very rigorous screening process-psychological, physical, and immunological-before being approved by a handpicked team of medical professionals. ${ }^{79}$ Although very promising, VCA is infrequently performed in the United States due to ethical considerations, which include the use of harsh immunosuppression protocols and relatively poor functional outcomes. Furthermore, cost analysis research has shown VCA to be more costly than conventional reconstruction. For example, Nguyen et al. determined facial transplantation to be costlier. However, once adjusted for case severity and the potential for needing further operations, the cost profiles were similar-except for costly immunosuppression protocols needed in the VCA cohort. ${ }^{80}$ That being said, standardized and widespread use are expected to lower costs, ultimately making these procedures more affordable for the health care system. ${ }^{80}$ For the reasons described, many researchers are working on ways to increase graft survival (primarily through immunotolerance) and improve functional outcomes (primarily through peripheral nerve regeneration). The goal of these technologies is to increase the success of VCA, allowing for its more widespread use, not just in face and hand transplantation, but in all aspects of reconstructive surgery.

\section{Improving graft acceptance}

Sustained, targeted, and controlled delivery of immunosuppressants and ROS scavengers. Progress in the biomaterials field has resulted in revolutionary drug delivery scaffolds that aid immunosuppressants through sustained, targeted, and controlled drug release. ${ }^{81}$ Several key advantages of controlled drug delivery are the ability to maintain therapeutic drug concentrations, reduce systemic toxicity, 
Table 2. Common Immunosuppressant Medications Currently Used in Transplantation, Their Mechanisms of Action, and Associated Systemic Side Effects

\begin{tabular}{|c|c|c|}
\hline Immunosuppressant & Mechanism of action & Systemic side effects \\
\hline $\begin{array}{l}\text { Tacrolimus } \\
\quad \text { (a.k.a. FK506) }\end{array}$ & Calcineurin inhibitor & $\begin{array}{l}\text { Nephrotoxic, neurotoxic, hypertension, glucose } \\
\text { intolerance, hyperkalemia, metabolic acidosis, } \\
\text { and hyperlipidemia }\end{array}$ \\
\hline $\begin{array}{l}\text { Corticosteroids } \\
\text { i.e. prednisone }\end{array}$ & $\begin{array}{l}\text { Inhibits production of IL- } 1 \text { and IL- } 6 \text {; } \\
\text { blocks T cell activation }\end{array}$ & $\begin{array}{l}\text { Osteonecrosis, osteoporosis, CNS effects, growth } \\
\text { suppression, glucose intolerance, hypertension, } \\
\text { obesity, poor wound healing, adrenal } \\
\text { suppression, cataracts, and cushingoid features }\end{array}$ \\
\hline Cyclosporine & Calcineurin inhibitor & $\begin{array}{l}\text { Nephrotoxic, neurotoxic, hypertension, mild tremor, } \\
\text { excess hair growth, gingival hyperplasia, glucose } \\
\text { intolerance, hyperkalemia, metabolic acidosis, } \\
\text { and hyperlipidemia }\end{array}$ \\
\hline Azathioprine & $\begin{array}{l}\text { Inhibits purine synthesis causing } \\
\text { decreased DNA and RNA synthesis }\end{array}$ & Bone marrow depression, hepatotoxic, and PTLD \\
\hline $\begin{array}{l}\text { Mycophenolate } \\
\text { mofetil }\end{array}$ & $\begin{array}{l}\text { Impairs } \mathrm{B} \text { cell and } \mathrm{T} \text { cell proliferation } \\
\text { by inhibiting de novo guanosine } \\
\text { nucleotide synthesis }\end{array}$ & $\begin{array}{l}\text { Gastrointestinal toxicity (abdominal pain, nausea, } \\
\text { vomiting, and diarrhea), leukopenia, } \\
\text { myelosuppression, viral infections, } \\
\text { and spontaneous abortions }\end{array}$ \\
\hline Sirolimus & $\begin{array}{l}\text { mTOR inhibitor; inhibits } \mathrm{T} \text { cell } \\
\text { proliferation }\end{array}$ & $\begin{array}{l}\text { Hypertension, myelosuppression, diarrhea, } \\
\text { proteinuria, poor wound healing, and skin rash }\end{array}$ \\
\hline Muromonab-CD3 & $\begin{array}{l}\text { Anti-CD3 antibody that prevents } \\
\mathrm{T} \text { cell activation }\end{array}$ & $\begin{array}{l}\text { Pulmonary edema, acute renal failure, severe } \\
\text { cytokine-release syndrome, digestive toxicity, } \\
\text { CNS effects (seizures), infections, and lymphoma }\end{array}$ \\
\hline
\end{tabular}

CNS, central nervous system; PTLD, post-transplant lymphoproliferative disorder; RNA, ribonucleic acid.

Source: Halloran. ${ }^{86}$

and being able to use biochemical stimuli to modulate release. $^{82}$ The most popular controlled drug delivery systems (DDS) are polymeric hydrogels and microparticles and nanoparticles (NPs) due to manipulative properties such as size, stimuli-responsivity, and kinetics that can be adjusted by fine-tuning their chemical composition, morphology, physicochemical properties, molecular weights, fabrication method, and degree of crosslinking. ${ }^{83-85}$ By modifying these features, scientists have been able to simultaneously improve clinical efficacy and reduce systemic toxicity of current FDA-approved immunosuppressants (Table 2).

Many DDS have been studied in SOT models. ${ }^{87}$ Even though the immunobiology of VCA has been shown to differ from SOT, ${ }^{88}$ scientists and surgeons have begun to study their use in VCA-relevant animal models due to NP success in SOT preclinical studies. For example, Gajanayake et al. loaded tacrolimus (TAC; a.k.a. FK506, Table 2) into a self-assembled triglycerol monostearate (TGMS) hydrogel that was designed to release the drug in response to proteolytic enzymes (MMP-2 and MMP-9), which are overexpressed in inflammatory environments (Fig. 3).

The authors found that with a single local injection of the TAC-based hydrogel, significantly prolonged graft survival in a full major histocompatibility complex (MHC) mismatches murine limb transplantation model, leading to a median graft survival of $>100$ days, compared to 33.5 days in mice infused with systemic TAC (Fig. 4).

Furthermore, the experimental group was shown to have less kidney and liver toxicity. ${ }^{89}$ Using a similar technique, Unadkat et al. developed double-walled FK506 (TAC)laden microspheres and evaluated immunosuppression in a rodent hind limb transplantation model. The FK506 disks were inserted subcutaneously either in the native nontransplanted leg or in a transplanted allograft. Systemic FK506 levels were drawn. The authors chose their endpoint to be either graft survival at 180 days or a grade 3 rejection. At the end of the study period, they measured tissue concentrations of FK506 levels and mixed lymphocytic reactions. The authors found that a sole disk maintained therapeutic systemic blood FK506 levels between 5 and $15 \mathrm{ng} / \mathrm{mL}$ for $146 \pm 11.1$ days. Past this point, the concentration of the drug decreased to below $5 \mathrm{ng} / \mathrm{mL}$, but there was an increased level of the immunosuppressive drug in the draining lymph nodes (DLNs). Unlike other groups, animals with an FK506 disk in the transplanted allograft had 100\% allograft survival for more than 180 days, despite subtherapeutic systemic levels below $5 \mathrm{ng} / \mathrm{mL}$. Characterization of lymphocytic reactions revealed $\mathrm{T}$ cell hyporesponsiveness in the inguinal nodes draining the FK506 disk. ${ }^{90}$ These two studies, along with others, show that targeted, controlled, and sustained immunosuppressant delivery systems can lower systemic toxicity and improve drug efficacy, and demonstrate their promise for implication in VCA.

Although local injection strategies have been successful, systemic therapies have been less so. Only recently, the importance of site-specific targeting of systemic therapies has been realized. Recently, it has been hypothesized that outcomes in transplantation and immune diseases have improved, when targeting drug delivery into DLNs. Bahmani et al. demonstrated this in murine cardiac allografts. ${ }^{91}$ They targeted their therapy through the knowledge that peripheral node addressin (PNAd) molecules are uniquely expressed in the high endothelial venule. PNAd is recognized by MECA79 monoclonal antibodies (mAb). They synthesized an anti-CD3 NP (described in Immunomodulation: Biomimetic Drug 
A

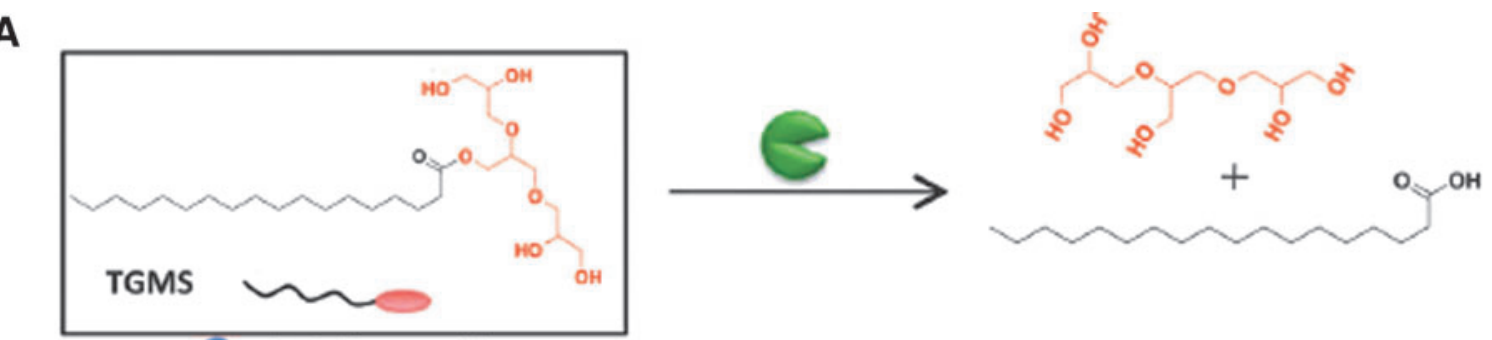

B

Tacrolimus $\downarrow$ Encapsulation of drug

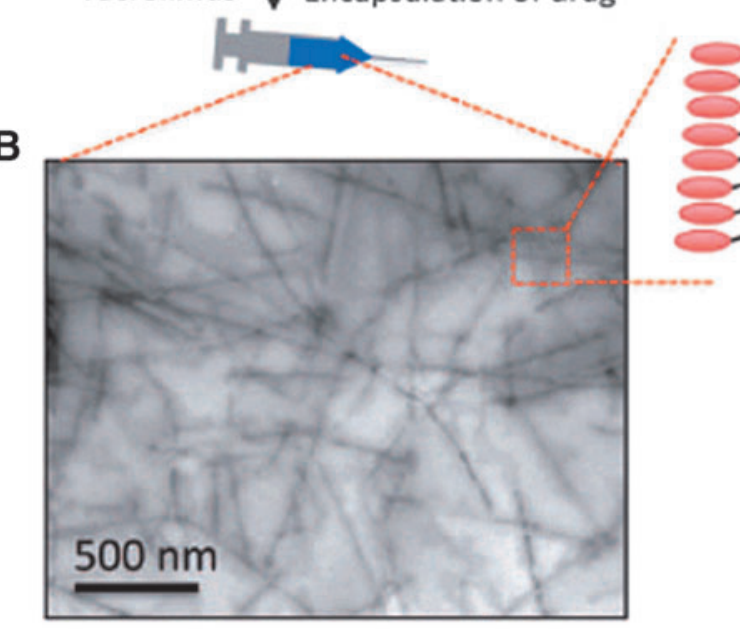

C

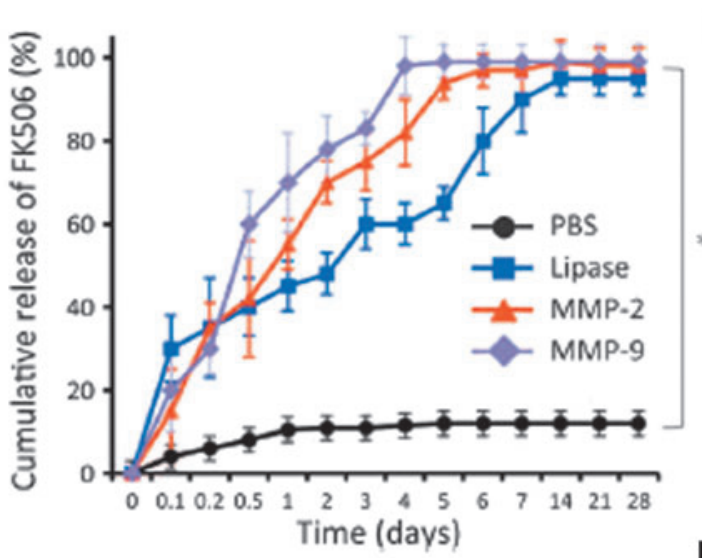

D

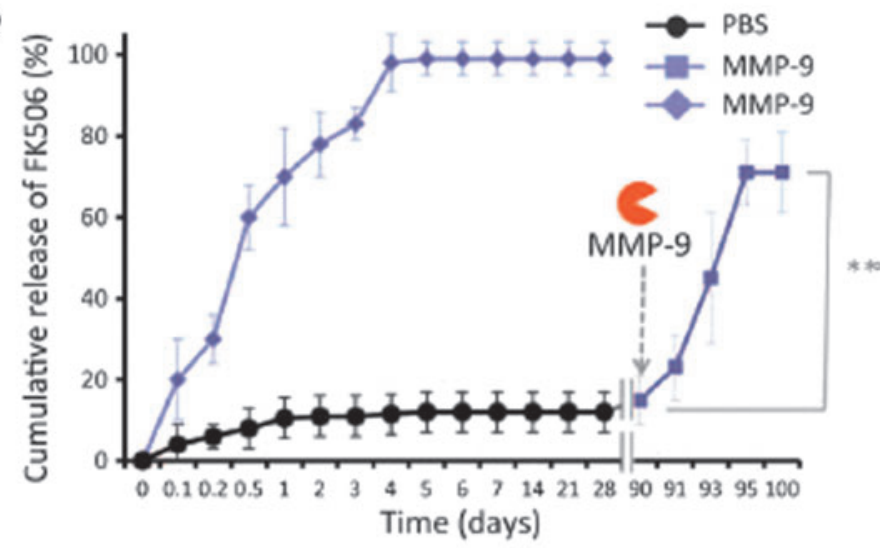

$\mathbf{E}$

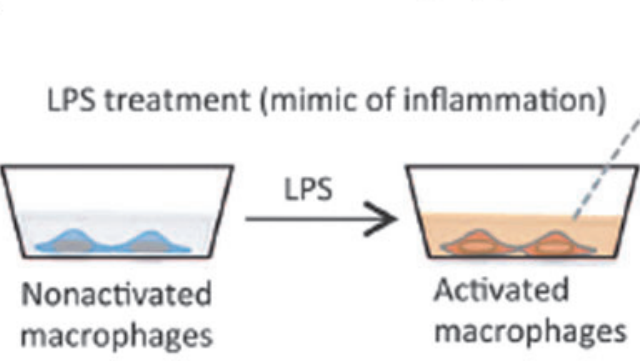

$\mathbf{F}$

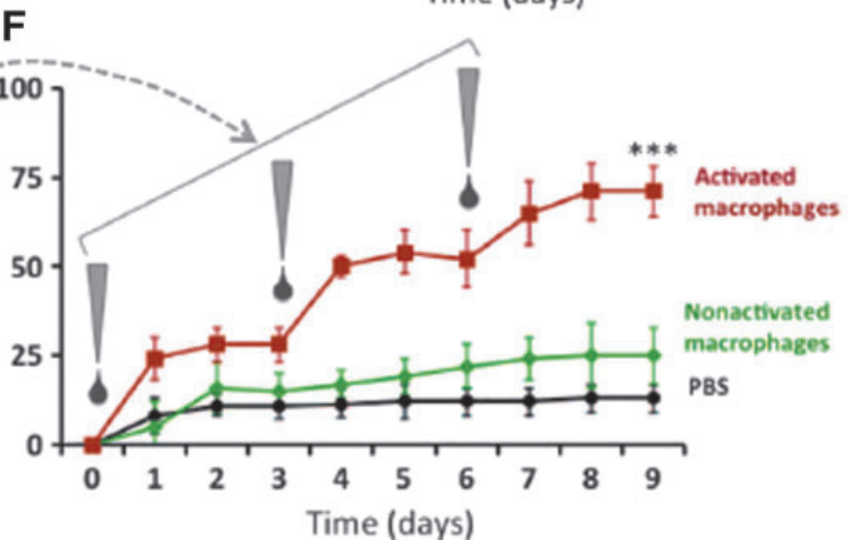

FIG. 3. Encapsulation of TAC in TGMS hydrogel and enzyme-responsive drug release by Gajanayake et al. (A) TGMS self-assembly and TAC encapsulation. (B) Transmission electron micrograph of TGMS-TAC hydrogel. (C, D) Proteolytic enzyme-responsive TAC release. Hydrogels incubated in PBS remained hydrolytically stable and did not release drug for at least 3 months. Addition of proteolytic enzymes (lipase, MMP-2, and MMP-9) induced the release of drug. * $p<0.002$ and $* * p<0.01$, PBS versus enzyme-treated groups. (E) Schematic of LPS activation of RAW 264.7 macrophages to mimic inflammation. (F) Cell culture supernatant from activated macrophages induced drug release (gray symbols, supernatant added on days 0,3 , and 6 ), meanwhile supernatant from nonactivated macrophages or PBS did not $(* * * p<0.03)$. LPS, lipopolysaccharide; PBS, phosphate-buffered saline; TAC, tacrolimus; TGMS, triglycerol monostearate. Figure reproduced with permission from The American Association for the Advancement of Science. ${ }^{89}$ Color images are available online. 
A

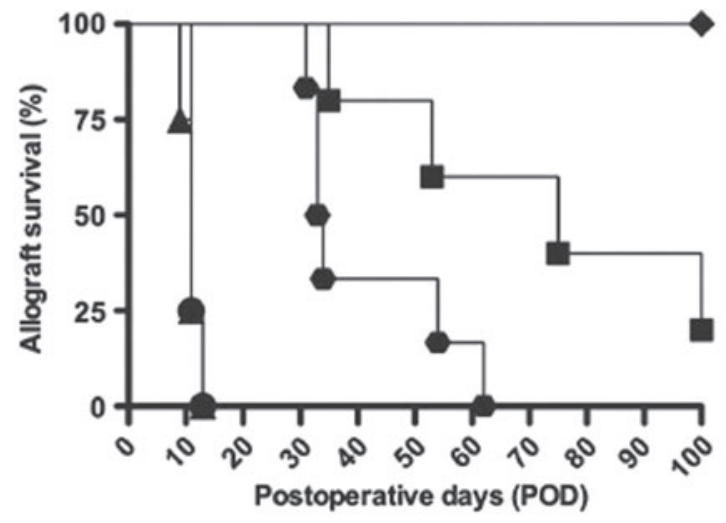

B

\begin{tabular}{llllll}
\hline Groups & Treatment & $\boldsymbol{n}$ & MST (days) & $\boldsymbol{P}$ \\
\hline- & I & No treatment & 4 & 11 & \\
- & II & TGMS & 4 & 11 & \\
- & III & TAC & 6 & 33.5 & \\
- & IV & TGMS-TAC & 6 & $>100$ & IV vs III; $P=0.0005$ \\
& V & TGMS-TAC/ConLat & 5 & 75 & IV vs. V; $P=0.0068$ \\
- & & & & V vs. III; $P=0.0352$
\end{tabular}

C

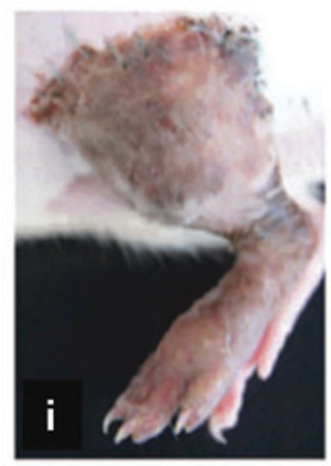

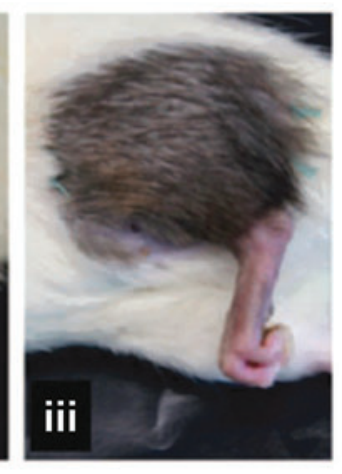

D

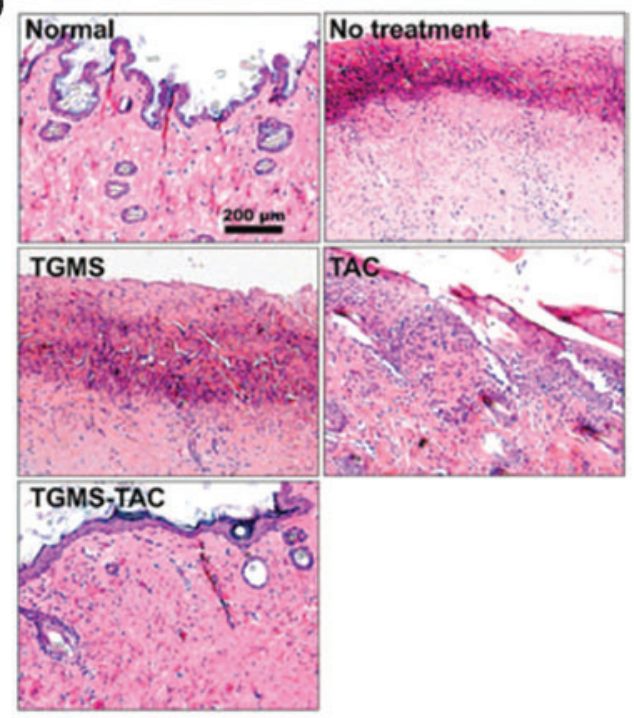

E

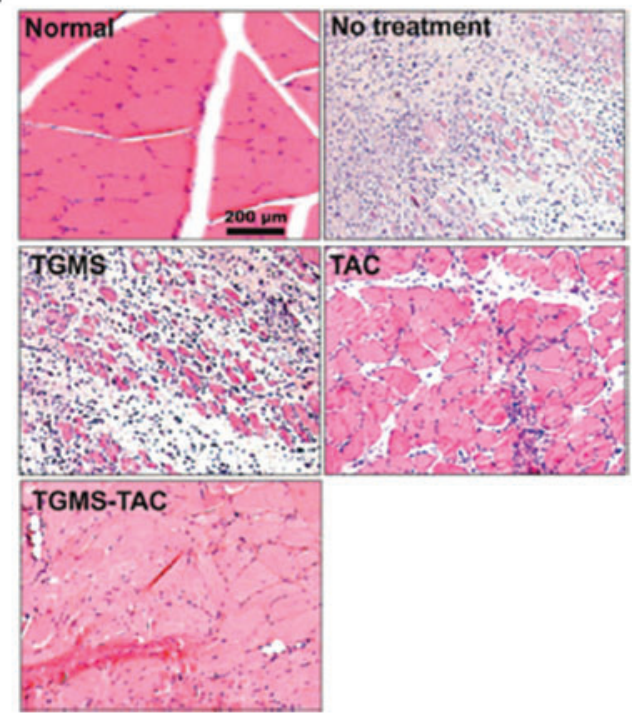

FIG. 4. VCA survival studies and histopathological features performed by Gajanayake et al. (A, B) Brown Norway-toLewis orthotopic hindlimb transplantation. Control groups were left untreated (I) or were treated with TGMS as a vehicle (II). Experimental groups were treated with a single injection of 7-mg TAC subcutaneously (III) or 7-mg TGMS-TAC (IV) into the transplanted or contralateral limb (TGMS-TAC/ConLat) (V), respectively, at POD 1. Kaplan-Meier graft survival curves are shown. (C) Representative macroscopic images of hindlimb allografts. (C.i) Groups I and II showed an acute rejection with a MST of 11 days. (C.ii) Group III allografts (single injection of 7-mg TAC), rejected with a MST of 33.5 days. (C.iii) No signs of rejection were seen in the long-term survival group IV on day 100. (D, E) Representative photomicrographs of the histology (hematoxylin and eosin staining) of skin (D) and gastrocnemic muscle (E) of normal rats, no treatment, TGMS-treated, TAC only-treated, and TGMS-TAC-treated groups. Rejected grafts showed cell infiltration, edema formation, and necrosis. MST, mean survival time. Figure reproduced with permission from The American Association for the Advancement of Science. ${ }^{89}$ Color images are available online.

Delivery and Materials section) and coated the surface with MECA79 mAb (MECA79-anti-CD3-NP) to increase lymphonodular accumulation. The accumulation of MECA79NPs at the DLN was significantly higher compared to nonconjugated particles. The MECA79-NPs experienced internalization by $\mathrm{T}$ cells and DCs within the LNs. Furthermore, short-term treatment of murine cardiac allograft recipients with MECA79-anti-CD3-NPs resulted in prolonged allograft survival. More specifically, a prominent presence of intragraft and DLN regulatory $\mathrm{T}$ (Treg) cell populations were observed. Many of the published studies regarding site-targeted systemic delivery have been done in SOT and not in VCA. Since the immunology and clinical applications of these procedures are vastly different, targeted systemic delivery studies in VCA are warranted.

IRI is also a main contributor to reduced graft function and graft rejection. ${ }^{77}$ The starring role in the pathophysiology of IRI is the rapid mass production of ROS. $\mathrm{H}_{2} \mathrm{O}_{2}$ is the most common form of ROS synthesized as a byproduct during IRI. This produces inflammation, apoptosis, and 
further tissue/organ damage. ${ }^{92}$ A variety of antioxidants have been investigated for their ability to reduce IRI. These include curcumin, quercetin, superoxide dismutase, Tempol, Coenzyme Q10, taurine, zinc aspartate, and others. ${ }^{93}$ Heme oxygenase 1 has demonstrated, in the literature, some encouraging benefits in renal transplants, by improving graft performance without affecting immunosuppressive therapy blood levels. ${ }^{94}$ However, no randomized controlled trials have been done to prove the role of antioxidants or combination of these reducing IRI. Thus, a recent idea in the field of biomaterials has been to create ROS "scavengers" or "sponges" that react or bind to excess ROS, especially $\mathrm{H}_{2} \mathrm{O}_{2}$, and create a benign reaction product. ${ }^{95}$ Lee et al. reported antioxidant NPs formulated from copolyoxalatecontaining vanillyl alcohol (VA) (PVAX) as a novel IRItargeted nanotherapeutic agent. The authors designed PVAX with antioxidant VA and $\mathrm{H}_{2} \mathrm{O}_{2}$-responsive peroxalate ester linkages covalently incorporated in its backbone. They showed that their PVAX NPs degrade in the presence of $\mathrm{H}_{2} \mathrm{O}_{2}$ causing the release of $\mathrm{VA}$, ultimately reducing the generation of ROS and concomitantly exerting antiinflammatory and antiapoptotic activity. ${ }^{96}$

Although the use of a VA release system has been common, Dollinger et al. applied a novel technology by creating the triblock polymer poly[(propylene sulfide)-block-(N,Ndimethylacrylamide)-block-(N-isopropylacrylamide)] $\left(\mathrm{PPS}_{135^{-}}\right.$ $b$-PDMA ${ }_{152}-b$-PNIPAAM 225 , or PDN). In this system, the poly(propylene sulfide) (PPS) chemistry reacts irreversibly with $\mathrm{ROS}$, such as $\mathrm{H}_{2} \mathrm{O}_{2}$, conveying intrinsic antioxidant capabilities to the system. In their studies, PDN hydrogels were satisfactorily integrated to type I collagen to form ROS-protective, composite hydrogels for the successful delivery of cell therapies which, in their case, were beta islet cells transplanted for diabetes. ${ }^{97}$ This approach also conceivably has potential for the protected transportation of stem cells (for immunomodulation and peripheral nerve regeneration) and/or for suppressing IRI in allogeneic tissue transfers.

Immunomodulation: stem cell delivery. Mesenchymal stem cells (MSCs) have been proven scientifically to improve outcomes in SOT and VCA by increasing allograft survival, promoting peripheral nerve axonal regeneration, decreasing reperfusion injury, and promoting tissue healing. ${ }^{98}$ MSCs are multipotent, having the capability of differentiating into any cell of mesenchymal origin such as muscle, bone, ligament, tendon, and adipose tissue. ${ }^{99,100}$ MSCs were originally discovered in bone marrow and account for $0.001-0.01 \%$ of bone marrow cells, but it is now known that they are also present in umbilical cord tissue, amniotic fluid, developing molar tooth buds, and the most clinically relevant location-adipose tissue. ${ }^{101}$ When used experimentally or clinically, MSCs are autologous (i.e., they are harvested from a donor site [usually bone marrow or adipose tissue], processed, and then implanted at a recipient site in the same animal or patient), thereby circumventing any adverse immunological responses. ${ }^{99}$ One of the major barriers to the successful use of stem cell-based therapies in regenerative medicine is limited survival and retention at the desired site of action. ${ }^{102}$ To address this barrier, researchers have developed several approaches, including the encapsulation of stem cells in synthetic, anti-inflammatory extracellular matrices, biomaterial scaffolds to enhance stem cell survival and engraftment, pharmacological preconditioning of MSCs before administration, genetic modification of MSCs, and cotransplantation with other, supportive cell types. ${ }^{103,104}$

Originally, MSCs were thought to solely mediate tissue repair and regeneration through replacement of injured cells. Lately, researchers have suggested that MSCs secrete immunomodulatory cytokines and trophic factors that act through autocrine, juxtacrine, paracrine, and endocrine signaling (e.g., HLA-G, IL-6, PGE2, NO, and IDO), in response to specific stimuli such as the onset of acute/chronic transplant rejection. ${ }^{105-107}$ More specifically, MSCs are thought to decrease the activity of immune cells such as B cells, T cells, DCs, natural killer cells, neutrophils, and monocytes, while inducing the upregulation of Tregs, which have been shown in a countless number of studies to be immunosuppressive. ${ }^{108,109}$ In a study by Plock et al., Brown Norway-to-Lewis rat hindlimb transplant recipient animals were assigned to groups receiving donor-derived AD-MSCs (adipose-derived mesenchymal stem cells) either on postoperative day (POD) 1, POD 4, or repeatedly on PODs 4, 8, and 15. These groups were then compared to untreated controls. In control animals, all transplanted limbs were rejected within 7 weeks. All animals receiving a single administration of AD-MSCs on POD 4 rejected within 8 weeks. In the group receiving single administration of ADMSCs on POD 1, 60\% of recipients demonstrated graft survival over 12 weeks and the remaining grafts survived over 15 weeks. Finally, repeated AD-MSC administration on PODs 4, 8, and 15 resulted in graft survival over 15 weeks in $50 \%$ of the recipients. Endpoint histological analysis of graft arteries revealed significant differences of arterial intimal thickness between control and AD-MSC-treated animals. The authors determined that chimerism was associated with the increased generation of $\mathrm{CD}^{+} \mathrm{CD} 25$ highFoxP ${ }^{+}$Tregs. Although this study provided evidence for AD-MSC delivery improving VCA outcomes, future animal studies are warranted to optimize dosing and frequency of administration and understanding their potential role in combinatorial therapies before their translation to clinical use. ${ }^{110}$

Immunomodulation: biomimetic drug delivery and materials. Although targeted and controlled delivery of immunosuppression have decreased adverse effects, resulting in more efficacious outcomes with fewer side effects, recently, researchers have proposed therapeutics that simulate the body's self-immunologic tolerance mechanisms, called "biomimetics"111 (Fig. 5). Currently, the objective is to produce synthetic cell lines to have similar effects as Tregs and tolerogenic dendritic cells (tDCs). There is also a special interest in developing ways to promote the natural synthesis of these cellular lineages throughout the body ${ }^{87}$ (Fig. 5C, D). Currently, the main classes and goals of biomimetic therapy are Treg-inducing and recruiting factors, induction of tDCs, and artificial antigen-presenting cells (aAPCs). Multiple immunologic studies have shown that Tregs have the potential to promote acquired tolerance in allotransplantation. ${ }^{112}$ Thus, investigators have developed NPs coated with poly(lactic acid-co-glycolic acid) (PLGA) that target CD4 $\mathrm{T}$ cells to release leukemia inhibitory factor (LIF), a cytokine that has been shown to induce FoxP3 expression in T cells. ${ }^{113-115}$ In addition to Treg-inducing factors, factors that can recruit 
A

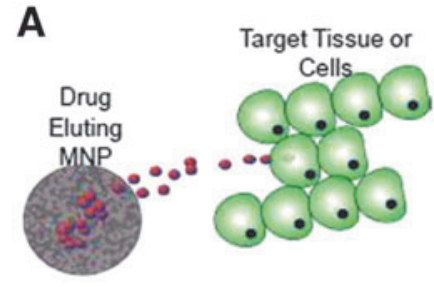

MNPs can provide sustained local delivery of immunosuppression to tissues of interest. Higher local concentrations result in decreased systemic toxicity and reduced dosing frequency.

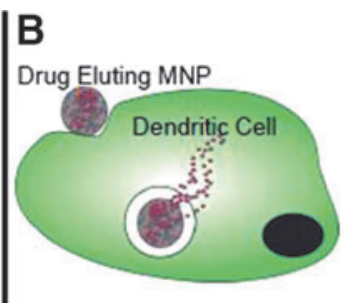

MNPs can be taken up by dendritic cells resulting in delivery of therapeutic factors to an intracellular target (mTOR, calcineurin, IMPDH2, etc.).
C

Signal 3

,

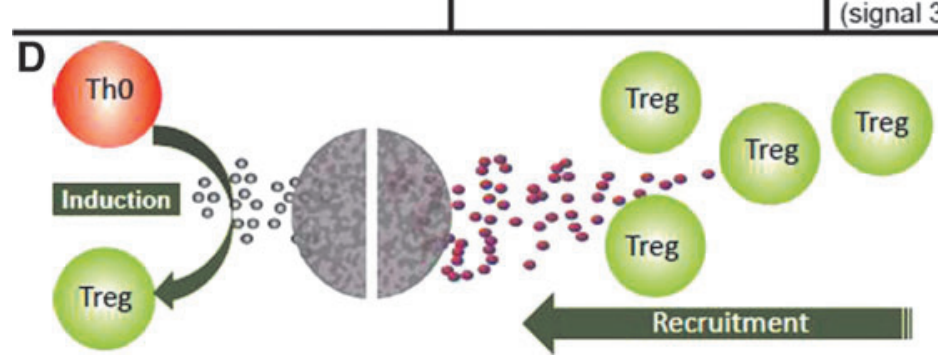

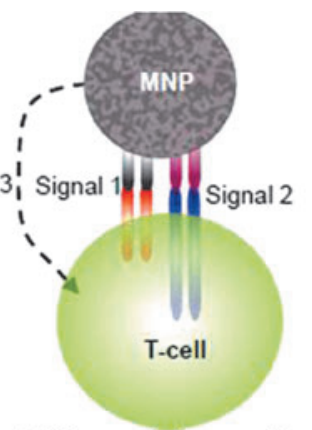

MNP aAPCs can influence T cell behavior by presenting antigen to the T cell receptor (signal 1), binding co-stimulatory molecules (signal 2) and eluting cytokines (signal 3)

Biomimetic delivery using MNPs can enrich for suppressor cells via chemokine/gradient based recruitment (right) or trophic factor based induction (left).
FIG. 5. Drug delivery routes and mechanisms using MNP-based drug delivery systems created by Fisher et al. (A) MNP's can deliver therapies locally. (B) MNP's can be uptaken by cells including immune cells such as dendritic cells to act intracellularly. (C) aAPCs can modulate signals 1,2 , and 3 ultimately affecting T-cell activation. (D) MNPs can be used to induce the production of and/or recruit endogenous Tregs. MNP, microparticle/nanoparticle. Image reproduced with permission from Elsevier. ${ }^{87}$ Color images are available online. endogenous Treg-cells are also promising. Fisher et al. were able to synthesize microparticles (MPs) referred to as Recruitment MPs (CCL22 loaded MPs), as well as Expansion MPs (IL2, transforming growth factor [TGF], and rapamycinloaded MPs) for the recruitment and expansion of endogenous Tregs, respectively. Following subcutaneous injections of recruitment and expansion MPs, transplanted rodent limbs survived indefinitely ( $>200$ days) and swine allografts survived more than 4 weeks without rejection. ${ }^{116}$ Along the same lines of immunomodulation, Lewis et al. showed that delivering cytokines and small molecules intracellularly and extracellularly to DCs hinders maturation, resulting in a tolerogenic (tDC) phenotype. They synthesized two classes of PLGA MPs: phagocytosable MPs loaded with either rapamycin or retinoic acid and unphagocytosable MPs loaded with either transforming growth factor beta (TGF- $\beta$ ) or IL-10. All combinations of these MPs, when cultured with DCs, demonstrated reduced surface expression levels of MHC II, CD80, and CD86, while leading to resistance of lipopolysaccharide (LPS) activation. Furthermore, DCs that received MPs were able to regulate $\mathrm{T}$ cell stimulation in mixed lymphocyte reactions and produce $\mathrm{T}$ cells toward a more regulatory class (Treg). ${ }^{117} \mathrm{MP}$ and NP formulations delivered locally in hydrogels or administered systemically have both been used to modulate immune tolerance in transplant applications. ${ }^{18,119}$ The size difference between NPs and MPs/ microspheres allows for precise control over drug loading efficiency, stability, cell membrane permeability, and local tissue retention. ${ }^{120}$ In general, the use of larger MP formulations or embedding NPs and MPs in hydrogels promotes local tissue retention due to limited diffusion, whereas NP formulation diffusion out of the site of delivery is inversely proportional to particle size and dependent on the site and/or method of administration. However, systemically adminis- tered NPs with systemic effects have been shown to be beneficial in certain applications. For example, Hlavaty et al. utilized systemically administered poly(lactide-co-glycolide) (PLG) NPs loaded with DBY, a model H-Y histocompatibility antigen, to induce tolerance induction in a murine bone marrow transplant model. ${ }^{121}$

Recently, immunotherapies for cancer have been a popular topic among researchers. A similar, but physiologically opposite technology could be useful for improved transplantation outcomes and treating autoimmune diseases among other applications. Instead of stimulating $\mathrm{T}$ cell proliferation and activity, scientists have recognized that a material that can downregulate the $\mathrm{T}$ cell response could result in significant therapeutic benefits. Thus, aAPCs have been of interest. These types of constructs aim to reach the $T$ cell receptor (TCR) in an indistinguishable way as innate antigen-presenting cells, but elicit a tolerogenic rather than immunogenic response. A well-accepted principle in immunology is that three "signals" are absolutely required for $\mathrm{T}$ cell activation, an all-or-none event termed the "3-signal hypothesis"122 (Fig. 5C). When APC MHC-peptide complex interacts initially with the T cell receptor this produces the first signal (signal 1) for cell activation. A secondary costimulatory signal, signal 2 , is needed, otherwise $\mathrm{T}$ cells are unresponsive even in the presence of signal 1. CD28 is the main receptor on $\mathrm{T}$ cells for signal 2, which has affinity to bind to the co-stimulatory molecules, B7-1 (CD80) and B72 (CD86). Finally, there is now significant proof that $\mathrm{CD} 8^{+}$ $\mathrm{T}$ cells also demand a cytokine-mediated signal (signal 3). This is mediated by macrophages and/or DCs. $\mathrm{CD} 8^{+} \mathrm{T}$ cells become unresponsive and fail to develop cytotoxic action when they do not receive a third signal, after signals 1 and 2 . Following these principles, the majority of aAPC constructs have a crowded surface bound to anti-CD3 (signal 1) and 
anti-CD28 (signal 2) ligands for TCR (CD3) and costimulatory receptors (CD28). They can then be synthesized or modified to control the lymphocytic immune response through specific interactions, targeted signaling, or localized drug/factor delivery, specifically to the $\mathrm{T}$ cell population (signal 3). ${ }^{123}$ In addition to Tregs, tDCs, and aAPCs, macrophages have been proposed to be important in transplantation. Based on signaling cues rising from their micromilieu, macrophages will differentiate into proinflammatory (M1), prohealing (M2), or regulatory (Mregs) macrophages. M1 macrophages are classically activated, attack the endothelial graft, and activate other leukocytes, resulting in tissue injury. This subclass is predominantly present in allografts that are acutely rejected. M2 macrophages are alternatively activated, and promote tissue repair and injury resolution, resulting in fibrosis. This phenotype is commonly found in allografts that are damaged chronically. Mregs are activated in a distinct pathway from M1 and M2 macrophages. They regulate antiinflammatory responses and have lymphocyte-suppressive capacity. For these reasons, Mregs have been attractive candidates for use as an adjunct cell-based suppressive therapy to prevent allograft rejection. ${ }^{124}$ Overall, biomimetic immunomodulatory biomaterials show great promise for the field of immunobiology.

\section{Improving peripheral nerve regeneration and postoperative functional outcomes}

Peripheral nerve injury remains a significant clinical problem as distal limb dysfunction severely affects patient QOL and results in substantial social and economic burdens. Peripheral nerve regeneration is a very complex process: the slow rate of nerve regeneration, Wallerian degeneration of nerve stumps, tissue adhesion, and muscular and motor end plate atrophy are severe limitations to functional rehabilitation. ${ }^{125}$ Physical therapy (i.e., kinetic therapy) is commonly utilized to promote functional recovery. However, stresses put on paralyzed muscles may hinder axonal recovery and should be initiated in later stages of nerve regeneration when gradual muscular strength return is demonstrated. ${ }^{126}$ Although preclinical animal models have demonstrated that physical exercise increases the number of regenerating axons, the rate of axonal growth, and the extent of muscle reinnervation following peripheral nerve injury, the evidence demonstrating a positive effect of exercise on nerve regeneration in humans is lacking. ${ }^{127}$ Consequently, current research and development are focused on methods to promote and guide axonal growth that results in functional remodeling, in conjunction with anatomical restoration.

Stem cell delivery. Like immunologic tolerance, the delivery of stem cells has also been hypothesized to improve peripheral nerve regeneration. ${ }^{128}$ They are thought to work through three main mechanisms of action: differentiating into Schwann-like cells, increasing neurotropic production, and by enhancing myelination of regenerating axons. A recent study by Cooney et al. determined that rats that underwent sciatic nerve transection with immediate repair and were treated with either local or systemic MSCs showed faster regain of compound muscle action potential amplitudes and higher axon counts when contrasted to negative controls. They also performed the same experiment in ro- dents receiving allogeneic hindlimb transplants. Subjects that received MSCs locally demonstrated an outstanding increase in axon counts. Overall, these researchers concluded that local and systemic MSC injections increased remarkably the rate and degree of axonal regeneration after injury and hindlimb transplantation model. ${ }^{129}$ Schwann cells are the key mediators of peripheral nerve regeneration (in comparison to oligodendrocytes in the central nervous system), but their use for cell-based therapy is restrained by the invasiveness of the harvesting and the resulting morbidity at the donor site. Schwann cells are embryologically originated from the neural crest. ${ }^{130,131}$ Therefore, neural crest stem cells have been studied extensively as a progenitor to Schwann cells. ${ }^{132}$ In addition, multiple other classes of stem cells have been studied for their ability to differentiate into Schwann-like cells. Other stem cells implicated and utilized in nerve regeneration include neural stem cells, embryonic stem cells, bone marrow-derived stem cells (BMSCs), adipose-derived stem cells, fetal-derived stem cells, skinderived precursor stem cells (SKP-SCs), hair follicle stem cells, dental pulp stem cells, muscle-derived stem/progenitor cells, and induced pluripotent stem cells (iPSCs). Every stem cell type has advantages and disadvantages, although mesenchymal stem cells (BMSCs and ADSCs) have been studied the most due to their differentiation potential, easy isolation, and immunomodulatory properties. ${ }^{128}$ Many preclinical studies have shown success, but progress to human clinical trials has been delayed due to ethical and safety concerns regarding stem cell therapies, including promotion of tumor growth, metastasis, and overestimated therapeutic potential. $^{133}$

Nerve guidance conduits. A nerve guidance conduit is a tubular structure, either synthetic or biological, whose purpose is to bridge the space between the two ends of a transected nerve, providing isolation from the surrounding tissue, avoiding scar formation, and functioning as a vessel for proximal axonal outgrowth into the distal nerve ${ }^{134,135}$ (Fig. 6). The conduit should provide an infrastructure for newly regenerated axons to reach the distal nerve stump, avoiding granulation (i.e., scar) tissue infiltration, and allowing the diffusion of neurotrophic factors synthesized at the nerve stumps. Some researchers have even incorporated materials that deliver cell therapies and/or neurotrophic molecules. ${ }^{136}$ Nerve conduits can be biologically derived from decellularized tissue (e.g., the FDA-approved decellularized allograft Avance ${ }^{\circledR}$ from Axogen, Inc.) or manufactured from synthetic or biological materials. ${ }^{136}$ Synthetic materials that have been studied include poly(lactic acid) (PLA), PLGA, poly( $\varepsilon$-caprolactone) (PCL), poly(amidoamine) (PAA), and PEG, and others. Some natural biological materials such as proteins and polysaccharides that have been studied include chitosan, collagen, fibrin, fibronectin, gelatin, keratin, silk fibroin, hyaluronic acid, alginate, and others. ${ }^{137}$ All these materials have their own benefits and drawbacks (e.g., batchto-batch variability is a limitation for biological materials) and their uses are dependent on the type of peripheral nerve injury acquired. Furthermore, synthesis adds another level of complexity. A large variety of fabrication methods exist for fabricating nerve conduits, including wet phase inversion for hollow fiber membrane production, immersion precipitation, cylindrical weaving, tubular braiding, transfer molding, various 


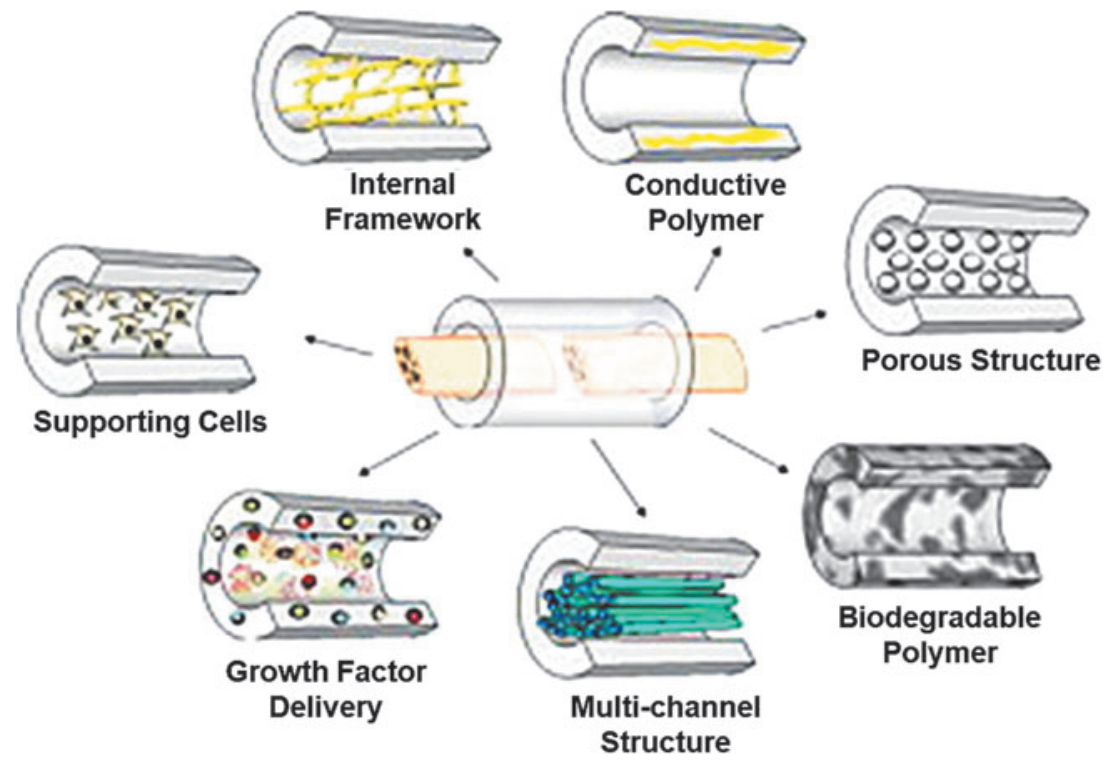

FIG. 6. Examples of nerve conduit designs for reconnection of the proximal nerve stump and the distal nerve stump by Dalamagkas et al. Figure reproduced with permission from Elsevier. ${ }^{34}$ Color images are available online. extrusion methods, three-dimensional (3D) bioprinting, electrospinning, solvent casting, and external magnetic field manipulation. ${ }^{138}$ Most materials have been studied on crush and partial crush sciatic nerve animal injury models, but their usefulness as nerve conduits in the rat hindlimb allotransplant model has not been well characterized. Furthermore, certain nerve conduits have shown benefits in clinical use, but never in the setting of VCA. ${ }^{139}$ Thus, further studies in a VCA animal model is warranted before a nerve conduit human clinical trial in VCA is carried out. ${ }^{78}$

Novel therapeutic approach highlight: modulating gene expression with microRNAs. MicroRNAs (miRNAs) are small noncoding ribonucleic acids (RNAs) that regulate the expression of target endogenous messenger RNA (mRNA). ${ }^{140-142}$ Throughout the years, many miRNAs have been described to be pertinent in axonal regeneration. ${ }^{143}$ miRNAs can either be delivered exogenously to enhance activity or inhibited to modulate miRNA activity for regenerative medicine and tissue engineering. ${ }^{144}$ For example, miR-338 and miR-21 co-transfection has been shown to expedite axonal regeneration and promote functional recovery after injury. ${ }^{145}$ In addition, miR-1 regulates Schwann cell proliferation. SCs have been shown to be the cell type most important for peripheral nerve regeneration outcomes, recovery time, and migration by regulating brain-derived neurotrophic factor (BDNF) after peripheral nerve injury. ${ }^{146}$ Terasawa et al. determined that miR-221/222 plays an important contribution in promoting SC proliferation and migration, and regulating nerve growth factor (NGF) expression through different signaling pathways. ${ }^{147}$ Due to these promising findings, Song et al. studied the potential of delivering miR-221 and miR-222 as an exogenous therapeutic. ${ }^{148}$ Because miRNAs are highly negatively charged and unstable, they often need a carrier molecule, most commonly a cationic, biocompatible polymer. ${ }^{144}$ Their results were promising as demonstrated by the upregulation of miR-221/222 in SCs, resulting in an increased expression of NGF and myelin basic protein, in vitro. After in vitro studies, they used an animal model (mice) to assess in vivo effectiveness of 2,6-pyridinedicarboxaldehyde (PDAPEI)/ miR-221/222 complexes, synthesized using polyethylenimine (PEI) crosslinked with PDAPEI, for axonal outgrowth after sciatic crush injuries. There final outcomes (nerve conduction, clinical, histologic, and immunohistochemical analyses) concluded that PDAPEI/miR-221/222 complexes stimulated considerable axonal regeneration after crush injury, mainly by promoting production of myelin. Overall, these findings demonstrate that the delivery of miR221/222 through PDAPEI might be an encouraging tool in the armamentarium when treating peripheral nerve injury. Ultimately, these basic science findings give optimism toward the discovery of novel therapeutics for nerve regeneration and highlight the importance of drug delivery technologies to optimize drug pharmacokinetics and pharmacodynamics (PK/PD).

\section{Extracorporeal perfusion systems and cross-circulation}

A recent approach that shows promise in addressing the composite tissue and organ shortage, immunogenicity, IRI, and other injuries, and allowing for better recipient-donor matching in both VCA and SOT is the use of extracorporeal perfusion systems. ${ }^{149,150}$ Ozer et al. demonstrated that perfusion of harvested limbs with fresh autologous plasma in a swine forelimb transplant model maintained muscle contractility and limb graft viability up to $12 \mathrm{~h}$, extending the narrow time frame for revascularization of procured extremities in limb transplantation. ${ }^{151}$ This group subsequently demonstrated that utilization of hourly neuromuscular electrical stimulation could prolong VCA survival up to 24 h. ${ }^{152}$ Slater et al. demonstrated that ex vivo oxygenated perfusion of free flaps (i.e., porcine myocutaneous rectus abdominis flaps) during ischemia time abrogated tissue damage (due to cell necrosis) over a 24 -h period compared to control groups where tissues were flushed with heparinized autologous blood followed by cold storage. ${ }^{153}$ This approach has also been successfully applied to muscle 
transplants $^{154}$ and heart grafts ${ }^{155}$ to prolong bridge-totransplantation time and improve metabolic preservation and functional recovery. In addition to traditional extracorporeal perfusion systems, O'Neill et al. developed a novel cross-circulation platform that sustained healthy lungs for $36 \mathrm{~h}$, compared to extracorporeal lung perfusion systems that have been limited to about $6 \mathrm{~h} .{ }^{156}$ Cross-circulation is a technique that involves connecting the graft to the recipient's circulatory system, ultimately allowing for extended support and time for therapeutic interventions. Overall, these results show clinical promise and support further investigation of utilizing extracorporeal perfusion systems and cross-circulation in a variety of transplant and/or tissue salvage applications.

\section{Wound Healing}

A single diabetic ulcer has been calculated to cost $\sim \$ 50,000$ and chronic wounds affect the health care budget by costs surpassing over 25 billion dollars every year in the United States alone. ${ }^{157}$ Thus, the prevention and treatment of chronic wounds represent a significant, unmet clinical need. Chronic wounds can arise from a skin graft donor site if healing is impaired, which is common in patients with poor circulation (e.g., diabetics and smokers), patients with autoimmune disease, and patients who are immunocompromised (e.g., cancer patients undergoing chemotherapy treatment). ${ }^{158}$ If wounds can be controlled at an earlier stage by restoring original form and function, than the need for large tissue transfer surgeries will decrease along with the number of amputations carried out, ultimately reducing health care costs and patient morbidity and mortality.

\section{Currently available FDA-approved materials}

Wound healing requires an orchestrated effort of molecular and biological processes at the extracellular compartment during the well-characterized phases of inflammation, proliferation, and matrix remodeling. ${ }^{159}$ This series of events are extremely choreographed in a normal state. Unfortunately, chronic wounds are unable to advance through these stages in an ordered manner, failing to heal, often requiring long-term therapy and high costs. Although a skin graft can be used, the surgical technique is painful, is timeconsuming, leaves significant donor site wounds, and is limited especially in large body surface area traumas and in congenital diseases such as epidermolysis bullosa. ${ }^{160}$ Currently, there are many FDA-approved advanced skin substitutes, most popularly Alloderm ${ }^{\circledR}$ from Lifecell Corporation, which comprises decellularized human dermis, and Integra ${ }^{\circledR}$ from Integra LifeSciences Corporation, which is a temporary acellular silicone epidermal substitute placed over a dermal scaffold. Most materials in clinical use bioactive dressings contain mammalian derived extracellular matrix (ECM) components (i.e., Alloderm and Integra) and/ or autologous or allogenic human cells such as BioSeed-S ${ }^{\circledR}$ from BioTissue Technologies, which contain autologous keratinocytes embedded in fibrin glue, or Dermagraft ${ }^{\circledR}$ from Advanced BioHealing, which contains living allogenic fibroblasts from neonatal skin embedded on biodegradable polyglactin mesh. ${ }^{161}$

\section{Novel biomaterials}

Although there are many wound healing materials currently on the market, it is a common sentiment that the available treatments are functionally equivalent. Toward developing superior products, recent research efforts have channeled their efforts in creating breakthrough biomaterials, such as acellular biopolymeric scaffolds, as better wound healing alternatives. ${ }^{162}$ The advantage behind these technologies is that they can be tailored to target specific phases of the healing cascade.

Biomaterial-based dressings currently under development involve standalone biomaterials such as collagen ${ }^{163}$ and dextran, ${ }^{164,165}$ those with bioactive components such as hyaluronic acid NPs that release vitamin $\mathrm{E},{ }^{166}$ cell-encapsulating biomaterials such as MSCs encapsulated in Poly $\beta$ amino ester scaffolds, ${ }^{167}$ nucleic acid delivering biomaterials such as a combined chitosan and dextran sulfate ultrathin polymer delivering small interfering ribonucleic acid (siRNA) targeting MMP-9, ${ }^{168}$ materials derived from animal products such as bovine lyophilized amniotic membrane, ${ }^{169}$ and drug-/ antibiotic-loaded biomaterials such as a ciprofloxacin-loaded PEG-chitosan scaffold. ${ }^{170}$ In addition to therapeutic biomaterials, many preventative biomaterial-based technologies are currently being synthesized and tested for chronic wound prophylaxis through alleviating ischemia and the associated tissue damage that can lead to nonhealing wounds.

A recent biomaterial was described that reduces ischemia and remedies the lack of revascularization associated with peripheral arterial disease (PAD), combined with diabetes; this approach could be used to reduce the impact of ischemic injury and the consequent formation of problematic skin wounds. Poole et al. synthesized a novel MP-based delivery system from ROS-responsive PPS and evaluated for on-demand antioxidant therapy (Fig. 7). PPS is an environmentally responsive polymer that is hydrophobic but becomes hydrophilic by oxidation, thus providing a resourceful mechanism for ROS-mediated delivery. Because the polymer reacts with ROS, it possesses inherent antioxidant properties, as was evident in the ability of drug-free polymer MPs to reduce ischemic tissue ROS (Fig. 7C). The researchers tested their platform for the delivery of curcumin, which has anti-inflammatory and antioxidant properties, but is used limited in free form due hydrophobicity and poor solubility. In this study, the cytocompatible microspheres containing curcumin specifically targeted and collected ROS inside of activated macrophages, decreasing cytoplasmic toxic levels of ROS and improving in vitro cell survival. This decreased the overall tissue concentration of ROS in vivo in a vasculopathic and diabetic mice hind limb model. PAD is a very common condition pathogenesis chronic wounds and ulcers. Delivery of curcumin-PPS microspheres (through intramuscular injections) expedited healing from hind limb ischemia, proven by noninvasive imaging techniques. Thus, this study reveals that PPS microspheres are a generalizable transport for ROS-mediated drug release, for preventing the progression of, and possibly treating, chronic wounds that occur commonly in PAD. ${ }^{171}$

An example of a therapeutic biomaterial used for treatment of existing chronic wounds is the application of siRNA delivered from ROS-degradable tissue engineering scaffolds, an approach shown to promote diabetic wound healing 


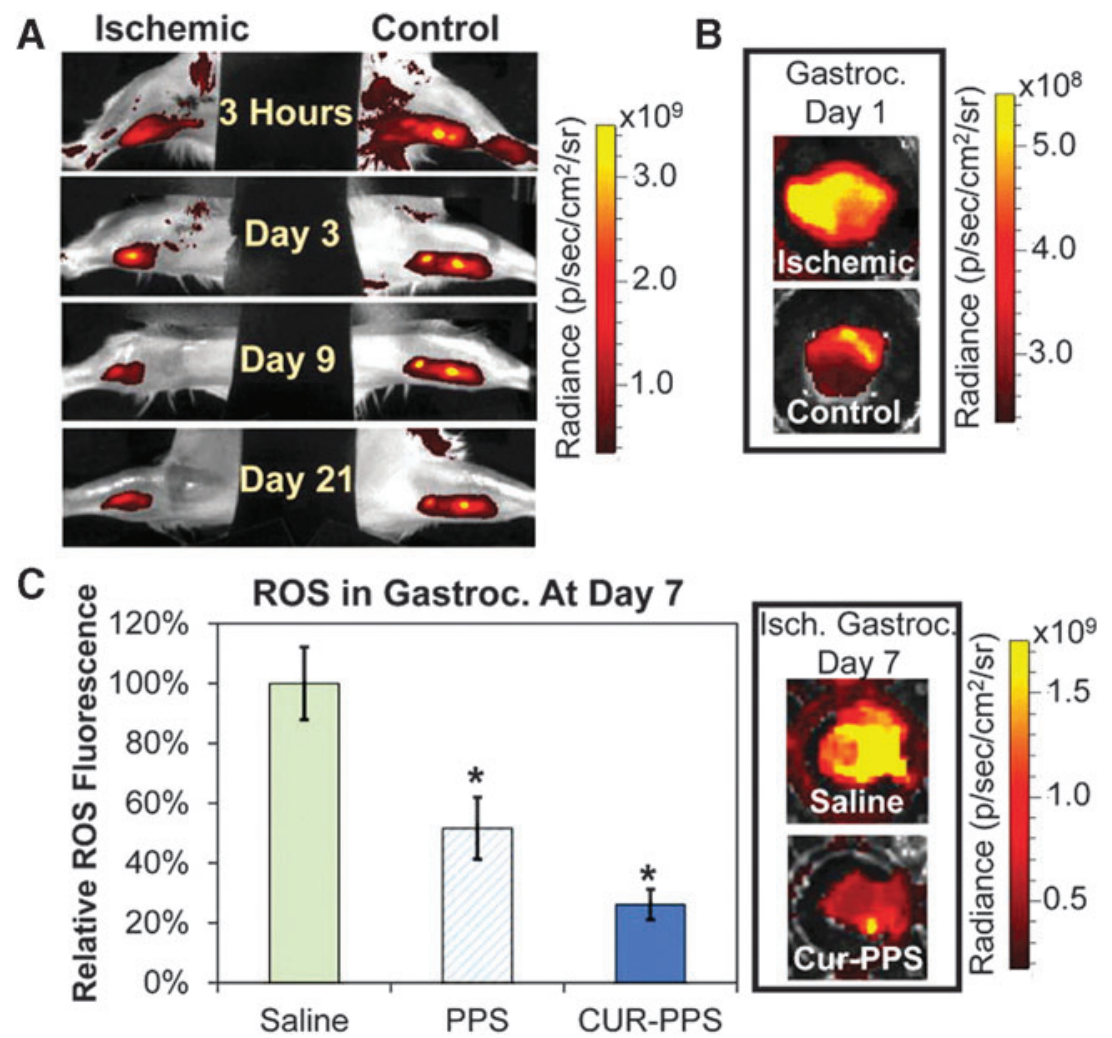

FIG. 7. Long-acting, antioxidant polymeric microparticles with on-demand release of antioxidant and antiinflammatory drug curcumin. Studies, performed by Poole et al., showing that PPS microspheres provide sustained, on-demand, local curcumin release and reduce tissue ROS levels. (A) CurcuminPPS microspheres release curcumin faster in the ischemic limb when compared to the nonischemic control limb. (B) ROS levels in the ischemic gastrocnemius muscle are increased at 1 day following induction of ischemic injury (ROS is 2.3-fold greater in ischemic vs. control gastrocnemius). (C) Blank PPS microspheres and curcumin-loaded PPS microspheres reduce ROS in gastrocnemius muscles extracted from ischemic limbs. Data are presented as mean \pm SEM. Saline group $n=8$, blank PPS group $n=11$, curcumin-PPS group $n=10$. $* p<0.05$ is relative to saline treatment. PPS, poly(propylene sulfide); ROS, reactive oxygen species; SEM, standard error of the mean. Figure reproduced with permission from Elsevier. ${ }^{171}$ Color images are available online. in rats $^{172}$ (Fig. 8). In this study, porous poly(thioketalurethane) scaffolds ${ }^{173}$ were inserted in diabetic wounds and were designed to locally and sustainably deliver siRNA that suppresses the expression of prolyl hydroxylase domain protein 2 (PHD2), a target previously proven to promote vascularization within subcutaneously applied scaffolds. ${ }^{174}$ PHD2 is an innate protein that downregulates the proangiogenic transcription factor HIF-1 $\alpha$ (hypoxia inducible factor 1-alpha). Under normoxia, PHD2 "marks" HIF-1 $\alpha$ for degradation, but in the setting of oxygen deprivation, PHD2 does not hydroxylate HIF-1 $\alpha$, stabilizing it to partner with HIF-1 $\beta$ to form an active heterodimer that traffics to the nucleus and ultimately stimulates transcription of hypoxia response element (HRE)-containing genes such as the proangiogenic growth factor vascular, endothelial growth factor (VEGF). ${ }^{175}$ Inhibition of PHD2 mimics or enhances the setting of hypoxia, leading to HIF- $1 \alpha$-driven expression of proangiogenic factors that spur the growth of blood vessels and facilitate wound healing. In this study, scaffoldbased delivery of PHD2 siRNA nanocarriers increased the expression of proangiogenic factors, cell proliferation, and tissue repair in diabetic wounds, with a substantial increase in vascularity-a threefold increase in vascular volume in 33 days when compared to untreated controls. This same class of polyurethane biomaterials can also promisingly be tuned for delivery of therapeutic cells such as bone marrowderived stem cells. ${ }^{176}$

Ultimately, the goal in biomaterials research is to create a wound dressing that is permeable to wound exudate, supports and encourages healing of deep cutaneous voids, has skin-like mechanical properties, undergoes resorption at a

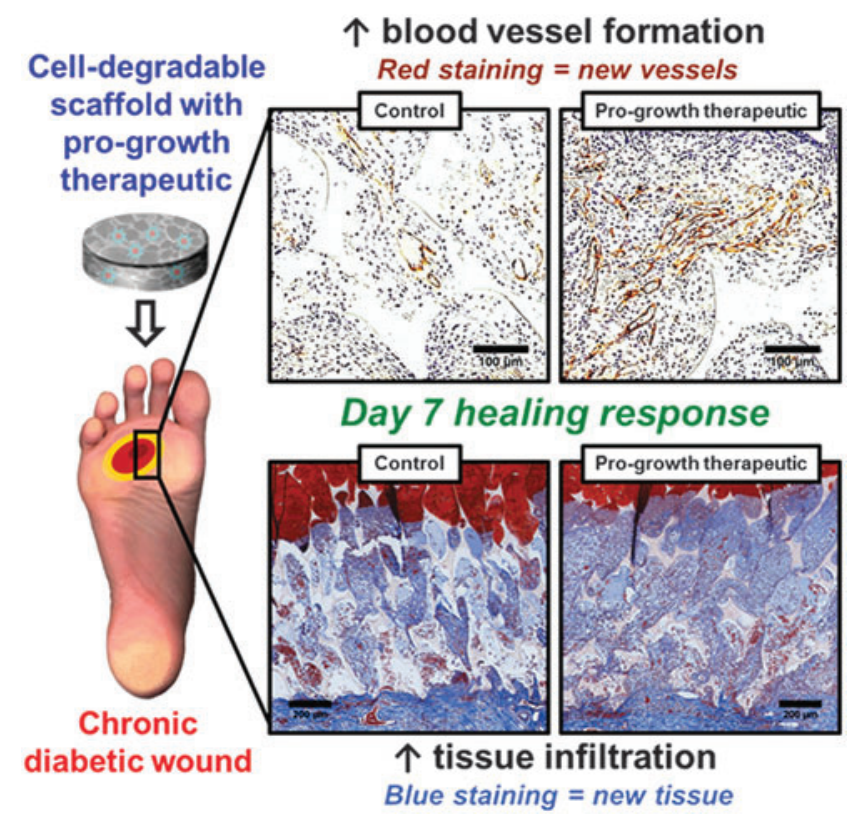

FIG. 8. siRNA delivered using ROS-degradable tissueengineered scaffolds, performed by Martin et al., promotes diabetic wound healing. Porous poly(thioketal-urethane) scaffolds implanted in diabetic wounds locally deliver siRNA that inhibits the expression of PHD2, thereby increasing vasculature, proliferating cells, and tissue development. PHD2, prolyl hydroxylase domain protein 2; siRNA, small interfering ribonucleic acid. Figure reproduced with permission from Elsevier. ${ }^{172}$ Color images are available online. 
rate that balances the rate of tissue regeneration, can act as a drug-eluting scaffold, and is ultimately cost-effective and efficient. Innovations in the field of biomaterials and NPs show significant promise in developing more efficacious clinical treatments for wound healing and chronic wounds.

\section{Tissue Engineering}

Langer and Vacanti defined tissue engineering as "an interdisciplinary field that applies the principles of engineering and life sciences toward the development of biological substitutes that restore, maintain, or improve function or a whole organ". ${ }^{177}$ It involves the use of a tissue scaffold, cells, and suitable biochemical and physicochemical factors for the synthesis of viable tissue for a therapeutic reason. Historically, it was considered an area under biomaterials, but due to its development and diversification, is currently recognized as its own field. Surgical reconstruction using bioengineered tissues has the potential to revolutionize clinical practice by reducing and/or removing donor-site morbidity and overcoming the hurdles of organ and composite tissue donation shortages.

\section{Simple tissues}

Since its official inception in 1993 by Langer and Vacanti, tissue engineering has made tremendous progress in "simple" or "homogenous" tissues, which are constructs that contain one or a few different cell types. Surgical subspecialties have already added tissue engineering into their armamentarium. It currently possesses a significant role in breast augmentation and reconstruction, as well in other fields such as dermal substitutes, wound care, valvular reconstruction, and osteochondral and nerve grafting. ${ }^{178}$ This field has advanced to the point that many laboratory-engineered constructs have been used clinically in patients. Atala et al. pioneered the field by using clinically tissue-engineered bladder constructs. ${ }^{179}$ This was followed by several reports in a plethora of tissues such as trachea, ${ }^{180,181}$ urethra, ${ }^{182}$ and nasal cartilage, ${ }^{183}$ with outcomes varying substantially. ${ }^{184}$ Notably, engineered tracheas are currently controversial due to the Paolo Macchiarini scandal following the revelation that a majority of his patients died after surgical implantation of tissue-engineered airways, which is in contrast to what was originally published. ${ }^{185}$ Ultimately, Macchiarini was charged with scientific misconduct and many of his articles have now been revoked. Currently, significant barriers for the translation of large-volume tissue substitutes include the incapability to reproduce "physiologically relevant tissue" and issues with vascularization, as constructs of lesser size may excel depending on local angiogenesis ${ }^{179,182}$; however, implanted cells in more complex composite tissue constructs have higher metabolic needs and the diffusion of oxygen is distance limited in larger constructs.

\section{Complex tissues: bioengineering composite tissue flaps}

The ultimate goal in reconstructive surgery is being able to reconstruct a collection of tissues de novo, which can fill large tissue defects, while biologically integrating into the body. Designing composite tissue flaps that are immunosuppression independent would be an optimal clinical choice over both autologous tissue flaps and allogenic tissue.
Utilizing decellularized tissue scaffolds and/or synthetic biomaterials, scientists have made substantial progress toward ideal "ready-to-use-off-the-shelf" composite tissue flaps that are biologically active, meanwhile being readily accepted by the host immune system.

Decellularized tissue scaffolds. The process of decellularization has been extensively studied for the creation of bioengineered organs, ${ }^{186-188}$ but has only recently been considered for the production of engineered composite tissue flaps. This method involves taking cadaveric organs or tissues, decellularizing them to leave only the ECM, and then repopulating the matrix with a patient's own autologous stem cells. This creates an engineered tissue flap that architecturally was constructed with the scaffold from a cadaver, but contains the patient's own cells to circumvent the risk of immune rejection.

Decellularization consists of removing all cellular material from the ECM, from any tissue, while avoiding loss or disruption of the tissue architecture. These outcomes can be obtained by applying chemical, physical, and enzymatic techniques. Specific methods include agitation in solution, thermal shock (i.e., freeze-thaw cycles), ultrasound, hydrostatic pressure, convective flow, and mechanical disruption. ${ }^{189}$ It is important to note that within these methods (e.g., chemical), there are many different individual options (i.e., ionic vs. nonionic vs. organic solvent, etc.) that vary in harshness and efficacy. As a result, standardization and consistency are currently difficult to achieve. ${ }^{190}$

The following provides an example of the complexity and variables involved in a decellularization protocol and why standardization is difficult, Zhang et al. used a combined chemical/perfusion decellularization protocol to achieve an acellular decellularized skin/adipose tissue flap (DSAF) comprising ECM and maintaining the vascular network from a donor rat $^{191}$ (Fig. 9): first, groin skin/adipose tissue flaps $\left(2 \times 4 \mathrm{~cm}^{2}\right)$ were harvested and subjected to three freeze-thaw cycles (which enhances decellularization by decreasing the amount of residual cellular material, including nuclei and $\mathrm{DNA}^{192}$ ). They were then washed in ultrapure water for 2 days and subsequently incubated in increasing concentrations of $\mathrm{NaCl}$. Following additional washes and treatment with $0.25 \%$ trypsin/EDTA (for chelation of minerals and proteolytic digestion), the samples were permeabilized with $1 \%$ Triton $\mathrm{X}-100$ for 5 days with the permeabilization solution being replaced daily, processed with DNase at $37^{\circ} \mathrm{C}$ for $3 \mathrm{~h}$, and washed with ultrapure water and phosphatebuffered saline solutions. After chemical treatment, the artery for each flap was connected to a perfusion system and perfused with ultrapure water $(2 \mathrm{~mL} / \mathrm{min})$ for $24 \mathrm{~h}$ at ambient temperature. Finally, the DSAF was sterilized with ethanol and stored in an antibiotic solution until use. Ultimately, the DSAF had a dominant vascular pedicle, microcirculatory vascularity, and a sensory nerve network. The authors were then able to successfully repopulate the flap with human adipose-derived stem/stromal cells (hASCs) and human umbilical vein endothelial cells (HUVECs), which integrated well with the formation of vessel-like structures in vitro. Microsurgery techniques were then performed to reanastomose the recellularized DSAF into a nude recipient. The newly engineered construct underwent neovascularization and constructive remodeling for 3 months postimplantation. 


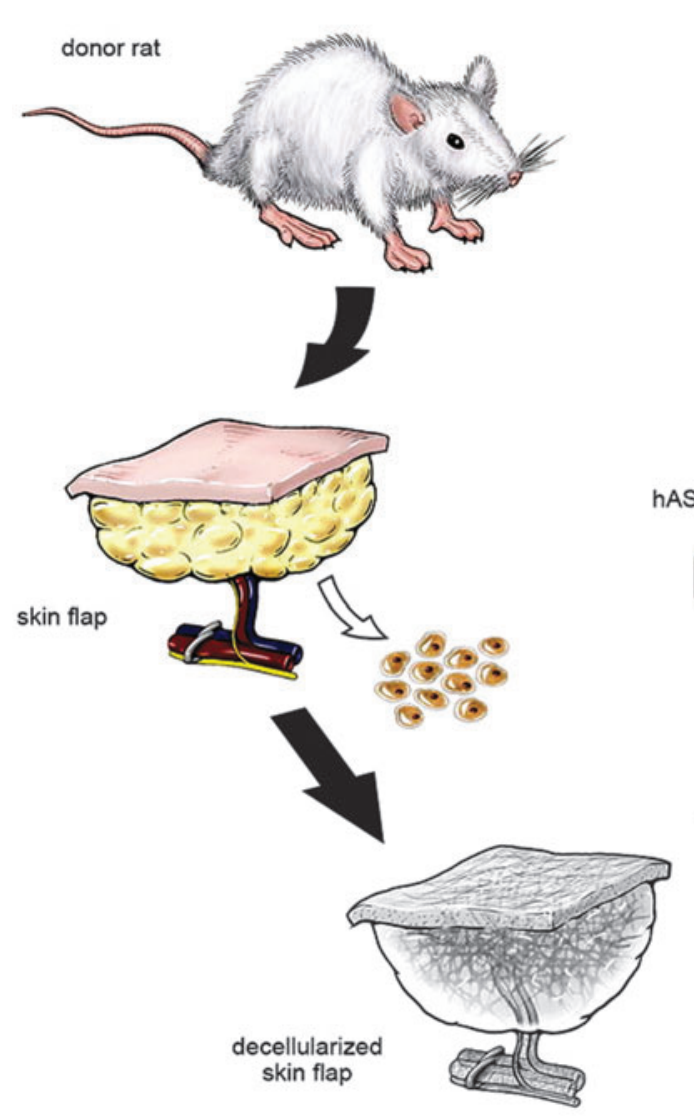

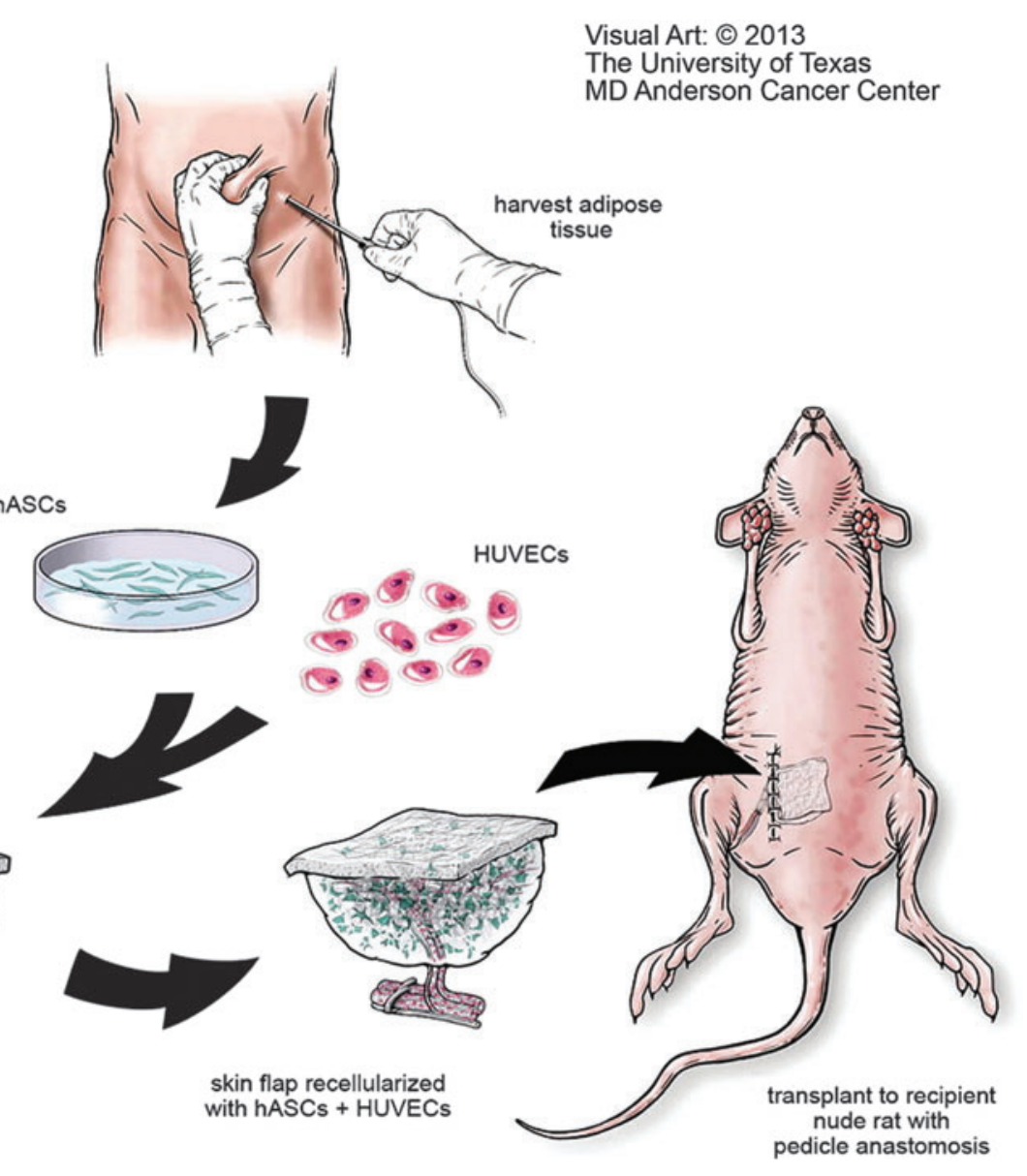

FIG. 9. Schematic of ex vivo microvascular free dermal/adipose flap engineered by Zhang et al. DSAF is harvested and prepared from the donor rat and recellularized with hASCs and HUVECs in vitro. Following vascular anastomosis to the recipient site, the engineered flap construct activated an M2 macrophage-mediated constructive remodeling process in vivo. Using this strategy, DSAFs could be translated as a commercial tissue engineering product for personalized tissue repair and regeneration. DSAF, decellularized skin/adipose tissue flap; hASCs, human adipose-derived stem/stromal cells; HUVECs, human umbilical vein endothelial cells. Figure reproduced with permission from Elsevier. ${ }^{191}$ Color images are available online.

Furthermore, the authors claim that this platform is not restricted by the extent of the flap because it could be perfused instantly through microanastamosis from the host's vessels. Thus, decellularized grafts coupled with recellularization show promise for the creation of large composite tissue flaps for reconstruction.

Synthetic tissue scaffolds. Along with decellularized matrix, another avenue of research utilizes synthetic polymer-based scaffolds for the growth, proliferation, and organization of cells. The major advantages of using synthetic materials over decellularized scaffolds are that they are more readily available, as they do not require donor tissue, and therefore can be made freely in the laboratory, there is less batch-to-batch variability, they are amenable to commercial scale-up, and they can be modified much more extensively in shape, size, and function.

Shandalov et al. were able to construct muscle tissue in vitro by introducing myoblasts, fibroblasts, and endothelial cells (ECs) into a tridimensional biodegradable poly-L-lactic acid (PLLA)/PLGA scaffold (Fig. 10). This was cultured until a small capillary network formed, which was then sutured in vivo around the recipient's vessels, allowing capillaries to sprout. Within 1 week of implantation, scaffolds showed extensive functional vascular density, perfusion, and anastomosis with host vessels. Once the graft showed adequate incorporation with surrounding tissues, the graft was then transferred with the femoral vessels, as an axial flap, to cover the abdominal wall defect. At 1 week post-transfer, the engineered muscle flaps were vastly vascularized, with satisfactory integration, and possessed sufficient strength to withstand intraabdominal pressure. ${ }^{193}$ This experimental procedure touches on the "body as a bioreactor" concept—a relatively new strategy that relies on the body's own regenerative capacity to grow functional tissues. This approach was first described by Stevens et al. when they created an artificial space (bioreactor) between the tibia and the periosteum in such a way that the body's healing mechanism was leveraged to engineer neotissue. Using their "in vivo bioreactor" in rabbits, they were able to engineer bone that was biomechanically identical to native bone. ${ }^{194}$ Since then, this concept has been applied to many different tissue types for a variety of applications. A clinical example of this concept includes implanting an 


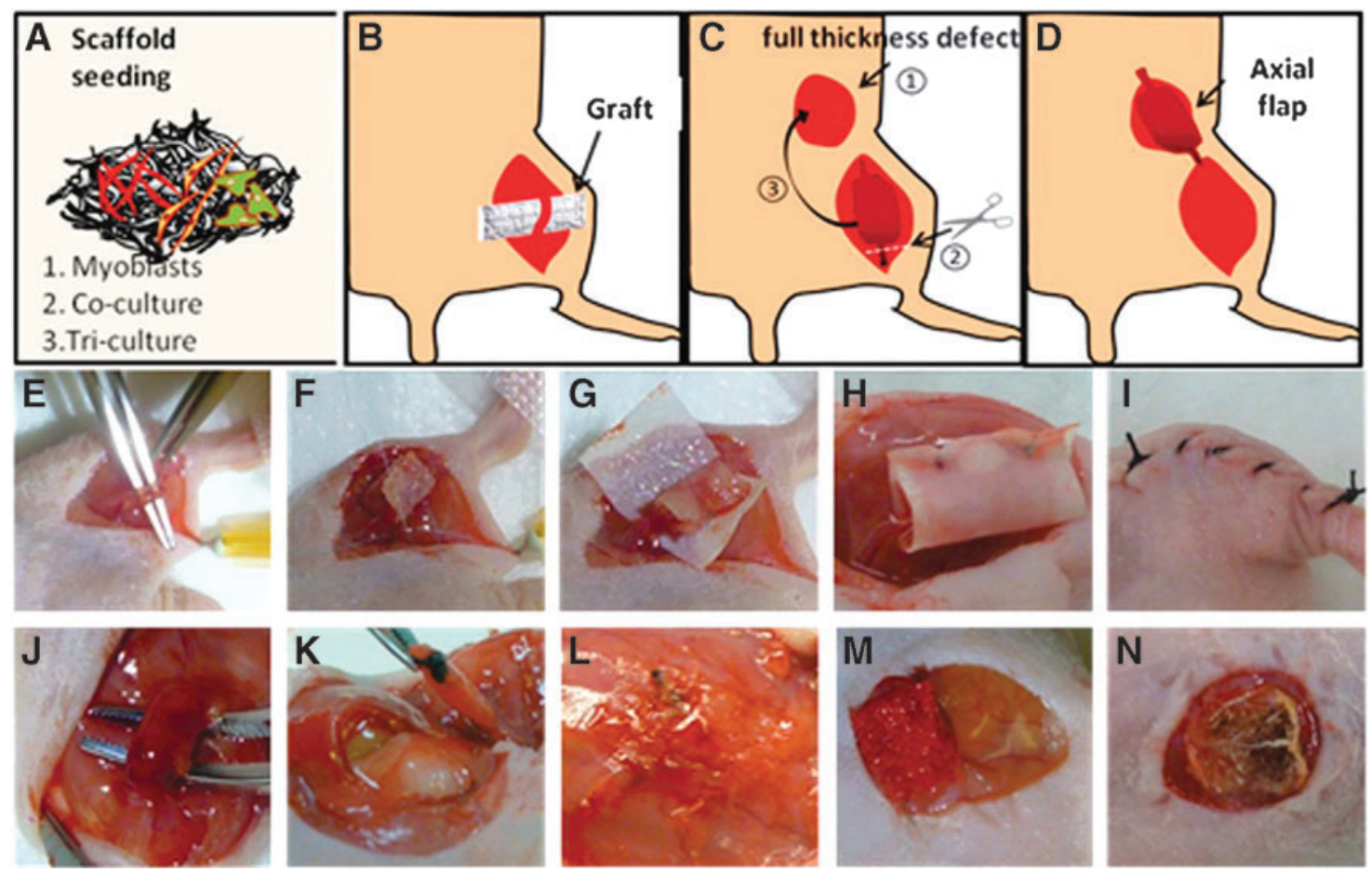

FIG. 10. Surgical implantation of fabricated tissue grafts followed by flap transfer performed by Shandalov et al. (A-D) Schematic of flap fabrication. (A) Cells were seeded within biodegradable PLLA/PLGA scaffolds. (B) The fabricated tissue graft was folded around blood vessels and sutured. (C, D) Transfer of the vascularized graft into the abdominal wall defect. (E) Isolation of the femoral artery and vein. (F) The fabricated tissue graft was folded around blood vessels and sutured. (G, H) The fabricated tissue graft was then separated from the skin and the surrounding tissue using a piece of sterile latex, which was then sutured. (I) Suturing of the overlying skin. (J) Representative image of a fabricated tissue graft 1 week postimplantation. (K) Transfer of the vascularized graft into the abdominal wall defect. (L) Appearance of the flap derived from cell-embedded scaffolds 1 week after transfer. (M) Image of a piece of a cell-free scaffold applied to close the abdominal wall defect. (N) Appearance of a graft derived from a cell-free scaffold 1 week post-transfer; the graft had become necrotic. PLGA, poly(lactic acid-co-glycolic acid); PLLA, poly-L-lactic acid. Figure reproduced with permission from Proceedings of the National Academy of Sciences of the United States of America. ${ }^{193}$ Color images are available online.

auricular construct underneath the forearm and letting it grow and develop vascularity before transplantation. ${ }^{195}$

3D bioprinting. 3D bioprinting is a novel technology able to design and produce tissue-specific constructs by creating complicated heterocellular structures with microscale precision. 3D bioprinting enables the deposition of various biologics, including growth factors, cells, genes, neo-tissues, and hydrogels modified with ECM proteins.

$3 \mathrm{D}$ bioprinting has shown promise in many tissue types important for reconstructive procedures, such as cartilage, muscle, skin, fat, bone, vasculature, and nerves (Fig. 11). Although these discoveries have garnered substantial progress throughout the years, bioprinting has been criticized for its short survival times, being limited to thin-tissue production, and for its inability to recapitulate complex composite tissues. ${ }^{196}$

Excitingly, Kolesky et al. recently proposed an innovative 3D bioprinting method that can create human tissues greater than 1-cm thickness, with an engineered ECM, corresponding vascular network, and different cell types-the exact components needed for a composite tissue flap (Fig. 12). They were able to integrate parenchyma, stroma, and endothelium into a unique block of tissue by printing simultaneously several inks of different cell linage as human
MSCs and human neonatal dermal fibroblasts within a suited ECM that composed of an intrinsic HUVEC-lined vascular system. Using this method, their bioengineered tissues were capable of programmable cellular heterogeneity and long-term ( $>6$ weeks) perfusion. ${ }^{238}$

Recent advances in 3D bioprinting methods show promise in constructing "physiologically relevant tissues" and hold a viable solution for facilitating the clinical translation of tissue-engineered constructs for their physiological testing capabilities and reconstruction purposes.

\section{The Vascularization Problem}

As tissue engineering and 3D bioprinting started to become more commonplace, a few scientists observed the lack of biologically realistic blood flow into engineered and printed tissue, and the "vascularization problem" was coined. ${ }^{239-241}$

In the human body, tissues are perfused by a complex branched vascular network that then subdivides all the way into smaller capillaries. The maximum distance between cells and capillaries is no longer than $200 \mu \mathrm{m}$ in distance, which corresponds also to the diffusion limit of oxygen. ${ }^{242,243}$ There are certain types of tissues where nutrients and oxygen can be supplied to cell when this distance is bigger. Examples of these are cornea, cartilage, and skin. In 


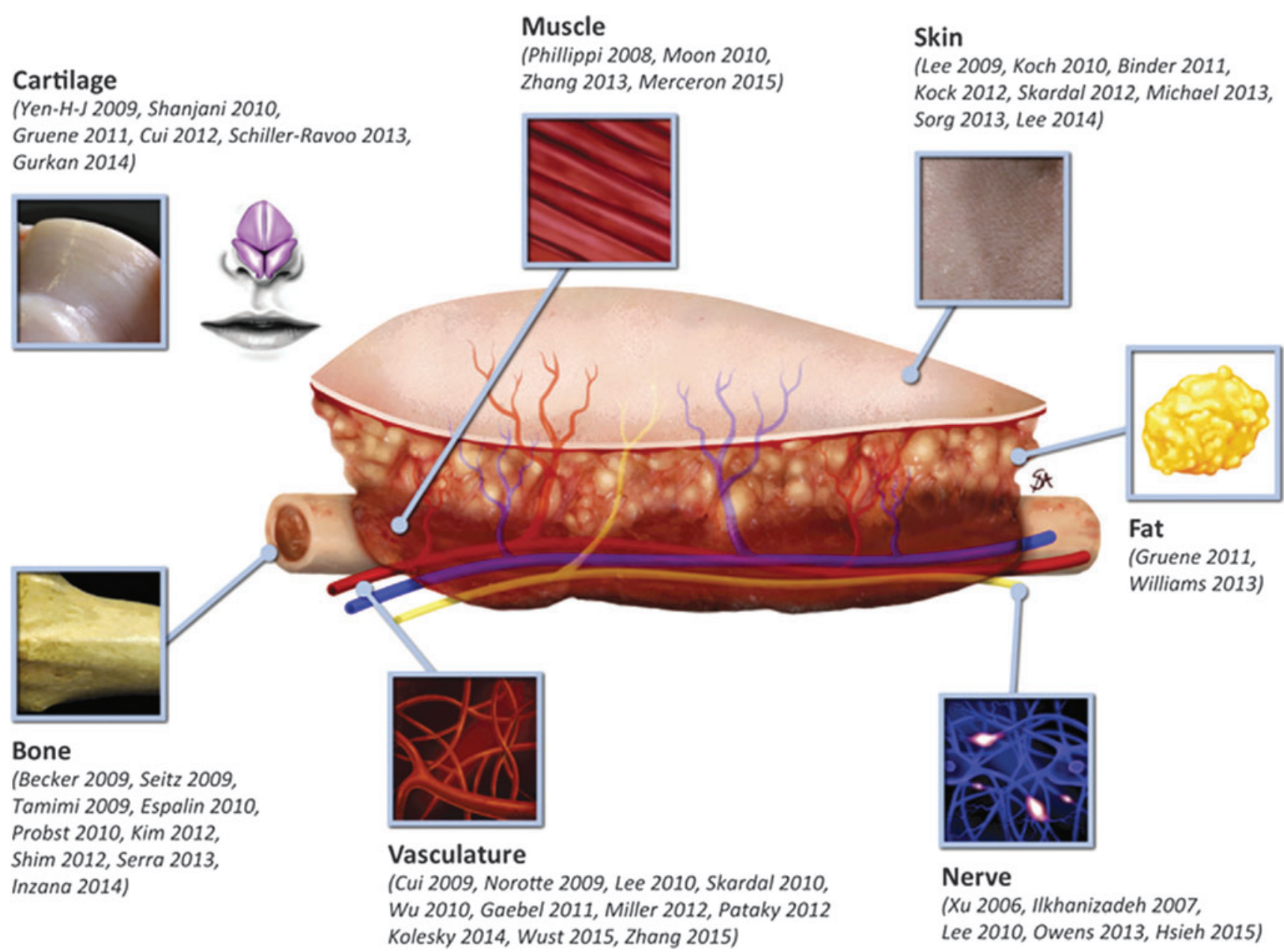

FIG. 11. Progress toward bioprinting composite flaps for reconstructive microsurgical implantation created by Jessop et al. Figure reproduced with permission from Elsevier. ${ }^{196}$ Individual references. ${ }^{197-237}$ Color images are available online.

cartilage, arteries and veins would compromise the biomechanical properties of the tissue. Researchers also posit that cartilage is aneural for this reason. Arteries and veins would also disrupt the main property of the cornea (outer lens of the eye), which is to refract light into the eye onto the retina. ${ }^{244}$ Furthermore, most of the nutrition of the articular cartilage comes from the synovial fluid through diffusion. ${ }^{245}$ Similarly, the cornea receives oxygen and other metabolites through the anterior chamber's aqueous humor. ${ }^{246}$ Their avascular nature in the human body is the main reason why there has been great success in tissue engineering. The majority of the remaining tissues, especially muscle, liver, and lung, are highly vascularized. The complex multitude of tissues currently used in composite tissue flaps rely on a highly organized vascular system with an ideal distance $<200 \mu \mathrm{m}^{247}$

\section{Engineering vascular grafts}

Adequate vascularization of recently engineered scaffolds is still a limiting factor when applying them clinically. Thus, many scientists are currently studying ways to make biologically competent vascular networks. The optimal vascular graft should have the following characteristics: mechanical strength, high compliance to confront prolonged hemody- namic insults, immunotolerance, biocompatibility, differing sizes, suturability and effortless handling, thrombosis resistant, capable to defy infection, complete incorporation into the recipient bed, and reasonable manufacturing costs. ${ }^{248}$

Synthetic grafts. For decades, the production of synthetic vascular prostheses have involved mainly (1) polyethylene terephthalate (PET-commonly known as Terylene in the United Kingdom, Lavsan in Russia, or Dacron in the United States), and (2) polytetrafluoroethylene (PTFE_commonly known as Teflon or Gore-Tex). These are currently clinically available for vascular prostheses and both polymers are highly crystalline, which prevents plastic deformation under prolonged cyclical strain that would render the material unsuitable for vascular graft construction, ${ }^{249}$ and hydrophobic, which decreases the internal reaction of water (hydrolysis) with internal esters of the polymer, hence prolonging degradation rate. ${ }^{250}$ The hydrophobicity of these materials also prevents cell adhesion to the surface, where hydrophilicity resulting in swelling and strong interactions between the graft and blood is known to be thrombogenic. $^{251}$

PET and PTFE are advantageous when treating largecaliber vessels, but they are less than ideal when used in 

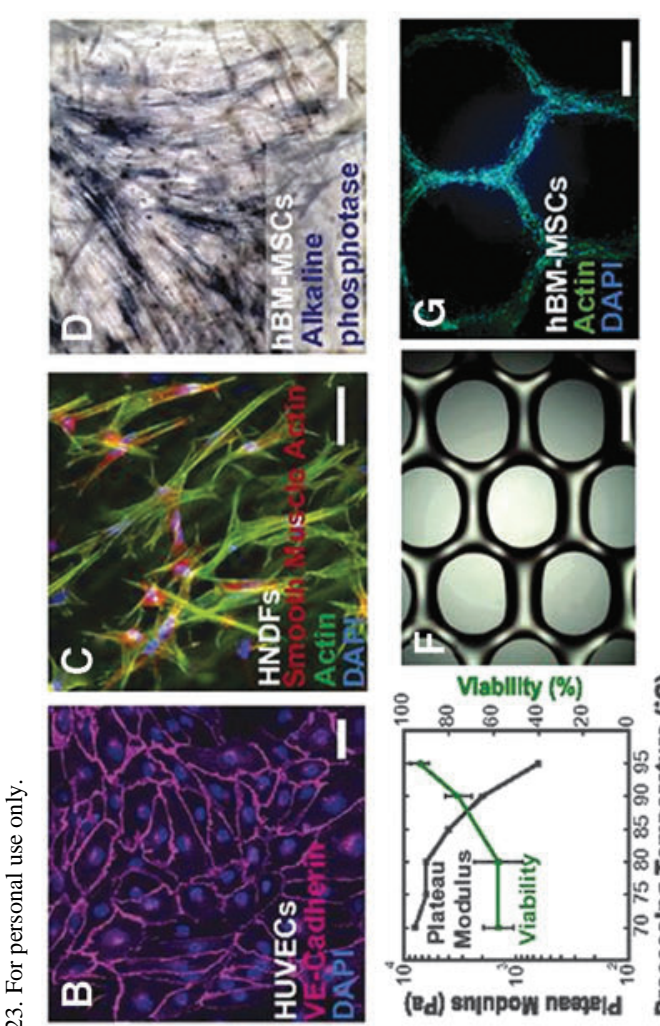

ш
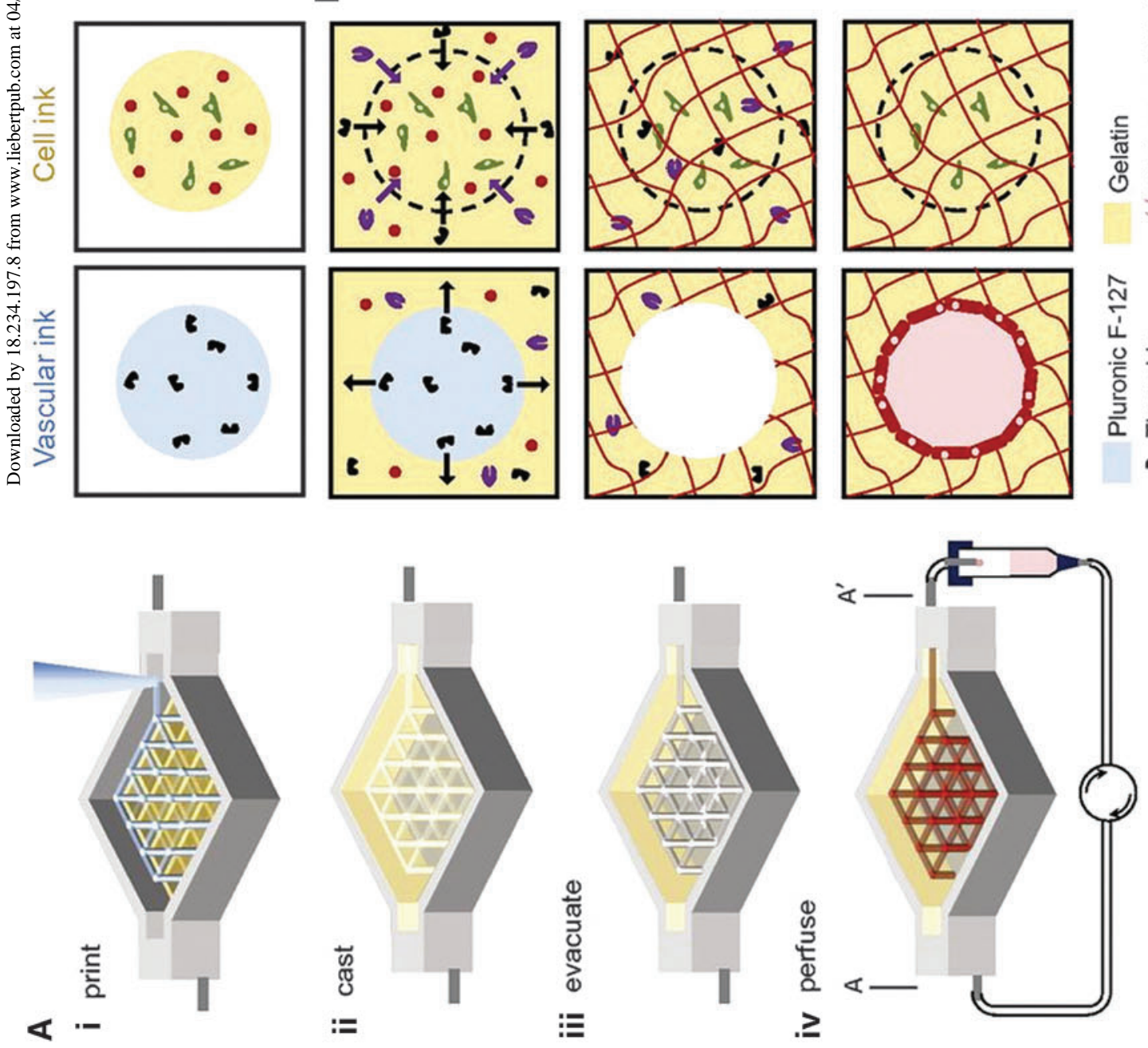

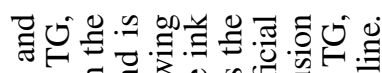
.

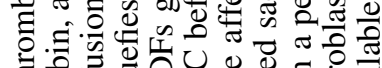

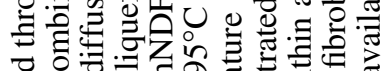

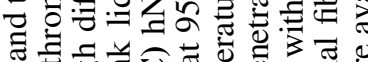
స :

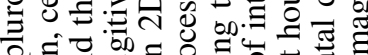

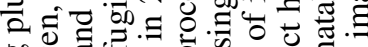

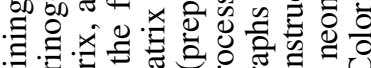

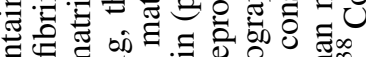

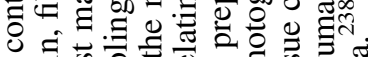

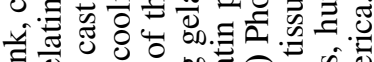

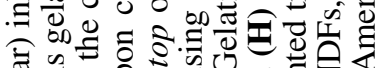
흑.

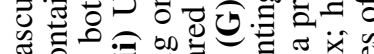

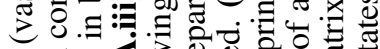

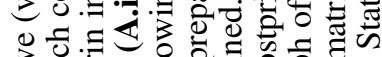

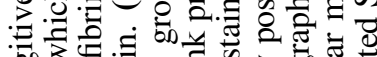

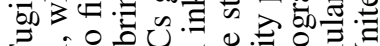

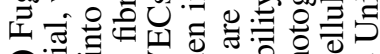

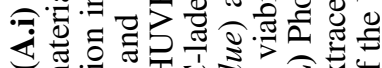
药

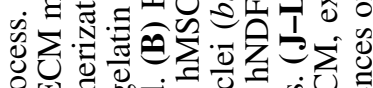
임

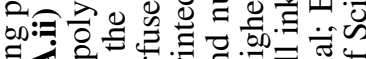

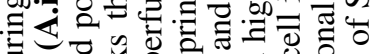

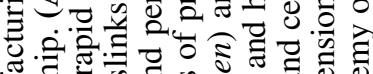

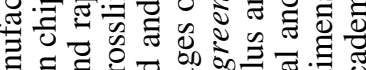
芩

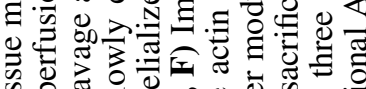

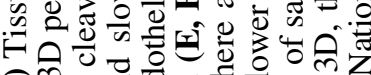
ङ

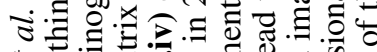

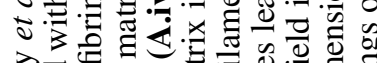

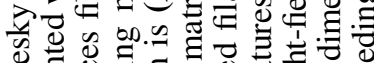

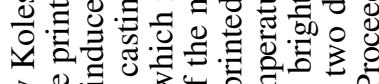

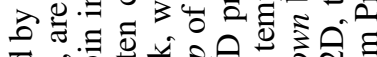
छ हु일

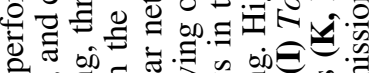

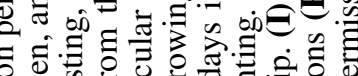

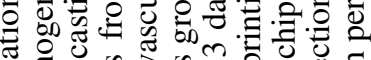

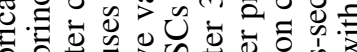

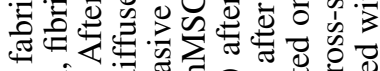

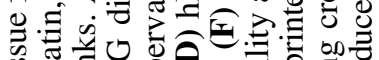

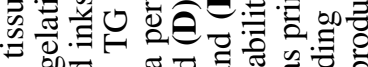

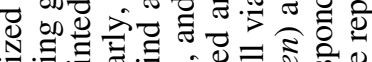

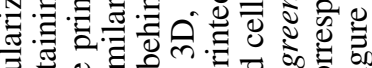

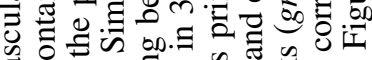

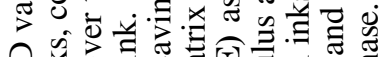
लि.

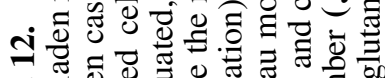

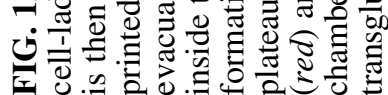


small-diameter vessels $(<6 \mathrm{~mm})$ in terms of long-term patency. Application of these polymer-based devices is discouraged in coronary, crural, or microsurgery. The reasons why these fail is due to hyperplasia caused by hemodynamic alterations and a thrombogenic surface devoid of ECs secondary to a dysfunctional healing cascade. ${ }^{248}$

Since complex tissues require large- and small-caliber vessels for microsurgical anastomosis and long-term vascular patency for survival, recent developments have focused on cellular and acellular approaches with the hope of increasing biocompatibility.

Autologous and cellularized grafts. Cardiovascular disease (CVD) leads the list of causes of mortality in the United States, and coronary heart disease (CHD) is the primary contributor, causing over 50\% of CVD-related mortality and about one in six of all deaths. ${ }^{252}$ Coronary artery bypass grafting is the traditional corrective procedure for severe CHD and is performed approximately a half million times in the United States annually. ${ }^{252}$ Despite the increased use of stenting, recent trials proved that $C A B G$ achieves increased survival and lowers the rate of repeat intervention in patients with complex, multivessel disease. ${ }^{253,254}$ In the context of tissue reconstruction and regeneration, the use of autologous vascularized tissue grafts remains the clinical standard, where an autologous vessel attached to/within the graft is commonly grafted to a primary vasculature in the implant/wound site as a source of blood perfusion. However, there are many issues with the use of autologous vascular grafts and vascularized tissue grafts. These issues include limited availability, the requirement of invasive harvesting procedures that result in donor-site morbidity, mismatches between the morphology and hemodynamics of the donor and implant site, mismatches between compliance of the donor vessel and native vasculature, and transition of vascular smooth muscle cells (SMCs) in the donor graft from a healthy, contractile capability to a synthetic, pathological phenotype. Usually the lack of sufficient arterial tissue, especially in the case of multivessel disease, necessitates the use of venous grafts (which cannot withstand higher hemodynamic stresses, and are prone to thromboembolism and intimal hyperplasia). To this end, a recent randomized, double-blind, placebo-controlled trial that tracked over 3000 patients receiving human saphenous vein (HSV) grafts discovered that $45 \%$ of the patients had graft failure in the first 18 months. ${ }^{255}$ To address these issues, recent advances have focused on the development of cellularized synthetic grafts.

It is well known that a viable endothelial layer is an optimal antithrombogenic agent. Thus, the idea of seeding autogenous ECs onto the graft lumen by adding an inoculum of autologous ECs harvested from the saphenous vein to the unheparinized blood used for preclotting the graft before implantation was experimentally implemented. ${ }^{556}$ This approach increased the rate of patency Dacron prostheses ${ }^{257}$ in a nonsmoker population. In recent years, the focus of this research has been finding more biocompatible and biodegradable matrices to seed with ECs. Endothelial and SMCs utilized in seeding cellularized grafts have several potential sources, including harvesting of endothelial progenitor cells isolated from peripheral blood, bone marrow, adipose tissue, umbilical cord blood, or blood vessel walls for ex vivo expansion, ${ }^{258,259}$ endothelial and SMCs derived from human iPSCs, ${ }^{260}$ ECs derived from hASCs,${ }^{261}$ or autologous cells obtained through biopsy. These cells are cultivated in vitro under specific conditions and characterized by endothelialspecific morphology and biomarkers. These cells are either seeded onto synthetic (degradable or nondegradable) or biologically derived vessel scaffolds (e.g., decellularized vessel tissue) or through sheet-based techniques that involve lifting contiguous layers of cell sheets cultured on a substrate and rolled onto the lumen of a tubular scaffold to form a tissue-engineered vascular graft (TEVG). ${ }^{262}$

An example of cellularized graft development is provided by Hooper et al., who were able to manufacture hydrogel constructs using Pluronic F127 as a sacrificial microfiber, elaborating microscopic channels inside collagen matrices. They seeded these microchannels with HUVEC-only or HUVEC and human aortic smooth muscle cells (HASMC) in co-culture, ultimately resulting in endothelial-lined microchannel. Then, HUVEC-only and HASMC/HUVEC-seeded microchannel-containing constructs were microsurgically anastomosed to a rat femoral artery and vein and perfused in vivo. Their results show that HUVEC-only and HUVEC/ HAMSC-seeded constructs were able to withstand hemodynamic pressures and they were capable of maintaining the inner infrastructure of the channels. ${ }^{263}$ In another article, the same authors extended the same technique and synthesized a biocompatible tissue-engineered vascular network (discussed more in Engineering Vascularized Networks and In Situ Recruitment of Endogenous Vasculature section) with macroinlet and macro-outlet vessels, connected by a dense system of cellularized microvessels. ${ }^{264}$ Ultimately, this increase in complexity recapitulates the body's hierarchical organization of the vascular system with arterioles, capillary beds, and venules. This work represents a significant advancement toward generating more complex vascularized tissue beds around which other cell types can be seeded to realize a clinical solution to the vascularization problem.

Acellular grafts. The ultimate goal is to have "off-theshelf" vascular grafts available for clinical translation. The decellularization process provides an advantage in this regard by removing antigenic cellular component from the graft, enabling the use of banked allogeneic cells to manufacture vascular grafts that are nonimmunogenic and inserted in any potential host, which would be of great necessity in a trauma case requiring urgent clinical and surgical care.

Dahl et al. created TEVGs, with the ability to be anastomosed, using human allogeneic or canine SMCs grown on a tubular poly(glycolic acid) (PGA) scaffold (Fig. 13). The SMCs were cultured for 7-10 weeks on PGA. While culturing, SMCs secrete mostly collagen, to synthesize vascular tissue, while the PGA degrades. Culminating the culture phase, the obtained tissue is decellularized with detergents rendering the grafts nonimmunogenic, leaving only the secreted collagenous matrix (i.e., TEVGs). When tested, the TEVGs were comparable to native blood vessels based on mechanical properties and were able to resist prolonged storage at $4^{\circ} \mathrm{C}$. TEVGs proved to have exceptional patency and were resistant to dilation, calcification, and intimal hyperplasia when tested on distinct animal models. ${ }^{264}$ Currently, these grafts have finished a phase 2 clinical trial. ${ }^{265}$ In this clinical trial, all human acellular vessel (HAV) implants did not trigger an unpleasant immunological reaction and there was no recollection of failure directly related to 


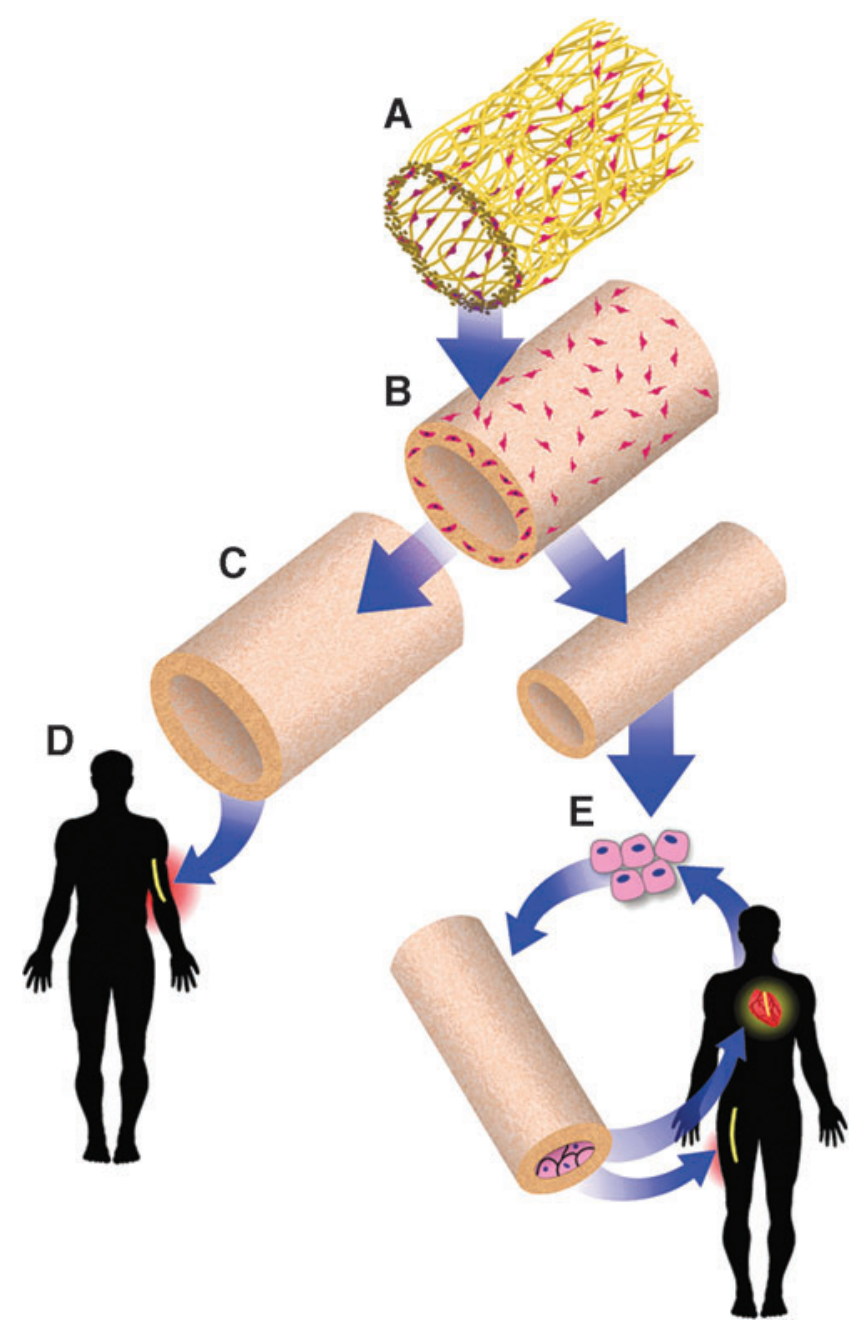

FIG. 13. Strategy for producing readily available TEVGs performed by Dahl et al. Each graft is generated in the laboratory by (A) culturing human cells on a polymer scaffold that degrades as cells produce ECM proteins to form (B) a tissue. Cellular material is then removed, leaving $(\mathbf{C})$ a decellularized ECM tube (the TEVG). Cell-derived TEVGs may be implanted without ECs (D), (diameters $\geq 6 \mathrm{~mm}$ ), or (E) may be seeded with ECs from the recipient for small-diameter (3-4 mm) applications. ECs, endothelial cells; TEVGs, tissueengineered vascular grafts. Figure reproduced with permission from The American Association for the Advancement of Science. ${ }^{264}$ Color images are available online.

the vessel. Furthermore, long-term patency rates measured at 2 years were significantly higher than previous controls comprising expanded poly(tetrafluoroethylene) or ePTFE.

\section{Engineering vascularized networks and in situ recruitment of endogenous vasculature}

Tissue engineering has recently yielded constructs that can be implanted as functional organs, including bladders, tracheas, and corneas. ${ }^{266}$ These constructs are thin enough that they do not require a complex vascular network to supply nutrients and oxygenation. However, thick tissues require vascular networks for adequate blood supply and waste removal, which requires increased complexity over established methods to provide vascular support through large singular or branched vascular segments. As a result, current efforts have focused on two areas: (1) the development of complex, tissue-engineered vascular networks and (2) in situ recruitment of endogenous vasculature to reestablish vascular networks.

To develop tissue-engineered vascular networks, researchers have utilized a variety of cellularized biomaterial scaffolds. Novel advancements include the use of celladhesive, MMP-degradable scaffolds (e.g., hydrogels) that allow for endothelial cellularization and remodeling that recapitulate in vivo vasculogenesis ${ }^{267}$ and $3 \mathrm{D}$ bioprinting methods using sacrificial fibers embedded in an ECM mimetic scaffold that are subsequently dissolved and perfused with ECs and blood/blood substitutes to facilitate vessel maturation. ${ }^{266}$ Two-dimensional and 3D cell patterning on tissue scaffold templates have been achieved through rapid prototyping methods, including bioprinting, extrusion-based printing, laser-based 3D printing (e.g., stereolithography), micropatterning, microfluidics, micromodule assembly, nanofabrication, decellularized vascular networks, biopolymerfree printing using cell aggregates as bioink, and cell sheet rolling methods. ${ }^{268}$ However, the formation of prevascularized networks still has its limitations: in vitro perfusion supports in vitro viability, but implantation in the in vivo environment results in delayed integration, angiogenesis, and vasculogenesis that cause ischemia and reduce cell viability. Utilizing multiple cell types and more physiologically relevant prevascularization conditions such as pulsatile flow and variable flow rates resulting in dynamic pressure/cyclical strain can alleviate these issues.

The alternative to creating cellularized vascular network preimplantation is in situ recruitment of endogenous vasculature and/or progenitor cells into a wound site or onto acellular tissue-engineered scaffolds. These approaches include micropatterning substrates to guide the formation of capillary networks integrated with the host tissue, ${ }^{269}$ incorporating and/or delivering growth factors (such as IGF-1, substance P, plateletderived growth factor [PDGF], VEGF, angiopoietins, and ephrins $^{270-272}$ ) to modulate endogenous cell recruitment and responses, and tethering of angiogenic ECM molecules such as fibronectin, collagen I and IV, elastin, and fibrin, to promote and guide neovascularization and angiogenesis. ${ }^{272,273}$

The "vascularization problem" is a commonly known problem in the field of tissue engineering. Therefore, many researchers have been studying ways to overcome this problem with promising results, specifically in engineering new vascular networks that can be anastomosed and can withstand high pressures with minimal to no loss of patency. With these technologies, scientists, engineers, and surgeons hope to grow larger and more physiologically relevant tissue constructs for more complex clinical reconstructions. However, we need to further our understanding and continue to develop technologies to control the complex interplay between the myriad signaling, biomechanical, ECM, and cellular interactions that underlie vascularization in the context of tissue reconstruction, replacement, and regeneration.

\section{Genetic Engineering}

Genetic engineering is the process in which an intentional alteration of the characteristics of an organism is produced 
by affecting its genetic code. This was first accomplished by Herbert Boyer and Stanley Cohen in $1973 .{ }^{274}$ These manipulations are made possible by a wide variety of methods such as gene targeting (e.g., modulating gene expression with siRNA or miRNA, which is transient as opposed to other permanent genetic engineering approaches that permanently modify DNA), nuclear transplantation, transfection of synthetic chromosomes, or viral insertion. Since its inception, many scientists and clinicians have studied this technology broadly, but its potential use in reconstructive surgery has been limited. Recently, Roh et al. discussed the potential impact of the revolutionary CRISPR (clustered regularly interspace short palindromic repeats) gene-editing technology in reconstructive surgery. ${ }^{275}$ Numerous press releases and news articles have begun to highlight the promise that CRISPR holds in several clinical areas. Between the benefits, we can increase tolerance and prevent rejection when modifying genetically VCAs. Also, humanization of donor animals has been described to yield production of less immunogenic and cheaper grafts. 776,277

Genome editing began long before the advent of CRISPR in the 1970s with the discovery that restriction enzymes that normally protect bacteria against phages could be utilized for recombinant DNA technology. In the 1980s, innovative work by Capecchi and Smithies demonstrated the ability to incorporate an exogenous copy of DNA into eukaryotic cells through a process called homologous recombination. ${ }^{278-280}$ However, this approach demonstrated very low efficiency and off-target, random integration into undesired genomic sites, so researcher began to seek alternative methods utilizing endonuclease enzymes to introduce double-strand breaks that resulted in several orders of magnitude increase in the frequency of target gene insertion. ${ }^{281,282}$ Toward this approach, the discovery of zinc finger proteins further advanced the field by allowing for high DNA binding specificity through recognition of specific 3-base pair DNA segments. ${ }^{283}$ Researchers then began fusing these proteins to nucleases to make programmable nuclease proteins. ${ }^{284}$ This approach was further refined with the discovery that fusion of transcription activator-like effector (TALE), which can recognize a single DNA base, with nucleases serves as an alternative programmable nuclease called TALEN. ${ }^{285}$ However, the complex and time-consuming process of engineering specific zinc-finger nucleases and TALENs for targeting specific sites in the genome prevented their widespread adoption. CRISPR then revolutionized the field because it was just as effective, if not more so, than previous approaches and could be programmed to target to specific DNA sites with a short guide RNA. ${ }^{286}$ CRISPR sequences and their adjacent CRISPR-associated (Cas) genes were discovered as a viral immune system in bacteria and archaea. ${ }^{287}$ This discovery resulted in the rapid development of this system leading to the ability to edit eukaryotic genes in vivo in $2013 .^{288,289}$

\section{Clinical use}

Although clinical use of these technologies has been sparse, Hirsch et al. carried out a gene therapy procedure on a 7-year-old boy suffering from severe junctional epidermolysis bullosa with $85 \%$ of his skin containing full-thickness damage $^{290}$ (Fig. 14). Historically, genetic therapy has been ethically controversial, predominantly since the "Gelsinger
Case" in 1999. ${ }^{291}$ The "Gelsinger Case" resulted in the death of 18-year-old Jesse Gelsinger after he was injected with an adenovirus vector during a clinical trial for the treatment of ornithine transcarbamylase deficiency, an Xlinked genetic disease of the liver. In this case by Hirsch et al., after the parents had provided informed consent, the compassionate use of combined ex vivo cell and gene therapy was authorized due to the severe state of the boy's condition. The clinician/researchers took a biopsy from the only nonaffected area in the left groin area to establish primary keratinocyte cultures. The retroviral vector expressing the fulllength LAMB3 complementary DNA (cDNA) was used to transduce the culturing cells. Once completing more than 30 days in culture, a total of $0.85-\mathrm{m}^{2}$ transgenic epidermal graft was harvested, enabling treating physicians to sequentially cover the patient's complete denuded body surface over a course of a couple of months. The scientific importance of this technique is that the researchers used his own skin and thus, immunological tolerance and skin tone alignment are not primary issues. Although this was a major success and celebrated worldwide, the long-term effects of viral genetic engineering on humans are currently largely unknown. Many scientists are worried about off-target effects possibly altering the phenotypic state of cells and stimulating tumorigenesis. For that matter, rare cases, like this one, should be followed and studied stringently over many years.

\section{Potential genetic targets}

siRNAs are known to transiently reduce protein expression by stimulating the degradation of the mRNA molecule it is directed against. Utilizing this biological mechanism, Cui et al. tested the hypothesis that the post-transplantation host response can be controlled by transfecting ECs preoperatively with siRNA, leading to reduced recruitment and activation of alloreactive T cells. ${ }^{292}$ To study this approach, they developed siRNA-releasing poly(amine-co-ester) (PACE) NPs recognized by the increased content of a hydrophobic lactone to neutralize the positive surface charge (yielding more biocompatible and hemocompatible formulations) and allow for formation into solid NPs using established emulsion fabrication methods. Using PACE NPs, the authors loaded a siRNA targeting the class II transactivator, which controls the expression of MHC class II. In vivo studies evidenced that MHC class II expression on the siRNA-PACE treated-ECs was depleted for at least 4-6 weeks after transplantation into mice. Furthermore, they found that silencing MHC class II reduced allogeneic $\mathrm{T}$ cell responses, both in vitro and in vivo. Overall, the data in these experiments ex vivo suggest that the delivery of siRNA targeted against immunological cascades modified ECs with persistent effect even after transplantation. Although siRNAs work transiently on protein expression levels, this study gives rise to the idea of using permanent genetic engineering technologies, such as CRISPR/Cas9, to knockdown molecules that interplay in allotransplantation or xenotransplantation rejection such as MHC class I, LFA-3, raptor, cytokines, and MHC class II. Furthermore, genetic studies have found multiple genes that are of importance to the field of reconstructive surgery. Some of these target genes include PDGF (mitogenic and chemotactic for cells of mesenchymal origin), fibroblast growth factor (FGF-mitogenic and chemoattractant to monocytes, neutrophils, macrophages, and 


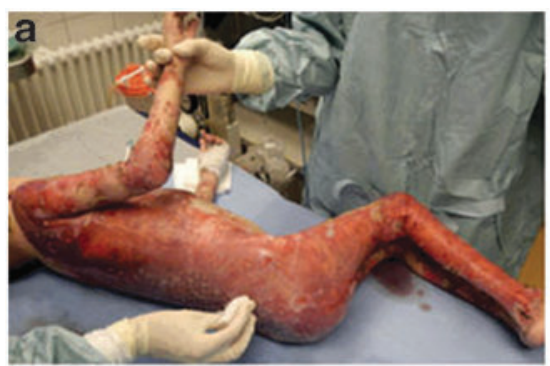

b
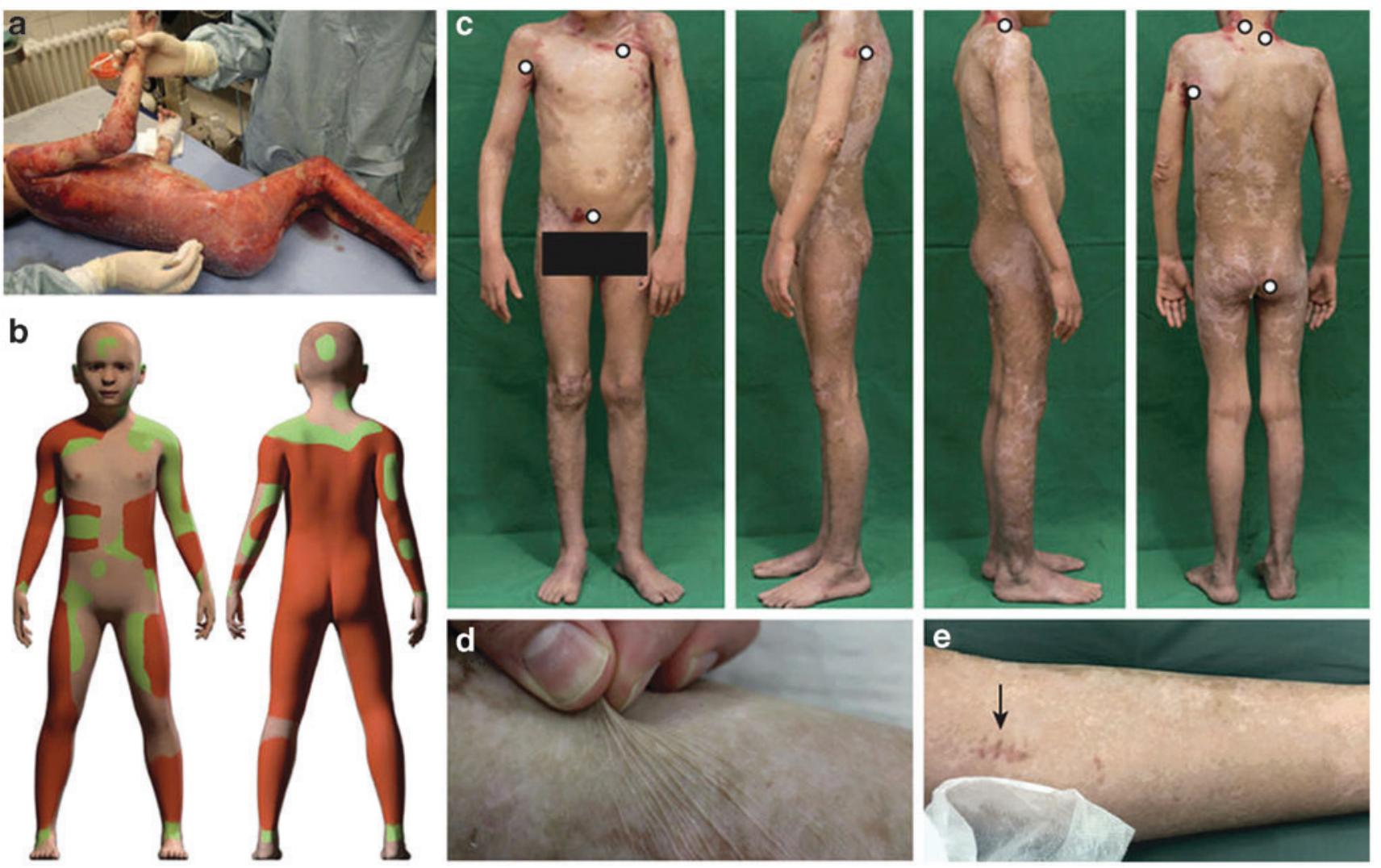

FIG. 14. Regeneration of the transgenic epidermis in epidermolysis bullosa, performed by Hirsch et al. (a) Clinical picture of the patient showing massive epidermal loss. (b) Schematic representation of the clinical picture. The denuded skin is indicated in red; blistering areas are indicated in green; flesh-colored areas indicate currently nonblistering skin. Transgenic grafts were applied on both red and green areas. (c) Restoration of patient's entire epidermis, except for very few areas on the right thigh, buttocks, upper shoulders/neck, and left axilla (white circles, altogether $\leq 2 \%$ of TBSA). (d) Normal skin functionality and elasticity. (e) Absence of blister formation at sites where postgraft biopsies were taken (arrow). TBSA, total body surface area. Figure reproduced with permission from Springer Nature. ${ }^{290}$ Color images are available online.

fibroblasts), and VEGF (increased angiogenesis). Others include BDNF (promotes the differentiation and survival of neurons) for peripheral nerve healing, bone morphogenetic protein (BMP-induces de novo bone formation and cartilage matrix macromolecules) for improved bone healing and/or regeneration, TGF- $\beta$ (increases ECM synthesis and deposition) for craniosynostosis, and many more. ${ }^{293}$ These factors should all hypothetically be upregulated/activated for improved wound healing/tissue regeneration. Upregulating of these factors can be achieved through a variety of genetic engineer approaches, including (1) RNA activation through small RNA-guided and Argonaute (Ago)-dependent gene regulation, (2) utilizing dead Cas9 proteins (that are unable to cleave DNA and, thus, only target specific DNA sites) fused with the $\omega$ subunit of RNA polymerase or transcription activators for activation, ${ }^{294}$ and (3) silencing of upstream negative regulators of expression for these genes (e.g., silencing PHD2, which inhibits the proangiogenic transcription factor HIF-1 $\alpha$ as shown in Fig. 8) through siRNA or CRISPR interference. However, the timing and interplay of multiple factors are important considerations in the complex tissue regeneration process and are dependent on the specific application and other contributing factors such as comorbidities. Due to the growth of this field and advancement in technology, this list of genes will only continue to grow and our toolset to modulate them in more precise and controlled ways will continue to expand.

\section{Current limitations}

Many vectors have been studied for the delivery of genetic material, all suffering from unique limitations. ${ }^{295}$ Viral vectors have been used widely, in vitro and in vivo, to deliver the CRISPR/Cas9 system. Their fundamental shortcomings include the risk of carcinogenesis, limited insertion size, adverse immune responses, and difficulty in large-scale production, all severely limiting their further application.

Li et al. described how to overcome these limitations at the molecular level: first, improving availability at target site. Second, better understanding how to control various repair pathways, and finally, improving efficiency of the CRISPR/Cas9 system. $^{296}$

\section{Biomaterial delivery systems: can they help?}

Current delivery methods build on the protocols that were developed for the delivery of traditional gene therapy (i.e., adding a functional copy of a gene that is missing or defective as opposed to genome editing where the genetic problem is modified at its source) and have been optimized over the years. Delivery vectors in gene therapy can be 
described in three main areas: (1) viral vectors, including retroviruses (including lentiviruses such as HIV), adenoviruses, adeno-associated viruses, and pseudotyped viruses; (2) nonviral vectors, including direct injection of DNA, electroporation, "gene guns," Sonoporation, magnetofection, and hydrodynamic delivery; and (3) chemical enhancers of delivery, including oligonucleotides, lipoplexes, polymersomes, polyplexes, dendrimers, inorganic NPs, and cell-penetrating peptides. To introduce CRISPR/Cas9 components, viral vectors have been the most common delivery method in preclinical models of disease. ${ }^{297,298}$ Viral vectors possess limitations like triggering both innate and adaptive immunological reactions and increased immunogenicity due to their sustained expression. ${ }^{299,300}$ For example, retroviruses stably integrate DNA into infected cells resulting in sustained expression of that gene that is maintained through mitotic division, ${ }^{301}$ but require actively dividing cells for integration (although a novel type of retroviral vectors made from lentiviruses can infect noncycling cells) and carry the risk of insertional mutagenesis and oncogene activation. ${ }^{302}$ In contrast, adenoviral vectors do not result in DNA integration into the genome and, thus, the effects do not persist through cell division. Adenoviruses have low pathogenicity, high infection rates, wide tropism, and high levels of viral protein expression during replication, but are severely limited by their immunogenicity. ${ }^{303}$ Technological advances and increased knowledge of molecular virology and virushost cell relationships continue to improve the safety profiles of viral vectors and allow for engineering vectors with defined tropism for specific tissue sites, but their widespread use is still limited due to concerns over gene integration, delivery, and rejection. ${ }^{304}$ It is for these reasons that nonviral delivery methods using novel encapsulation strategies with a variety of biomaterials to yield increased specificity and efficiency without immunogenicity have become a central focus in gene therapy. ${ }^{305}$ There are a variety of gene therapy-based therapeutics that have been recently approved by the FDA for clinical use (e.g., mipomersen for familial hypercholesterolemia approved by the FDA in 2013, eteplirsen for Duchenne muscular dystrophy approved by the FDA in 2016, nusinersen for spinal muscular atrophy in 2016, and patisiran for transthyretin-mediated amyloidosis approved by the FDA in 2018). Most of these therapeutics are modified oligonucleotide-based analogues, whereas patisiran comprised a siRNA-loaded lipid NP formulation to facilitate RNA interference. ${ }^{306}$ These advances set the stage for future development and clinical translation of gene therapies for a wide variety of indications, including tissue reconstruction and regeneration. With the robust development of nonviral DDS, lipid- or polymer-based nanocarriers are prospects to be efficacious vectors for the delivery of CRISPR-based systems. ${ }^{307}$

\section{Future Outlooks: What Does This Mean?}

\section{For researchers}

Along with creating novel ideas and procedures, researchers need to think about the clinical applicability of their technologies and how to move them forward from the bench to the bedside. Furthermore, researchers should seek out collaborations with clinically active surgeons and ob- serve the types of technologies needed for different reconstructive patient populations.

\section{For clinicians}

Clinicians should be aware of new technologies and should be on the forefront in helping basic scientists move promising technologies from the bench to the bedside through clinical development. Many of these technologies have the potential to decrease operative time, meaning that surgeons may be able to provide medical care to more patients and in the meantime, provide better individual care due to reduced donor-site morbidity.

\section{For patients}

As technologies and techniques progress along the translational "assembly line" and make their way to the clinic, patient donor-site morbidity will decrease, and regenerative outcomes should increase. Patients undergoing elective surgeries will be given an ever-increasing number of options for their reconstructive choices. Since these technologies have their own individual risks and benefits, patients will need to think deeply so that they can choose a technology, with the help of their clinician, which will best suit their needs.

\section{Acknowledgments}

One of the authors (J.M.C.) is supported by NIGMS of the National Institutes of Health under award number T32GM007347. The content in this report is solely the responsibility of the authors and does not necessarily represent the official views of the National Institutes of Health.

\section{Disclosure Statement}

No competing financial interests exist.

\section{References}

1. Glicenstein, J. Aesthetic surgery and history[in French]. Ann Chir Plast Esthet 48, 257, 2003.

2. Kayser, M.R. Surgical flaps. Selected Readings Plast Surg 9, 1, 1999.

3. Blocker, T.G., Jr., and Stout, R.A. Mandibular reconstruction, World War II. Plast Reconstr Surg 4, 153, 1949.

4. American Society of Plastic Surgeons. 2017 Plastic Surgery Statistics Report, A.N.C.o.P.S.P. Statistics, ed., 2017.

5. Duyn, J.V. Robbing Peter to Pay Paul. Plast Reconstr Surg 23, 77, 1959.

6. Hauben, D.J., Baruchin, A., and Mahler, D. On the history of the free skin-graft. Ann Plast Surg 9, 242, 1982.

7. Anderson, K., and Hamm, R.L. Factors that impair wound healing. J Am Coll Clin Wound Spec 4, 84, 2012.

8. Mellette, J.R., and Ho, D.Q. Interpolation flaps. Dermatol Clin 23, 87, vi, 2005.

9. Tschoi, M., Hoy, E.A., and Granick, M.S. Skin flaps. Clin Plast Surg 32, 261, 2005.

10. Guyuron, B., Chung, K.C., et al. Plastic Surgery: Indications and Practice. Saunders, 2009.

11. Cormack, G.C., and Lamberty B.G.H. The Arterial Anatomy of Skin Flaps. 2nd ed. Edinburgh: Churchill Livingstone, 1994. 
12. Demirtas, Y., et al. Management of split-thickness skin graft donor site: a prospective clinical trial for comparison of five different dressing materials. Burns 36, 999, 2010.

13. Voineskos, S.H., et al. Systematic review of skin graft donor-site dressings. Plast Reconstr Surg 124, 298, 2009.

14. Thomson, H.G., Kim, T.Y., and Ein, S.H. Residual problems in chest donor sites after microtia reconstruction: a long-term study. Plast Reconstr Surg 95, 961, 1995.

15. Chauhan, D.S., and Guruprasad, Y. Auricular reconstruction of congenital microtia using autogenous costal cartilage: report of 27 cases. J Maxillofac Oral Surg 11, 47, 2012.

16. Edsander-Nord, A., Jurell, G., and Wickman, M. Donorsite morbidity after pedicled or free TRAM flap surgery: a prospective and objective study. Plast Reconstr Surg 102, 1508, 1998.

17. Kroll, S.S., et al. Abdominal-wall strength, bulging, and hernia after tram flap breast reconstruction. Plast Reconstr Surg 96, 616, 1995.

18. Smith, S.L. Functional morbidity following latissimus dorsi flap breast reconstruction. J Adv Pract Oncol 5, 181, 2014.

19. Sun, Q., et al. Does pectoralis major flap harvesting induce upper extremity dysfunction? J Int Med Res 43, 555, 2015.

20. Boahene, K. Reanimating the paralyzed face. F1000Prime Rep 5, 49, 2013.

21. Dimitriou, R., et al. Complications following autologous bone graft harvesting from the iliac crest and using the RIA: a systematic review. Injury $\mathbf{4 2}$ Suppl 2, S3, 2011.

22. Neumann, C.G. The expansion of an area of skin by progressive distention of a subcutaneous balloon; use of the method for securing skin for subtotal reconstruction of the ear. Plast Reconstr Surg 19, 124, 1957.

23. Radovan, C. Breast reconstruction after mastectomy using the temporary expander. Plast Reconstr Surg 69, 195, 1982.

24. Radovan, C. Tissue expansion in soft-tissue reconstruction. Plast Reconstr Surg 74, 482, 1984.

25. Argenta, L.C., Watanabe, M.J., and Grabb, W.C. The use of tissue expansion in head and neck reconstruction. Ann Plast Surg 11, 31, 1983.

26. Wagh, M.S., and Dixit, V. Tissue expansion: concepts, techniques and unfavourable results. Indian J Plast Surg 46, 333, 2013.

27. Hurvitz, K.A., Rosen, H., and Meara, J.G. Pediatric cervicofacial tissue expansion. Int J Pediatr Otorhinolaryngol 69, 1509, 2005.

28. Varga, J., et al. Acrylamide, acrylic acid and nisopropylacrylamide hydrogels as osmotic tissue expanders. Skin Pharmacol Physiol 22, 305, 2009.

29. Ascherman, J.A., et al. Carbon dioxide-based versus saline tissue expansion for breast reconstruction: results of the XPAND prospective, randomized clinical trial. Plast Reconstr Surg 138, 1161, 2016.

30. Vandamme, P.A., et al. Cranio-maxillo-facial tissue expansion, experimentally based or clinically empiric-a review of the literature. J Craniomaxillofac Surg 20, 61, 1992.

31. Austad, E.D., and Rose, G.L. A self-inflating tissue expander. Plast Reconstr Surg 70, 588, 1982.

32. Wiese, K.G. Osmotically induced tissue expansion with hydrogels: a new dimension in tissue expansion? A preliminary report. J Craniomaxillofac Surg 21, 309, 1993.
33. Akbari, M., et al. Textile technologies and tissue engineering: a path toward organ weaving. Adv Healthc Mater 5, 751, 2016.

34. Wiese, K.G., et al. Biomaterial properties and biocompatibility in cell culture of a novel self-inflating hydrogel tissue expander. J Biomed Mater Res 54, 179, 2001.

35. Tran, T.H., et al. Biodegradable elastic hydrogels for tissue expander application. In: Handbook of Biodegradable Polymers: Synthesis, Characterization and Applications, 2011, pp. 217-236.

36. Downes, R., Lavin, M., and Collin, R. Hydrophilic expanders for the congenital anophthalmic socket. Adv Ophthalmic Plast Reconstr Surg 9, 57, 1992.

37. Kobus, K.F. Cleft palate repair with the use of osmotic expanders: a preliminary report. J Plast Reconstr Aesthet Surg 60, 414, 2007.

38. Swan, M.C., et al. Cleft palate repair with the use of osmotic expanders: a response. J Plast Reconstr Aesthet Surg 61, 220, 2008.

39. von See, C., et al. Bone augmentation after soft-tissue expansion using hydrogel expanders: effects on microcirculation and osseointegration. Clin Oral Implants Res 21, 842, 2010.

40. Smith, J.R., Radzi, Z., and Czernuszka, J.T. The effects of hot pressing on the swelling behavior of P(MMA-coNVP) hydrogel discs. Polym Eng Sci 55, 1290, 2015.

41. Janovák, L., et al. Investigation of the structure and swelling of poly( $\mathrm{N}$-isopropyl-acrylamide-acrylamide) and poly(N-isopropyl-acrylamide-acrylic acid) based copolymer and composite hydrogels. Colloid Polym Sci 286, 1575, 2008.

42. Jamadi, M., et al. Poly (ethylene glycol)-based hydrogels as self-inflating tissue expanders with tunable mechanical and swelling properties. Macromol Biosci 17, 2017.

43. Swan, M.C., et al. Synthesis and properties of a novel anisotropic self-inflating hydrogel tissue expander. Acta Biomater 7, 1126, 2011.

44. Swan, M.C., et al. Development of a novel anisotropic self-inflating tissue expander: in vivo submucoperiosteal performance in the porcine hard palate. Plast Reconstr Surg 129, 79, 2012.

45. Edtinger, K., et al. Current status of vascularized composite tissue allotransplantation. Burns Trauma 2, 53, 2014.

46. Birchall, M. Human laryngeal allograft: shift of emphasis in transplantation. Lancet 351, 539, 1998.

47. Guidance on optimizing VCA recovery from deceased donors. OPTN/UNOS Vascularized Composite Allograft (VCA) Transplantation Committee. 2018.

48. Diaz-Siso, J.R., et al. Vascularized composite tissue allotransplantation-state of the art. Clin Transplant 27, 330, 2013.

49. Siemionow, M.Z., et al. First U.S. near-total human face transplantation: a paradigm shift for massive complex injuries. Plast Reconstr Surg 125, 111, 2010.

50. Cetrulo, C.L., Jr., et al. Penis transplantation: first US experience. Ann Surg 267, 983, 2018.

51. Pomahac, B., et al. Vascularized composite allotransplantation research: the emerging field. Am J Transplant 12, 1062, 2012.

52. Caplan, A.L., et al. The ethics of penile transplantation: preliminary recommendations. Transplantation 101, 1200, 2017.

53. Dubernard, J.M., et al. Human hand allograft: report on first 6 months. Lancet 353, 1315, 1999. 
54. Strome, M., et al. Brief report: laryngeal transplantation and 40-month follow-up. N Engl J Med 344, 1676, 2001.

55. Cavadas, P.C., et al. Bilateral transfemoral lower extremity transplantation: result at 1 year. Am J Transplant 13, 1343, 2013.

56. Barret, J.P., et al. Full face transplant: the first case report. Ann Surg 254, 252, 2011.

57. Devauchelle, B., et al. First human face allograft: early report. Lancet 368, 203, 2006.

58. Jiang, H.Q., et al. Composite tissue allograft transplantation of cephalocervical skin flap and two ears. Plast Reconstr Surg 115, 31e, 2005.

59. Landin, L., et al. Preliminary results of bilateral arm transplantation. Transplantation 88, 749, 2009.

60. Hofmann, G.O., and Kirschner, M.H. Clinical experience in allogeneic vascularized bone and joint allografting. Microsurgery 20, 375, 2000.

61. Doi, K., et al. Vascularized bone allografts-review of current concepts. Microsurgery 15, 831, 1994.

62. Hofmann, G.O., et al. Allogenic vascularized transplantation of a human femoral diaphysis under cyclosporin A immunosuppression. Transpl Int 8, 418, 1995.

63. Birchall, M. Tongue transplantation. Lancet 363, 1663, 2004.

64. Tintinago, L.F., et al. Ultrasonographic evaluation of a vascularized tracheal transplantation. J Ultrasound Med 24, 1145, 2005

65. Levi, D.M., et al. Transplantation of the abdominal wall. Lancet 361, 2173, 2003.

66. $\mathrm{Hu}, \mathrm{W}$., et al. A preliminary report of penile transplantation. Eur Urol 50, 851, 2006.

67. Fageeh, W., et al. Transplantation of the human uterus. Int J Gynaecol Obstet 76, 245, 2002.

68. Li, X.C., and Jevnikar, A.M., eds. Transplant Immunology. L. John Wiley \& Sons, 2015.

69. McCaffery, D. A review of transplant immunology. Crit Care Nurs Clin North Am 23, 393, 2011.

70. Rao, S., et al. Long-term functional recovery, quality of life, and pregnancy after solid organ transplantation. Med Clin North Am 100, 613, 2016.

71. Brandacher, G., Sachs, D.H., and Thomson, A.W. Immunology of vascularized composite allografts. Clin Dev Immunol 2013, 689071, 2013.

72. Fischer, S., et al. Acute rejection in vascularized composite allotransplantation. Curr Opin Organ Transplant 19, $531,2014$.

73. Kueckelhaus, M., et al. Vascularized composite allotransplantation: current standards and novel approaches to prevent acute rejection and chronic allograft deterioration. Transpl Int 29, 655, 2016.

74. Issa, F. Vascularized composite allograft-specific characteristics of immune responses. Transpl Int 29, 672, 2016.

75. Kanitakis, J. The challenge of dermatopathological diagnosis of composite tissue allograft rejection: a review. J Cutan Pathol 35, 738, 2008.

76. Cendales, L.C., et al. The Banff 2007 working classification of skin-containing composite tissue allograft pathology. Am J Transplant 8, 1396, 2008.

77. Khalifian, S., Cooney, D.S., Brandacher, G., and Lee, W.P.A. The role of ischemia-reperfusion injury in reconstructive transplantation. J Transplant Technol Res 2013.

78. Arun, A., Abt, N.B., Tuffaha, S., Brandacher, G., and Barone, A.A.L. Nerve regeneration in vascularized composite allotransplantation: current strategies and future directions. Plast Aesthet Res 2, 226, 2015.
79. Kumnig, M., et al. The psychological assessment of candidates for reconstructive hand transplantation. Transpl Int 25, 573, 2012.

80. Nguyen, L.L., et al. Cost Analysis of conventional face reconstruction versus face transplantation for large tissue defects. Plast Reconstr Surg 135, 260, 2015.

81. Hubbell, J.A., Thomas, S.N., and Swartz, M.A. Materials engineering for immunomodulation. Nature 462, 449, 2009.

82. Kohane, D.S. Microparticles and nanoparticles for drug delivery. Biotechnol Bioeng 96, 203, 2007.

83. Balmert, S.C., and Little, S.R. Biomimetic delivery with micro- and nanoparticles. Adv Mater 24, 3757, 2012.

84. Champion, J.A., Walker, A., and Mitragotri, S. Role of particle size in phagocytosis of polymeric microspheres. Pharm Res 25, 1815, 2008.

85. Moon, J.J., Huang, B., and Irvine, D.J. Engineering nano- and microparticles to tune immunity. Adv Mater 24, 3724, 2012.

86. Halloran, P.F. Immunosuppressive drugs for kidney transplantation. N Engl J Med 351, 2715, 2004.

87. Fisher, J.D., Acharya, A.P., and Little, S.R. Micro and nanoparticle drug delivery systems for preventing allotransplant rejection. Clin Immunol 160, 24, 2015.

88. Kaufman, C.L., et al. Immunobiology in VCA. Transpl Int 29, 644, 2016

89. Gajanayake, T., et al. A single localized dose of enzymeresponsive hydrogel improves long-term survival of a vascularized composite allograft. Sci Transl Med 6, 249ra110, 2014.

90. Unadkat, J.V., et al. Single implantable FK506 disk prevents rejection in vascularized composite allotransplantation. Plast Reconstr Surg 139, 403e, 2017.

91. Bahmani, B., et al. Targeted delivery of immune therapeutics to lymph nodes prolongs cardiac allograft survival. J Clin Invest 128, 4770, 2018.

92. Eltzschig, H.K., and Eckle, T. Ischemia and reperfusionfrom mechanism to translation. Nat Med 17, 1391, 2011.

93. Shoskes, D., et al. Beneficial effects of the bioflavonoids curcumin and quercetin on early function in cadaveric renal transplantation: a randomized placebo controlled trial (vol 80, 1556, 2006). Transplantation 82, 715, 2006.

94. Soares, M.P., et al. Heme oxygenase-1, a protective gene that prevents the rejection of transplanted organs. Immunol Rev 184, 275, 2001.

95. Lee, S.H., et al. Current progress in reactive oxygen species (ROS)-responsive materials for biomedical applications. Adv Healthc Mater 2, 908, 2013.

96. Lee, D., et al. $\mathrm{H}_{2} \mathrm{O}_{2}$-responsive molecularly engineered polymer nanoparticles as ischemia/reperfusion-targeted nanotherapeutic agents. Sci Rep 3, 2233, 2013.

97. Dollinger, B.R., et al. Reactive oxygen species shielding hydrogel for the delivery of adherent and nonadherent therapeutic cell types. Tissue Eng Part A 23, 1120, 2017.

98. Schweizer, R., Gorantla, V.S., and Plock J.A. Premise and promise of mesenchymal stem cell-based therapies in clinical vascularized composite allotransplantation. Curr Opin Organ Transplant 20, 608, 2015.

99. Ankrum, J.A., Ong, J.F., and Karp, J.M. Mesenchymal stem cells: immune evasive, not immune privileged. Nat Biotechnol 32, 252, 2014.

100. Mahla, R.S. Stem cells applications in regenerative medicine and disease therapeutics. Int $\mathrm{J}$ Cell Biol 2016, 6940283, 2016.

101. Bunnell, B.A., et al. Adipose-derived stem cells: isolation, expansion and differentiation. Methods 45, 115, 2008. 
102. Behfar, A., et al. Optimized delivery system achieves enhanced endomyocardial stem cell retention. Circ Cardiovasc Interv 6, 710, 2013.

103. Prestwich, G.D. Delivery, retention and engraftment of progenitor cells in cell therapy. Biomatter 3, 2013.

104. Li, L.P., et al. How to improve the survival of transplanted mesenchymal stem cell in ischemic heart? Stem Cells Int 2016.

105. Krampera, M., et al. Bone marrow mesenchymal stem cells inhibit the response of naive and memory antigen-specific T cells to their cognate peptide. Blood 101, 3722, 2003.

106. Gonzalez-Rey, E., et al. Human adipose-derived mesenchymal stem cells reduce inflammatory and $\mathrm{T}$ cell responses and induce regulatory $\mathrm{T}$ cells in vitro in rheumatoid arthritis. Ann Rheum Dis 69, 241, 2010.

107. Ren, G., et al. Mesenchymal stem cell-mediated immunosuppression occurs via concerted action of chemokines and nitric oxide. Cell Stem Cell 2, 141, 2008.

108. Ye, Z., et al. Immunosuppressive effects of rat mesenchymal stem cells: involvement of $\mathrm{CD} 4{ }^{+} \mathrm{CD} 25^{+}$regulatory T cells. Hepatobiliary Pancreat Dis Int 7, 608, 2008.

109. Kuo, Y.R., et al. Modulation of immune response and Tcell regulation by donor adipose-derived stem cells in a rodent hind-limb allotransplant model. Plast Reconstr Surg 128, 661e, 2011.

110. Plock, J.A., et al. The influence of timing and frequency of adipose-derived mesenchymal stem cell therapy on immunomodulation outcomes after vascularized composite allotransplantation. Transplantation 101, e1, 2017.

111. Zan, G., and $\mathrm{Wu}, \mathrm{Q}$. Biomimetic and bioinspired synthesis of nanomaterials/nanostructures. Adv Mater 28, 2099, 2016.

112. Sakaguchi, S., et al. Regulatory T cells and immune tolerance. Cell 133, 775, 2008.

113. Metcalfe, S.M., et al. Leukemia inhibitory factor is linked to regulatory transplantation tolerance. Transplantation 79, 726, 2005.

114. Lu, L., et al. Characterization of protective human CD4CD25 FOXP3 regulatory T cells generated with IL-2, TGF-beta and retinoic acid. PloS One 5, e15150, 2010.

115. Park, J., et al. Modulation of $\mathrm{CD} 4^{+} \mathrm{T}$ lymphocyte lineage outcomes with targeted, nanoparticle-mediated cytokine delivery. Mol Pharm 8, 143, 2011.

116. Fisher, J., et al. Establishing donor specific tolerance in vascularized composite allotransplantation via local enrichment of endogenous regulatory T cells. J Immunol 192, 2014.

117. Lewis, J.S., et al. Combinatorial delivery of immunosuppressive factors to dendritic cells using dual-sized microspheres. J Mater Chem B 2, 2562, 2014.

118. Luo, X.R., Miller, S.D., and Shea, L.D. Immune tolerance for autoimmune disease and cell transplantation. Annu Rev Biomed Eng 18, 181, 2016.

119. Ochando, J., and Braza, M.S. Nanoparticle-based modulation and monitoring of antigen-presenting cells in organ transplantation. Front Immunol 8, 1888, 2017.

120. Wong, C.Y., Al-Salami, H., and Dass, C.R. Microparticles, microcapsules and microspheres: a review of recent developments and prospects for oral delivery of insulin. Int J Pharm 537, 223, 2018.

121. Hlavaty, K.A., et al. Tolerance induction using nanoparticles bearing HY peptides in bone marrow transplantation. Biomaterials 76, 1, 2016.

122. Goral, S. The three-signal hypothesis of lymphocyte activation/targets for immunosuppression. Dial Transplant 40, 14, 2011.
123. Steenblock, E.R., and Fahmy, T.M. A comprehensive platform for ex vivo T-cell expansion based on biodegradable polymeric artificial antigen-presenting cells. Mol Ther 16, 765, 2008.

124. Salehi, S., and Reed, E.F. The divergent roles of macrophages in solid organ transplantation. Curr Opin Organ Transplant 20, 446, 2015.

125. Jiang, B.G., et al. Advance of peripheral nerve injury repair and reconstruction. Chin Med J 130, 2996, 2017.

126. Suszynski, K., Marcol, W., and Gorka, D. Physiotherapeutic techniques used in the management of patients with peripheral nerve injuries. Neural Regen Res 10, 1770, 2015.

127. Armada-da-Silva, P.A.S., et al. Role of physical exercise for improving posttraumatic nerve regeneration. In: Tissue Engineering of the Peripheral Nerve: Biomaterials and Physical Therapy. 109, 2013, pp. 125-149.

128. Jiang, L.F., Jones, S., and Jia, X.F. Stem cell transplantation for peripheral nerve regeneration: current options and opportunities. Int J Mol Sci 18, 2017.

129. Cooney, D.S., et al. Mesenchymal stem cells enhance nerve regeneration in a rat sciatic nerve repair and hindlimb transplant model. Sci Rep 6, 2016.

130. Le Douarin, N.M., and Dupin, E. Multipotentiality of the neural crest. Curr Opin Genet Dev 13, 529, 2003.

131. Woodhoo, A., and Sommer, L. Development of the Schwann cell lineage: from the neural crest to the myelinated nerve. Glia 56, 1481, 2008.

132. Sakaue, M., and Sieber-Blum, M. Human epidermal neural crest stem cells as a source of Schwann cells. Development 142, 3188, 2015.

133. Volarevic, V., et al. Ethical and safety issues of stem cellbased therapy. Int J Med Sci 15, 36, 2018.

134. Dalamagkas, K., Tsintou, M., and Seifalian, A. Advances in peripheral nervous system regenerative therapeutic strategies: a biomaterials approach. Mater Sci Eng C Mater Biol Appl 65, 425, 2016.

135. Isaacs, J., and Browne, T. Overcoming short gaps in peripheral nerve repair: conduits and human acellular nerve allograft. Hand 9, 131, 2014.

136. Arslantunali, D., et al. Peripheral nerve conduits: technology update. Med Devices (Auckl) 7, 405, 2014.

137. Belanger, K., et al. Recent strategies in tissue engineering for guided peripheral nerve regeneration. Macromol Biosci 16, 472, 2016.

138. Sarker, M., et al. Strategic design and fabrication of nerve guidance conduits for peripheral nerve regeneration. Biotechnol J 13, e1700635, 2018.

139. Schlosshauer, B., et al. Synthetic nerve guide implants in humans: a comprehensive survey. Neurosurgery 59, 740; discussion 747, 2006.

140. Ambros, V. The functions of animal microRNAs. Nature 431, 350, 2004.

141. Bartel, D.P. MicroRNAs: target recognition and regulatory functions. Cell 136, 215, 2009.

142. Zhang, H., Li, Y., and Lai, M. The microRNA network and tumor metastasis. Oncogene 29, 937, 2010.

143. Wu, D., and Murashov, A.K. Molecular mechanisms of peripheral nerve regeneration: emerging roles of microRNAs. Front Physiol 4, 55, 2013.

144. Beavers, K.R., Nelson, C.E., and Duvall, C.L. miRNA inhibition in tissue engineering and regenerative medicine. Adv Drug Deliv Rev 88, 123, 2015. 
145. Wang, J., et al. MicroRNA-338 and microRNA-21 cotransfection for the treatment of rat sciatic nerve injury. Neurol Sci 37, 883, 2016.

146. Yi, S., et al. Regulation of Schwann cell proliferation and migration by miR-1 targeting brain-derived neurotrophic factor after peripheral nerve injury. Sci Rep 6, 29121, 2016.

147. Terasawa, K., et al. Sustained activation of ERK $1 / 2$ by NGF induces microRNA-221 and 222 in PC12 cells. FEBS J 276, 3269, 2009.

148. Song, J., et al. Biodegradable and biocompatible cationic polymer delivering microRNA-221/222 promotes nerve regeneration after sciatic nerve crush. Int J Nanomedicine 12, 4195, 2017.

149. Kueckelhaus, M., et al. Extracorporeal perfusion in vascularized composite allotransplantation: current concepts and future prospects. Ann Plast Surg 80, 669, 2018.

150. Henry, S.D., and Guarrera, J.V. Protective effects of hypothermic ex vivo perfusion on ischemia/reperfusion injury and transplant outcomes. Transplant Rev 26, 163, 2012.

151. Ozer, K., et al. Ex situ limb perfusion system to extend vascularized composite tissue allograft survival in swine. Transplantation 99, 2095, 2015.

152. Ozer, K., et al. The effect of ex situ perfusion in a swine limb vascularized composite tissue allograft on survival up to 24 hours. J Hand Surg Am 41, 3, 2016.

153. Slater, N.J., et al. Ex-vivo oxygenated perfusion of free flaps during ischemia time: a feasibility study in a porcine model and preliminary results. J Surg Res 205, 292, 2016.

154. Taeger, C.D., et al. Assessing viability of extracorporeal preserved muscle transplants using external field stimulation: a novel tool to improve methods prolonging bridge-to-transplantation time. Sci Rep 5, 2015.

155. Van Caenegem, O., et al. Hypothermic continuous machine perfusion improves metabolic preservation and functional recovery in heart grafts. Transpl Int 28, 224, 2015.

156. O'Neill, J.D., et al. Cross-circulation for extracorporeal support and recovery of the lung. Nat Biomed Eng 1, 2017.

157. Han, G., and Ceilley, R. Chronic wound healing: a review of current management and treatments. Adv Ther 34, 599, 2017.

158. Frykberg, R.G., and Banks, J. Challenges in the treatment of chronic wounds. Adv Wound Care 4, 560, 2015.

159. Gurtner, G.C., et al. Wound repair and regeneration. Nature 453, 314, 2008.

160. Izadi, K., and Ganchi, P. Chronic wounds. Clin Plast Surg 32, 209, 2005.

161. Basu, P., Kumar, U.N., and Manjubala, I. Wound healing materials-a perspective for skin tissue engineering. Curr Sci 112, 2392, 2017.

162. Das, S., and Baker, A.B. Biomaterials and nanotherapeutics for enhancing skin wound healing. Front Bioeng Biotechnol 4, 82, 2016.

163. Lew, D.H., Liu, P.H.T., and Orgill, D.P. Optimization of UV cross-linking density for durable and nontoxic collagen GAG dermal substitute. J Biomed Mater Res B Appl Biomater 82B, 51, 2007.

164. Sun, G.M., et al. Dextran hydrogel scaffolds enhance angiogenic responses and promote complete skin regeneration during burn wound healing. Proc Natl Acad Sci U S A 108, 20976, 2011.

165. Shen, Y.I., et al. Acellular hydrogels for regenerative burn wound healing: translation from a porcine model. J Invest Dermatol 135, 2519, 2015.
166. Pereira, G.G., et al. Hyaluronate nanoparticles included in polymer films for the prolonged release of vitamin $\mathrm{E}$ for the management of skin wounds. Eur J Pharm Sci 83, 203, 2016.

167. Yang, F., et al. Genetic engineering of human stem cells for enhanced angiogenesis using biodegradable polymeric nanoparticles. Proc Natl Acad Sci U S A 107, 3317, 2010.

168. Castleberry, S.A., et al. Self-assembled wound dressings silence mmp-9 and improve diabetic wound healing in vivo. Adv Mater 28, 1809, 2016.

169. Kang, M., Choi, S., and Lee, A.R.C. Effect of freeze dried bovine amniotic membrane extract on full thickness wound healing. Arch Pharm Res 36, 472, 2013.

170. Sinha, M., et al. Development of ciprofloxacin hydrochloride loaded poly(ethylene glycol)/chitosan scaffold as wound dressing. J Porous Mat 20, 799, 2013.

171. Poole, K.M., et al. ROS-responsive microspheres for on demand antioxidant therapy in a model of diabetic peripheral arterial disease. Biomaterials 41, 166, 2015.

172. Martin, J.R., et al. Local delivery of PHD2 siRNA from ROS-degradable scaffolds to promote diabetic wound healing. Adv Healthc Mater 5, 2751, 2016.

173. Martin, J.R., et al. A porous tissue engineering scaffold selectively degraded by cell-generated reactive oxygen species. Biomaterials 35, 3766, 2014.

174. Nelson, C.E., et al. Tunable delivery of siRNA from a biodegradable scaffold to promote angiogenesis in vivo. Adv Mater 26, 607, 5062014.

175. Appelhoff, R.J., et al. Differential function of the prolyl hydroxylases PHD1, PHD2, and PHD3 in the regulation of hypoxia-inducible factor. J Biol Chem 279, 38458, 2004.

176. Guo, R.J., et al. A transient cell-shielding method for viable MSC delivery within hydrophobic scaffolds polymerized in situ. Biomaterials 54, 21, 2015.

177. Langer, R., and Vacanti, J.P. Tissue engineering. Science 260, 920, 1993.

178. Golas, A.R., Hernandez, K.A., and Spector, J.A. Tissue engineering for plastic surgeons: a primer. Aesthetic Plast Surg 38, 207, 2014.

179. Atala, A., et al. Tissue-engineered autologous bladders for patients needing cystoplasty. Lancet 367, 1241, 2006.

180. Macchiarini, P., et al. Clinical transplantation of a tissueengineered airway. Lancet 372, 2023, 2008.

181. Baiguera, S., Birchall, M.A., and Macchiarini, P. Tissueengineered tracheal transplantation. Transplantation 89, 485, 2010.

182. Raya-Rivera, A., et al. Tissue-engineered autologous urethras for patients who need reconstruction: an observational study. Lancet 377, 1175, 2011.

183. Fulco, I., et al. Engineered autologous cartilage tissue for nasal reconstruction after tumour resection: an observational first-in-human trial. Lancet 384, 337, 2014.

184. Al-Himdani, S., et al. Tissue-engineered solutions in plastic and reconstructive surgery: principles and practice. Front Surg 4, 4, 2017.

185. Teixeira da Silva, J.A. Ethical perspectives and ramifications of the Paolo Macchiarini case. Indian J Med Ethics 2, 270, 2017.

186. Ott, H.C., et al. Perfusion-decellularized matrix: using nature's platform to engineer a bioartificial heart. Nat Med 14, 213, 2008.

187. Ott, H.C., et al. Regeneration and orthotopic transplantation of a bioartificial lung. Nat Med 16, 927, 2010.

188. Uygun, B.E., et al. Organ reengineering through development of a transplantable recellularized liver graft using decellularized liver matrix. Nat Med 16, 814, 2010. 
189. Gilbert, T.W. Strategies for tissue and organ decellularization. J Cell Biochem 113, 2217, 2012.

190. Arenas-Herrera, J.E., et al. Decellularization for whole organ bioengineering. Biomed Mater 8, 2013.

191. Zhang, Q.X., et al. Decellularized skin/adipose tissue flap matrix for engineering vascularized composite soft tissue flaps. Acta Biomater 35, 166, 2016.

192. Burk, J., et al. Freeze-thaw cycles enhance decellularization of large tendons. Tissue Eng Part C Methods 20, 276, 2014.

193. Shandalov, Y., et al. An engineered muscle flap for reconstruction of large soft tissue defects. Proc Natl Acad Sci U S A 111, 6010, 2014.

194. Stevens, M.M., et al. In vivo engineering of organs: the bone bioreactor. Proc Natl Acad Sci U S A 102, 11450, 2005.

195. Collar, R.M., and Byrne, P.J. Prelaminated free flap for auricular reconstruction. N Engl J Med 369, 1151, 2013.

196. Jessop, Z.M., et al. 3D bioprinting for reconstructive surgery: principles, applications and challenges. J Plast Reconstr Aesthet Surg 70, 1155, 2017.

197. Zhang, T., et al. Mechanical characterization of bioprinted in vitro soft tissue models. Biofabrication 5, 2013.

198. Schuller-Ravoo, S., et al. Flexible and elastic scaffolds for cartilage tissue engineering prepared by stereolithography using poly(trimethylene carbonate)-based resins. Macromol Biosci 13, 1711, 2013.

199. Gurkan, U.A., et al. Engineering anisotropic biomimetic fibrocartilage microenvironment by bioprinting mesenchymal stem cells in nanoliter gel droplets. Mol Pharm 11, 2151, 2014.

200. Hsieh, F.Y., Lin, H.H., and Hsu, S.H. 3D bioprinting of neural stem cell-laden thermoresponsive biodegradable polyurethane hydrogel and potential in central nervous system repair. Biomaterials 71, 48, 2015.

201. Skardal, A., et al. Bioprinted amniotic fluid-derived stem cells accelerate healing of large skin wounds. Stem Cells Transl Med 1, 792, 2012.

202. Michael, S., et al. Tissue engineered skin substitutes created by laser-assisted bioprinting form skin-like structures in the dorsal skin fold chamber in mice. PloS One $\mathbf{8}$, e57741, 2013.

203. Cui, X.F., et al. Direct human cartilage repair using threedimensional bioprinting technology. Tissue Eng Part A 18, 1304, 2012.

204. Koch, L., et al. Laser printing of skin cells and human stem cells. Tissue Eng Part C Methods 16, 847, 2010.

205. Owens, C.M., et al. Biofabrication and testing of a fully cellular nerve graft. Biofabrication 5, 2013.

206. Wu, P.K., and Ringeisen, B.R. Development of human umbilical vein endothelial cell (HUVEC) and human umbilical vein smooth muscle cell (HUVSMC) branch/ stem structures on hydrogel layers via biological laser printing (BioLP). Biofabrication 2, 2010.

207. Miller, J.S., et al. Rapid casting of patterned vascular networks for perfusable engineered three-dimensional tissues. Nat Mater 11, 768, 2012.

208. Pataky, K., et al. Microdrop printing of hydrogel bioinks into 3D tissue-like geometries. Adv Mater 24, 391, 2012.

209. Kolesky, D.B., et al. 3D bioprinting of vascularized, heterogeneous cell-laden tissue constructs. Adv Mater 26, 3124, 2014.

210. Wust, S., Muller, R., and Hofmann, S. 3D bioprinting of complex channels-effects of material, orientation, geometry, and cell embedding. J Biomed Mater Res A 103, 2558, 2015.

211. Zhang, Y.H., et al. In vitro study of directly bioprinted perfusable vasculature conduits. Biomater Sci 3, 134, 2015.
212. Gaebel, R., et al. Patterning human stem cells and endothelial cells with laser printing for cardiac regeneration. Biomaterials 32, 9218, 2011.

213. Skardal, A., et al. Photocrosslinkable hyaluronan-gelatin hydrogels for two-step bioprinting. Tissue Eng Part A 16, 2675, 2010.

214. Norotte, C., et al. Scaffold-free vascular tissue engineering using bioprinting. Biomaterials 30, 5910, 2009.

215. Cui, X.F., and Boland, T. Human microvasculature fabrication using thermal inkjet printing technology. Biomaterials 30, 6221, 2009.

216. Seitz, H., et al. Different calcium phosphate granules for 3-D printing of bone tissue engineering scaffolds. Adv Eng Mater 11, B41, 2009.

217. Becker, S.T., et al. Endocultivation: 3D printed customized porous scaffolds for heterotopic bone induction. Oral Oncol 45, E181, 2009.

218. Tamimi, F., et al. Craniofacial vertical bone augmentation: a comparison between 3D printed monolithic monetite blocks and autologous onlay grafts in the rabbit. Biomaterials 30, 6318, 2009.

219. Shim, J.H., et al. Stimulation of healing within a rabbit calvarial defect by a PCL/PLGA scaffold blended with TCP using solid freeform fabrication technology. J Mater Sci Mater Med 23, 2993, 2012.

220. Probst, F.A., et al. Calvarial reconstruction by customized bioactive implant. Hand Surg Microsurg Plast Surg 42, 369, 2010.

221. Shanjani, Y., et al. Solid freeform fabrication and characterization of porous calcium polyphosphate structures for tissue engineering purposes. J Biomed Mater Res B Appl Biomater 93B, 510, 2010.

222. Yen, H.J., et al. Evaluation of chondrocyte growth in the highly porous scaffolds made by fused deposition manufacturing (FDM) filled with type II collagen. Biomed Microdevices 11, 615, 2009.

223. Gruene, M., et al. Laser printing of stem cells for biofabrication of scaffold-free autologous grafts. Tissue Eng Part C Methods 17, 79, 2011.

224. Phillippi, J.A., et al. Microenvironments engineered by inkjet bioprinting spatially direct adult stem cells toward muscleand bone-like subpopulations. Stem Cells 26, 127, 2008.

225. Merceron, T.K., et al. A 3D bioprinted complex structure for engineering the muscle-tendon unit. Biofabrication 7, 2015.

226. Ilkhanizadeh, S., Teixeira, A.I., and Hermanson, O. Inkjet printing of macromolecules on hydrogels to steer neural stem cell differentiation. Biomaterials 28, 3936, 2007.

227. Williams, S.K., et al. Encapsulation of adipose stromal vascular fraction cells in alginate hydrogel spheroids using a direct-write three-dimensional printing system. Biores Open Access 2, 448, 2013.

228. Lee, W., et al. Multi-layered culture of human skin fibroblasts and keratinocytes through three-dimensional freeform fabrication. Biomaterials 30, 1587, 2009.

229. Lee, V., et al. Design and fabrication of human skin by three-dimensional bioprinting. Tissue Eng Part C Methods 20, 473, 2014.

230. Lee, M.H., et al. Considerations for tissue-engineered and regenerative medicine product development prior to clinical trials in the United States. Tissue Eng Part B Rev 16, 41, 2010.

231. Xu, T., et al. Viability and electrophysiology of neural cell structures generated by the inkjet printing method. Biomaterials 27, 3580, 2006. 
232. Inzana, J.A., et al. 3D printing of composite calcium phosphate and collagen scaffolds for bone regeneration. Biomaterials 35, 4026, 2014.

233. Serra, T., et al. 3D printed PLA-based scaffolds A versatile tool in regenerative medicine. Organogenesis 9, 239, 2013.

234. Kim, J., et al. Rapid-prototyped PLGA/beta-TCP/ hydroxyapatite nanocomposite scaffolds in a rabbit femoral defect model. Biofabrication 4, 025003, 2012.

235. Espalin, D., et al. Fused deposition modeling of patientspecific polymethylmethacrylate implants. Rapid Prototyp J 16, 164, 2010.

236. Moon, S., et al. Layer by layer three-dimensional tissue epitaxy by cell-laden hydrogel droplets. Tissue Eng Part C Methods 16, 157, 2010.

237. Koch, L., et al. Skin tissue generation by laser cell printing. Biotechnol Bioeng 109, 1855, 2012.

238. Kolesky, D.B., et al. Three-dimensional bioprinting of thick vascularized tissues. Proc Natl Acad Sci U S A 113, 3179, 2016.

239. Lovett, M., et al. Vascularization strategies for tissue engineering. Tissue Eng Part B Rev 15, 353, 2009.

240. Rouwkema, J., Rivron, N.C., and van Blitterswijk, C.A. Vascularization in tissue engineering. Trends Biotechnol 26, 434, 2008.

241. Phelps, E.A., and Garcia, A.J. Engineering more than a cell: vascularization strategies in tissue engineering. Curr Opin Biotechnol 21, 704, 2010.

242. Carmeliet, P., and Jain, R.K. Angiogenesis in cancer and other diseases. Nature 407, 249, 2000.

243. Kannan, R.Y., et al. The roles of tissue engineering and vascularisation in the development of micro-vascular networks: a review. Biomaterials 26, 1857, 2005.

244. Cursiefen, C., et al. Nonvascular VEGF receptor 3 expression by corneal epithelium maintains avascularity and vision. Proc Natl Acad Sci U S A 103, 11405, 2006.

245. Sophia Fox, A.J., Bedi, A., and Rodeo, S.A. The basic science of articular cartilage: structure, composition, and function. Sports Health 1, 461, 2009.

246. Sweeney, D.F., et al. Nutritional requirements of the corneal epithelium and anterior stroma: clinical findings. Invest Ophthalmol Vis Sci 39, 284, 1998.

247. Jain, R.K., et al. Engineering vascularized tissue. Nat Biotechnol 23, 821, 2005.

248. Chlupac, J., Filova, E., and Bacakova, L. Blood vessel replacement: 50 years of development and tissue engineering paradigms in vascular surgery. Physiol Res 58 Suppl 2, S119, 2009.

249. Hiob, M.A., Crouch, G.W., and Weiss, A.S. Elastomers in vascular tissue engineering. Curr Opin Biotechnol 40, 149, 2016.

250. Brown, D.A., et al. A new wave in treatment of vascular occlusive disease: biodegradable stents-clinical experience and scientific principles. J Vasc Interv Radiol 20, 315; quiz 325, 2009.

251. Popryadukhin, P.V., et al. Tissue-engineered vascular graft of small diameter based on electrospun polylactide microfibers. Int J Biomater 2017, 9034186, 2017.

252. American Heart Association. Heart Disease and Stroke Statistics-2010 Update, Dallas, TX: American Heart Association, 2010.

253. Hannan, E.L., et al. Drug-eluting stents vs. coronaryartery bypass grafting in multivessel coronary disease. $\mathrm{N}$ Engl J Med 358, 331, 2008.
254. Yang, J.H., et al. Comparison of coronary artery bypass grafting with drug-eluting stent implantation for the treatment of multivessel coronary artery disease. Ann Thorac Surg 85, 65, 2008.

255. Alexander, J.H., et al. Efficacy and safety of edifoligide, an E2F transcription factor decoy, for prevention of vein graft failure following coronary artery bypass graft surgery: PREVENT IV: a randomized controlled trial. JAMA 294, 2446, 2005.

256. Herring, M., Gardner, A., and Glover, J. A single-staged technique for seeding vascular grafts with autogenous endothelium. Surgery 84, 498, 1978.

257. Herring, M., Gardner, A., and Glover, J. Seeding human arterial prostheses with mechanically derived endothelium. The detrimental effect of smoking. J Vasc Surg 1, 279, 1984.

258. Kaushal, S., et al. Functional small-diameter neovessels created using endothelial progenitor cells expanded ex vivo. Nat Med 7, 1035, 2001.

259. Salingova, B., Madarasova, M., Stejskal, S., Tesarova, L., Simara, P., and Koutna, I. From endothelial progenitor cells to tissue engineering: how far have we come? J Stem Cell Res Ther 4, 2014.

260. Nakayama, K.H., et al. Bilayered vascular graft derived from human induced pluripotent stem cells with biomimetic structure and function. Regen Med 10, 745, 2015.

261. de Carvalho, J.L., et al. Production of human endothelial cells free from soluble xenogeneic antigens for bioartificial small diameter vascular graft endothelization. Biomed Res Int 2015.

262. Tara, S., et al. Vessel bioengineering-development of small-diameter arterial grafts. Circ J 78, 12, 2014.

263. Hooper, R.C., et al. Fabrication and in vivo microanastomosis of vascularized tissue-engineered constructs. Tissue Eng Part A 20, 2711, 2014.

264. Dahl, S.L., et al. Readily available tissue-engineered vascular grafts. Sci Transl Med 3, 68ra9, 2011.

265. Lawson, J.H., et al. Bioengineered human acellular vessels for dialysis access in patients with end-stage renal disease: two phase 2 single-arm trials. Lancet 387, 2026, 2016.

266. Forgacs, G. Tissue engineering: perfusable vascular networks. Nat Mater 11, 746, 2012.

267. Zanotelli, M.R., et al. Stable engineered vascular networks from human induced pluripotent stem cell-derived endothelial cells cultured in synthetic hydrogels. Acta Biomater 35, 32, 2016.

268. Sarker, M.D., et al. 3D biofabrication of vascular networks for tissue regeneration: a report on recent advances. J Pharm Anal 8, 277, 2018.

269. Chaturvedi, R.R., et al. Patterning vascular networks in vivo for tissue engineering applications. Tissue Eng Part C Methods 21, 509, 2015.

270. Shafiq, M., Jung, Y., and Kim, S.H. In situ vascular regeneration using substance P-immobilised poly(l-lactide-co-epsiloncaprolactone) scaffolds: stem cell recruitment, angiogenesis, and tissue regeneration. Eur Cell Mater 30, 282, 2015.

271. Friedrich, C.C., et al. Enhancing engineered vascular networks in vitro and in vivo: the effects of IGF1 on vascular development and durability. Cell Prolif 51, 2018.

272. Jiang, B., and Brey, E.M. Formation of stable vascular networks in engineered tissues. In: Regenerative Medicine and Tissue Engineering — Cells and Biomaterials. 2011, pp. 477502.

273. Bachmann, B., et al. Engineering of three-dimensional pre-vascular networks within fibrin hydrogel constructs by 
microfluidic control over reciprocal cell signaling. Biomicrofluidics 12, 2018.

274. Cohen, S.N., et al. Construction of biologically functional bacterial plasmids in vitro. Proc Natl Acad Sci U S A 70, 3240, 1973.

275. Roh, D.S., Li, E.B.H., and Liao, E.C. CRISPR craft: DNA editing the reconstructive ladder. Plast Reconstr Surg 142, 1355, 2018.

276. Nip, Tuck, CRISPR: gene editing could give plastic surgery a lift. 2018. www.genengnews.com/news/nip-tuck-crisprgene-editing-could-give-plastic-surgery-a-lift (accessed January 24, 2019).

277. CRISPR gene editing will find applications in plastic and reconstructive surgery. 2018. www.plasticsurgery.org/news/ press-releases/crispr-gene-editing-will-find-applications-inplastic-and-reconstructive-surgery (accessed January 24, 2019).

278. Capecchi, M.R. Altering the genome by homologous recombination. Science 244, 1288, 1989.

279. Thomas, K.R., Folger, K.R., and Capecchi, M.R. Highfrequency targeting of genes to specific sites in the mammalian genome. Cell 44, 419, 1986.

280. Smithies, O., et al. Insertion of DNA-sequences into the human chromosomal beta-globin locus by homologous recombination. Nature 317, 230, 1985.

281. Rouet, P., Smih, F., and Jasin, M. Introduction of doublestrand breaks into the genome of mouse cells by expression of a rare-cutting endonuclease. Mol Cell Biol 14, 8096, 1994.

282. Rudin, N., Sugarman, E., and Haber, J.E. Genetic and physical analysis of double-strand break repair and recombination in Saccharomyces cerevisiae. Genetics 122, $519,1989$.

283. Klug, A., and Rhodes, D. Zinc fingers-a novel protein fold for nucleic-acid recognition. Cold Spring Harb Symp Quant Biol 52, 473, 1987.

284. Kim, Y.G., Cha, J., and Chandrasegaran, S. Hybrid restriction enzymes: zinc finger fusions to Fok I cleavage domain. Proc Natl Acad Sci U S A 93, 1156, 1996.

285. Christian, M., et al. Targeting DNA double-strand breaks with TAL effector nucleases. Genetics 186, 757, 2010.

286. Adli, M. The CRISPR tool kit for genome editing and beyond. Nat Commun 9, 2018.

287. Mojica, F.J.M., et al. Intervening sequences of regularly spaced prokaryotic repeats derive from foreign genetic elements. J Mol Evol 60, 174, 2005.

288. Jinek, M., et al. RNA-programmed genome editing in human cells. Elife 2, 2013.

289. Mali, P., et al. RNA-guided human genome engineering via Cas9. Science 339, 823, 2013.

290. Hirsch, T., et al. Regeneration of the entire human epidermis using transgenic stem cells. Nature 551, 327, 2017.

291. Rubanyi, G.M. The future of human gene therapy. Mol Aspects Med 22, 113, 2001.

292. Cui, J., et al. Ex vivo pretreatment of human vessels with siRNA nanoparticles provides protein silencing in endothelial cells. Nat Commun 8, 191, 2017.

293. Roman, S., et al. Gene therapy in plastic and reconstructive surgery. Curr Gene Ther 5, 81, 2005.

294. La Russa, M.F., and Qi, L.S. The new state of the art: Cas9 for gene activation and repression. Mol Cell Biol 35, 3800, 2015.

295. Chira, S., et al. Progresses towards safe and efficient gene therapy vectors. Oncotarget 6, 30675, 2015.
296. Li, L., Hu, S., and Chen, X. Non-viral delivery systems for CRISPR/Cas9-based genome editing: challenges and opportunities. Biomaterials 171, 207, 2018.

297. Ran, F.A., et al. In vivo genome editing using Staphylococcus aureus Cas9. Nature 520, 186, 2015.

298. Schmidt, F., and Grimm, D. CRISPR genome engineering and viral gene delivery: a case of mutual attraction. Biotechnol J 10, 258, 2015.

299. Mingozzi, F., and High, K.A. Immune responses to AAV vectors: overcoming barriers to successful gene therapy. Blood 122, 23, 2013.

300. Manno, C.S., et al. Successful transduction of liver in hemophilia by AAV-factor IX and limitations imposed by the host immune response (vol 12, pg 342, 2006). Nat Med 12, 592, 2006.

301. Robbins, P.D., and Ghivizzani, S.C. Viral vectors for gene therapy. Pharmacol Ther 80, 35, 1998.

302. Anson, D.S. The use of retroviral vectors for gene therapy-what are the risks? A review of retroviral pathogenesis and its relevance to retroviral vector-mediated gene delivery. Genet Vaccines Ther 2, 9, 2004.

303. Vannucci, L., et al. Viral vectors: a look back and ahead on gene transfer technology. New Microbiol 36, 1, 2013.

304. Hardee, C.L., et al. Advances in non-viral DNA vectors for gene therapy. Genes 8, 2017.

305. Ramamoorth, M., and Narvekar, A. Non viral vectors in gene therapy - an overview. J Clin Diagn Res 9, GE01, 2015.

306. Hoy, S.M. Patisiran: first global approval. Drugs 78, 1625, 2018.

307. Li, L., et al. Challenges in CRISPR/CAS9 delivery: potential roles of nonviral vectors. Hum Gene Ther 26, 452, 2015.

Address correspondence to: Juan Manuel Colazo, BSc Medical Scientist Training Program, Vanderbilt University Medical Center 2nd Floor Eskind Biomedical Library and Learning Center, Vanderbilt University School of Medicine 2209 Garland Avenue Nashville, TN 37240

E-mail: juan.m.colazo@vanderbilt.edu

Wesley P. Thayer, MD, PhD

Department of Plastic Surgery

Vanderbilt University Medical Center

1161 21st Avenue South, MCN D4207

Nashville, TN 37232-2345

E-mail: wesley.thayer@vumc.org

Craig L. Duvall, PhD

Department of Biomedical Engineering

Vanderbilt University

Engineering and Science Building, ESB 444

2301 Vanderbilt Place, PMB 351631

Nashville, TN 37235-1631

E-mail: craig.duvall@vanderbilt.edu

Received: November 16, 2018

Accepted: March 14, 2019

Online Publication Date: July 31, 2019 